\title{
Isocyanide-based multicomponent reactions towards cyclic constrained peptidomimetics
}

\author{
Gijs Koopmanschap, Eelco Ruijter and Romano V.A. Orru*
}

\author{
Review \\ Address: \\ Department of Chemistry \& Pharmaceutical Sciences, Amsterdam \\ Institute of Molecules, Medicines and Systems, VU University \\ Amsterdam, de Boelelaan 1083, $1081 \mathrm{HV}$, Amsterdam, The \\ Netherlands \\ Email: \\ Romano V.A. Orru* - r.v.a.orru@vu.nl \\ * Corresponding author \\ Keywords: \\ heterocycles; isocyanides; macrocycles; multicomponent reaction; \\ medicinal chemistry; organic synthesis; peptidomimetics
}

Beilstein J. Org. Chem. 2014, 10, 544-598. doi:10.3762/bjoc. 10.50

Received: 06 November 2013

Accepted: 24 January 2014

Published: 04 March 2014

This article is part of the Thematic Series "Multicomponent reactions II".

Guest Editor: T. J. J. Müller

(c) 2014 Koopmanschap et al; licensee Beilstein-Institut. License and terms: see end of document.

\begin{abstract}
In the recent past, the design and synthesis of peptide mimics (peptidomimetics) has received much attention. This because they have shown in many cases enhanced pharmacological properties over their natural peptide analogues. In particular, the incorporation of cyclic constructs into peptides is of high interest as they reduce the flexibility of the peptide enhancing often affinity for a certain receptor. Moreover, these cyclic mimics force the molecule into a well-defined secondary structure. Constraint structural and conformational features are often found in biological active peptides. For the synthesis of cyclic constrained peptidomimetics usually a sequence of multiple reactions has been applied, which makes it difficult to easily introduce structural diversity necessary for fine tuning the biological activity. A promising approach to tackle this problem is the use of multicomponent reactions (MCRs), because they can introduce both structural diversity and molecular complexity in only one step. Among the MCRs, the isocyanidebased multicomponent reactions (IMCRs) are most relevant for the synthesis of peptidomimetics because they provide peptide-like products. However, these IMCRs usually give linear products and in order to obtain cyclic constrained peptidomimetics, the acyclic products have to be cyclized via additional cyclization strategies. This is possible via incorporation of bifunctional substrates into the initial IMCR. Examples of such bifunctional groups are $N$-protected amino acids, convertible isocyanides or MCR-components that bear an additional alkene, alkyne or azide moiety and can be cyclized via either a deprotection-cyclization strategy, a ringclosing metathesis, a 1,3-dipolar cycloaddition or even via a sequence of multiple multicomponent reactions. The sequential IMCRcyclization reactions can afford small cyclic peptide mimics (ranging from four- to seven-membered rings), medium-sized cyclic constructs or peptidic macrocycles (>12 membered rings). This review describes the developments since 2002 of IMCRs-cyclization strategies towards a wide variety of small cyclic mimics, medium sized cyclic constructs and macrocyclic peptidomimetics.
\end{abstract}




\section{Introduction}

Peptides and proteins fulfill a key role in many biological and physiological functions of living organisms. Therefore, they are interesting starting points for the development of novel drugs $[1,2]$. Peptides may act as neurotransmitters, hormones or antibodies and are involved in the progress of several diseases. However, natural peptides and proteins possess several properties which make them less suitable as a drug candidate. First, the amide bond is easily cleaved by proteases and their hydrophilic character results in a low permeability, rapid metabolic processing and excretion. Also, natural peptides often occur in an ensemble of conformations thereby reducing their specificity for biological targets resulting in unwanted side effects $[3,4]$. Consequently, chemists started to develop so-called peptidomimetics; compounds that mimic the action or active conformation of a peptide by incorporating non-peptidic structural and functional features that imitate those of the parent peptide but with improved biological properties. During the last decades, several classes of peptidomimetics have been described such as peptide bond isosteres or conformational constraint mimics [5,6]. Insertion of conformational restrictions is of high interest since they reduce the number of conformations, which may result in higher affinity for the target/receptor and improved protease stability, bioavailability and specificity [6-8]. Conformational bias can be achieved via $\mathrm{N}$-alkylation, $\alpha$-alkylation or the introduction of alkene amide bond isosteres, but also via local or global cyclization. A prominent advantage of cyclized constraints is that they force the molecule into a well-defined secondary structure. Such structural features are often found in biologically active peptides and proteins [8]. Mimicking the secondary structure is of high interest since these motifs are regularly located at the surface of peptide-peptide interactions [9]. Another important reason for the design and synthesis of these cyclic mimics is that they can give in-depth insight in the biologically active conformation of a peptide or protein [10].

In the context of design and synthesis of peptidomimetics, several approaches have been applied and most of them include a sequence of multiple reactions along with a variety of protection and deprotection steps. However, via these rather long sequential procedures it is often not straightforward to introduce structural diversity in a set of targeted peptide mimics, which is essential for effective fine tuning of biological activity [11-13]. Therefore, the use of more straightforward and robust reactions that can introduce complexity and structural diversity in only a few steps is highly desirable. A promising approach that combines those features is the use of multicomponent reactions (MCRs). Multicomponent reactions are convergent onepot transformations involving three or more substrates that give a single product with high atom-economy. The reagents herein react in a sequential manner and all intermediate-steps are in equilibrium except often the last irreversible step, which provides the product. Besides saving time and reagents, another major advantage of these reactions is the ability to combine commercially available or readily accessible starting materials with a variety of functionalities in one-step. Further, MCRbased strategies can cover a broader range of chemical space because a large set of structurally different starting materials is tolerated and structural diversity is relatively easily achieved. Finally, the highly convergent nature of MCRs results in the generation of highly complex structures in only one step. In addition, because of their practical simplicity they are also ideally suited for automated synthesis [14-18]. Among the MCRs, the isocyanide-based multicomponent reactions (IMCRs), such as the Ugi and the Passerini reaction, are the most relevant reactions for constructing peptidomimetics since they give access to (depsi)peptide-like structures. However, these IMCRs provide linear products, whereas their cyclic analogues are highly desirable as discussed above for potentially improved structural and biological properties. Fortunately, these linear products can be cyclized via post-condensation transformations since a wide range of unreactive functional groups are tolerated in the IMCRs [19].

In this overview we focus on all recent developments in the last decade in the field of cyclic peptidomimetics obtained from IMCRs and their subsequent cyclization reactions. The cyclic mimics herein range from small rings (four to seven membered), medium sized rings (9-12 membered) to macrocycles.

\section{Isocyanide-based multicomponent reactions for cyclic peptidomimetics}

Multicomponent reactions that include isocyanide or isocyanide derivatives (e.g. isocyanoacetates) have been widely applied for the synthesis of peptidomimetics. The main advantage of these isocyanide-based reactions is that the isocyanide functionality can act both as nucleophile and electrophile at the C1-carbon, which makes the construction of linear peptide-like structures possible [20]. Cyclic peptidomimetics can be obtained via subsequent transformations that in turn are possible via e.g. the incorporation of bifunctional substrates or by activation of functionalized substrates in the initial MCR [19].

\section{The Passerini reaction}

The first isocyanide-based MCR was described by Mario Passerini in 1921 and named after him. The Passerini reaction is a three-component reaction (3-CR) and provides $\alpha$-acyloxy carboxamides by reacting carbonyl compounds, carboxylic acids and isocyanides. The reaction is usually performed with 


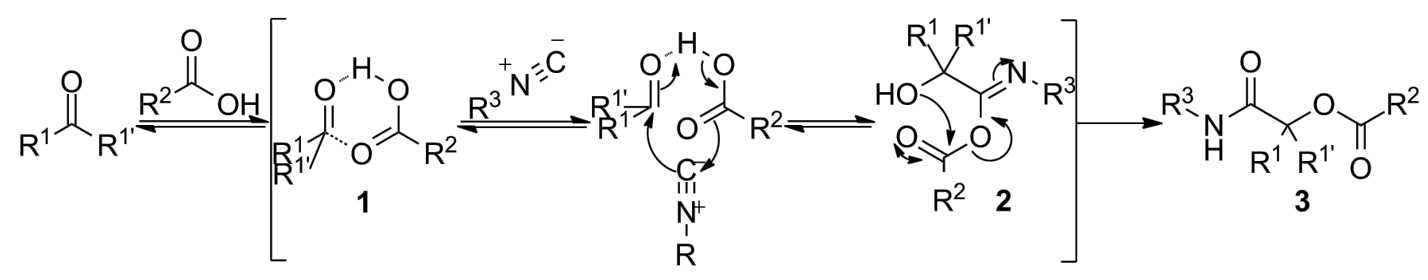

Scheme 1: The proposed mechanism of the Passerini reaction.

high concentrations of starting materials using aprotic solvents. A wide range of all three components is tolerated in the Passerini 3-CR, which makes this reaction ideally suited for addressing scaffold diversity. The higher rates observed in aprotic solvents suggest that the Passerini 3-CR proceeds via a non-ionic pathway. A generally accepted mechanism starts with the generation of the loosely hydrogen-bonded adduct 1 from the oxo-component and the carboxylic acid (Scheme 1). The next step involves the $\alpha$-addition of both the electrophilic carbonyl-carbon of the oxo-component and the nucleophilic oxygen of the acid component to the isocyanide, to afford the $\alpha$-adduct 2. A subsequent rearrangement then provides the $\alpha$-acyloxy amide 3 [20-22].

With regard to peptidomimetic design, the incorporation of $\mathrm{N}$-protected aldehydes 4 (Scheme 2) is of great importance since deprotection of the $\alpha$-adduct $\mathbf{5}$ allows acyl-migration and give access to $\alpha$-hydroxy- $\beta$-amino amide derivatives 7 that possess important biological properties. This Passerini-amine deprotection-acyl migration (PADAM) strategy was reported for the first time by Banfi and co-workers in 2003 [23]. In addition, subsequent oxidation of $\mathbf{7}$ gives access to $\alpha$-keto amides $\mathbf{8}$ that show important protease inhibitory activities.

\section{The Ugi reaction}

One of the most important MCRs that generates peptide-like structures was reported for the first time by Ivar Ugi in 1959. This Ugi four-component reaction (U-4CR) furnishes $\alpha$-acylamino amides 11 by combining oxo-substrates, carboxylic acids, amines and isocyanides in one-pot and like the Passerini reaction a wide variety of substrates is tolerated. In contrast to the Passerini 3-CR, the Ugi 4-CR is favoured in polar protic solvents like low-molecular weight alcohols such as methanol, ethanol or trifluoroethanol. However, many examples in polar aprotic solvents are also reported. The generally accepted mechanism for the Ugi reaction proceeds via in situ imine formation of $\mathbf{9}$, followed by the generation of $\alpha$-adduct $\mathbf{1 0}$ formed via an attack of the isocyanide to the imine and a subsequent attack of the carboxylate to the resulting nitrilium ion (Scheme 3). The final dipeptide-like product is formed via a subsequent Mumm rearrangement of the $\alpha$-adduct 10. In addition, pre-formation of the imine or the use of bifunctional inputs (e.g. amino acids) can reduce this Ugi-4CR to an Ugi-3CR. In particular, the Ugi reaction with bifunctional inputs is called an Ugi-four-center-three-component reaction (U-4C-3CR) and has been extensively applied in peptidomimetic synthesis $[21,22,24,25]$.

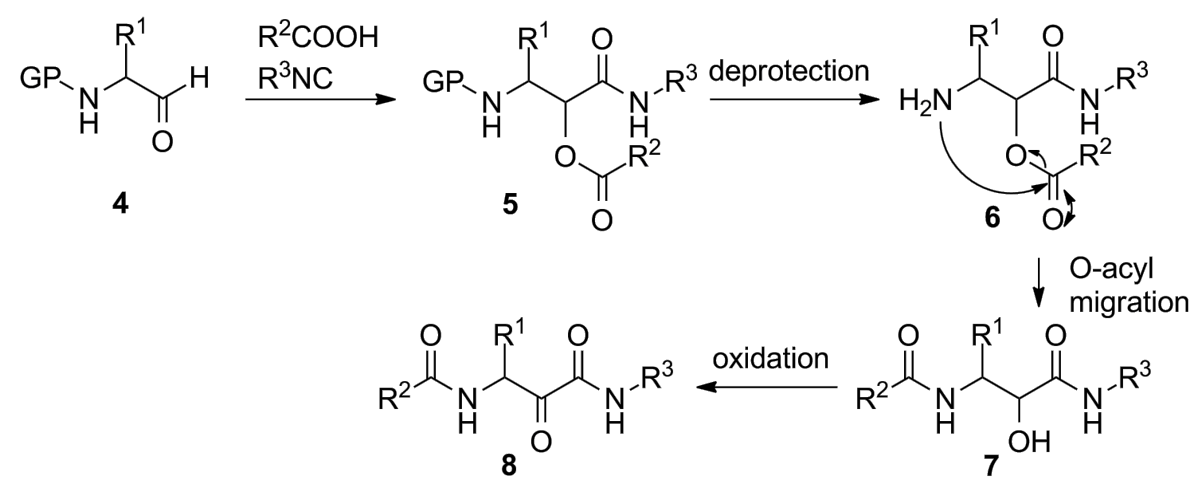




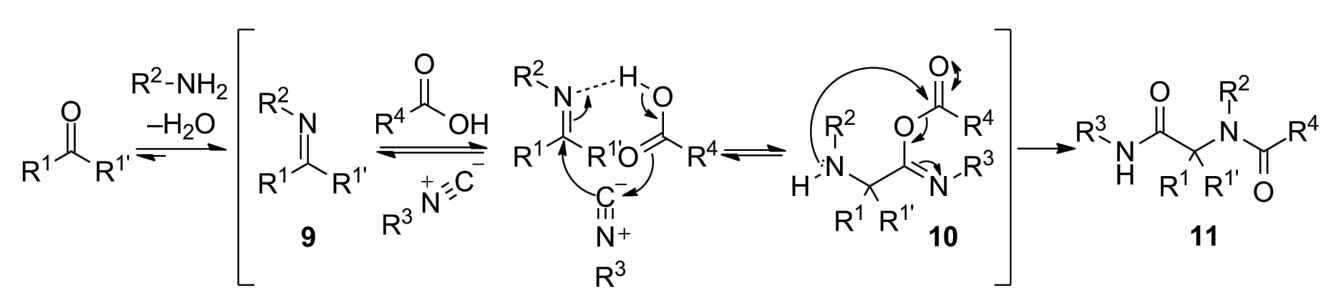

Scheme 3: The general accepted Ugi-mechanism.

\section{Post-condensation strategies}

In the last decade, several peptidomimetics containing four to seven membered rings (including bicyclic systems), medium sized rings and macrocyclic systems have been reported via IMCRs. However, as both the Ugi and Passerini reactions provide linear products, several cyclization strategies have been utilized in order to obtain cyclic constructs. For example, the incorporation of cyclic imines immediately gives cyclic MCRproducts, whereas other strategies make use of unreactive, convertible or protected functional Ugi-substrates that can be cyclized via subsequent transformations [19,22,26]. Examples of IMCR orthogonal species or functionalities are alkenes, alkynes and azides which may give the cyclic analogues via subsequent ring closing metathesis (RCM) or 1,3-dipolar cycloadditions. In contrast, protected functional groups first require a deprotection before a follow-up cyclization event can take place. An example of this is the use of $N$-Boc protected amino acids in the Ugi reaction. Subsequent deprotection of the linear Ugi-product allows cyclization and reactions of this type are classified as Ugi Deprotection-Cyclizations (UDC, Scheme 4). Moreover, cyclizations can also be initiated by activation of the Ugi-product via an Ugi Activation-Cyclization

a) Ugi Deprotection-Cyclization (UDC)

- 3 monofunctional Ugi-reactive components

- 1 bifunctional monoprototected Ugi-reactive component

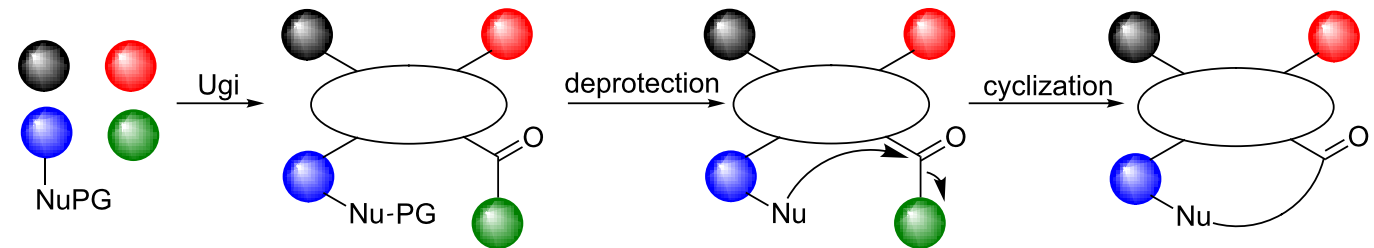

b) Ugi Activation-Cyclization (UAC)

- 2 monofunctional Ugi-reactive components

- 1 bifunctional component

- 1 activatible component

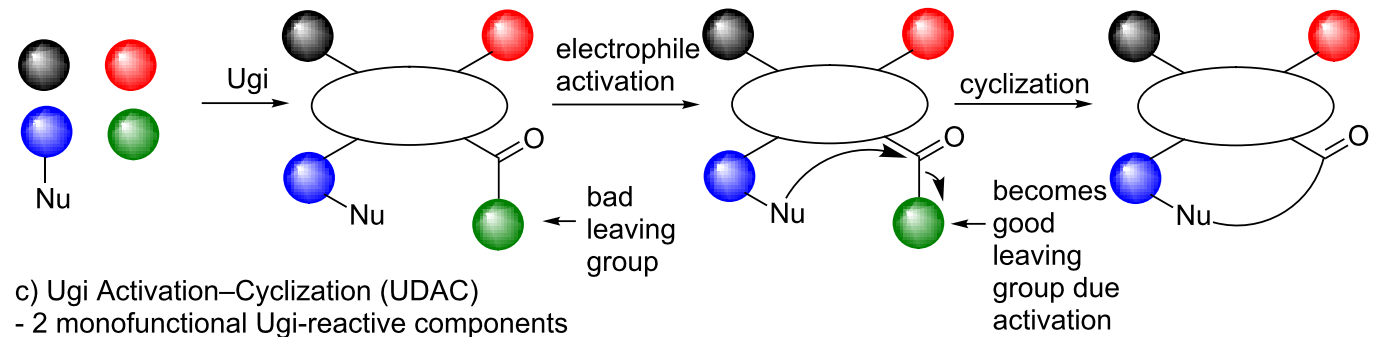

- 2 monofunctional Ugi-reactive components

- 1 bifunctional monoprototected component

- 1 activatible component

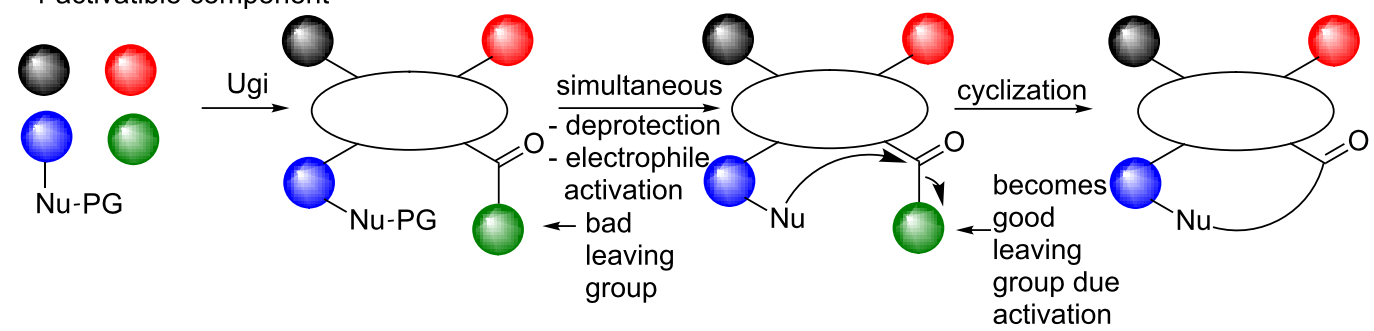

Scheme 4: Three commonly applied Ugi/cyclization approaches. a) UDC-process, b) UAC-sequence, c) UDAC-combination. 


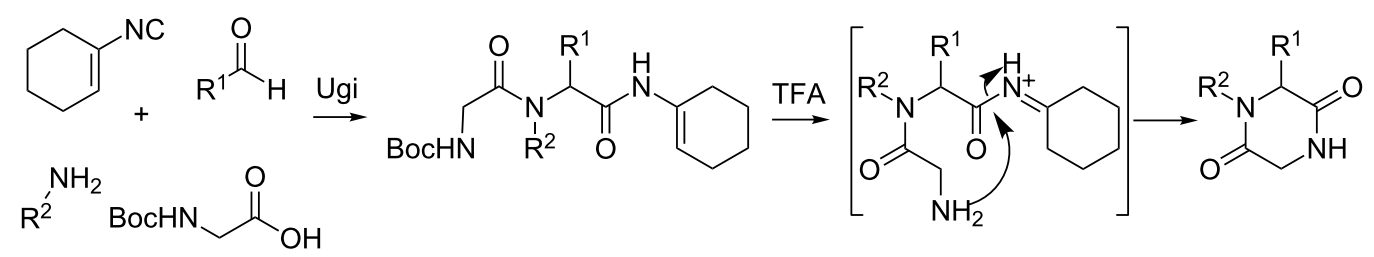

Scheme 5: Ugi reaction that involves the condensation of Armstrong's convertible isocyanide.

procedure and involves the use of convertible isocyanides as Ugi-substrates. An example of a convertible isonitrile is Armstrong's isocyanide which can be cleaved after acidic treatment (Scheme 5). A combination of deprotection and activation is also possible and is found in the literature as an Ugi Deprotection/Activation-Cyclisation (UDAC). In addition, other MCR-post-condensation reactions, especially for macrocycles, include intramolecular aryl couplings, amidations, $\mathrm{S}_{\mathrm{n}} \mathrm{Ar}$ reactions, nucleophilic substitutions, and macrolactonizations. Even more interestingly, it is possible to perform the cyclization step via a second multicomponent reaction [22] or the MiB (multiple multicomponent macrocyclizations including $b$ ifunctional building blocks) protocol developed by Wessjohann et al. (vide infra) [26].

\section{Review}

\section{Small ring constraints}

In the first part of this review four- to seven-membered cyclic peptidomimetics will be discussed. These small rings, particularly heterocycles, have received much attention as dipeptide mimics due to their capable interaction with defined protein motifs and due to their ease of preparation via IMCRs [27-29]. First, the $\beta$-lactams will be described followed by fivemembered rings varying from pyrrolidines to tetrazoles based amide bond isosteres. Examples of the six-membered rings showing peptide like-properties are the piperazines, homoprolines, dihydropyrimidones and triazines, whereas azepines form an important class of seven-membered cyclic peptidomimetics.

\section{Four membered ring constraints $\beta$-Lactams}

The smallest class of cyclic peptidomimetics is that of the $\beta$-lactams. $\beta$-lactams are effective antibiotics [30] but also show inhibitory activities against serine- [31], elastase- [32-35], and HIV-1 protease [36] and papain [37]. For the design of $\beta$-lactams, the Staudinger reaction involving a $[2+2]$ cycloaddition of ketenes and imines is the most common method used [38]. However, Ugi reactions starting form $\beta$-amino acids are also described. In 2002, the group of Fülöp reported an efficient synthesis of bicyclic $\beta$-lactams from monocyclic $\beta$-amino acids via an Ugi four-center three-component reaction (U-4C3R) [39]. Herein, the monocyclic $\beta$-amino acid acts as bifunctional moiety containing both an amino and carboxylic acid group. A variety of cyclic $\beta$-amino acids, in which the ring was varied, were combined with a variety of aldehydes and isocyanides in methanol to obtain the desired $\beta$-lactams. In Scheme 6, a plausible mechanism of this reaction is shown.

The $\beta$-lactam ring herein is formed via a ring contraction of the seven-membered oxazepanone intermediate $\mathbf{1 4}$, which in turn is formed from $\alpha$-addition of the isocyanide to the bifunctional imine. Fülöp considered both racemic cis- and trans- $\beta$-amino acids, in which only the cis-racemates resulted in cyclized product $\mathbf{1 5}$. The cis-products were obtained in moderate to good yields (23-86\%) with diastereoselectivities varying from 14 to $90 \%$ (de). In 2007 , they extended their protocol by performing the MCR in water, which is considered as environmentally benign, cheap and allowing simple isolation as the products

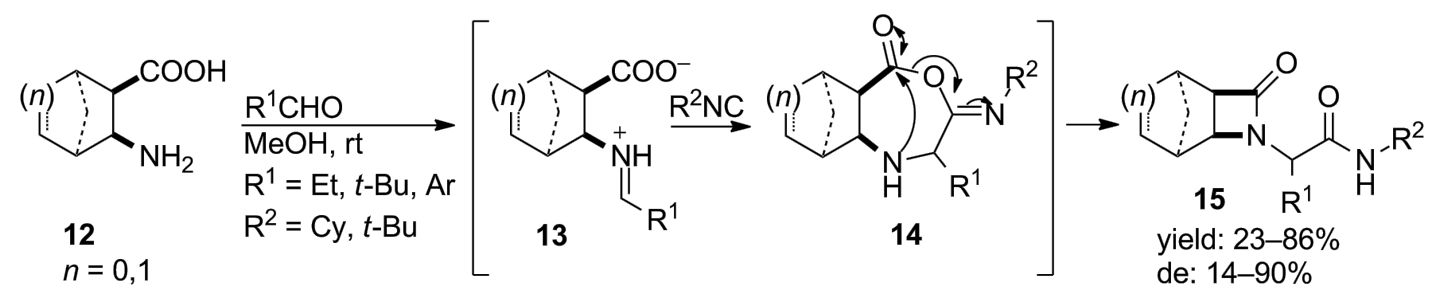



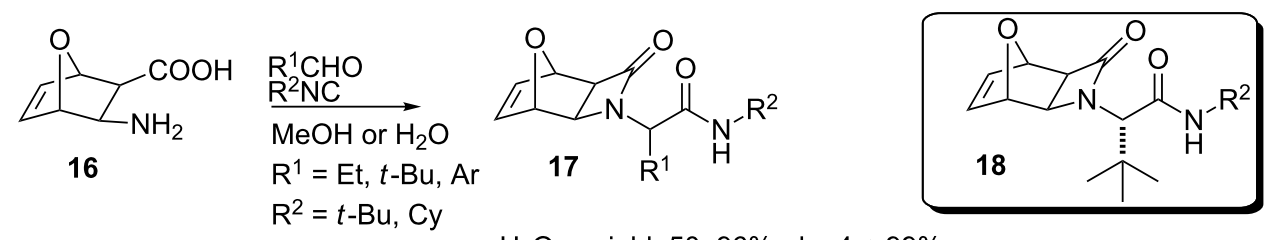

$\mathrm{H}_{2} \mathrm{O}$, yield: $50-96 \%$, de: $4->99 \%$

$\mathrm{MeOH}$, yield: $43-76 \%$, de: $12-72 \%$

Scheme 7: The Ugi 4C-3CR towards oxabicyclo $\beta$-lactams

precipitate [40]. Although, no improvements in yield or diastereoselectivity were observed, the reaction time was remarkably reduced in water $(24 \mathrm{~h}$ vs. $72 \mathrm{~h}$ ). One explanation for this acceleration could be the enhanced hydrogen bonding effect in the transition state [41]. Unfortunately, the construction of a large library was hampered, due to the poor solubility of several aldehydes in the aqueous media.

In a variation, the same group constructed a 10 -membered library of oxabicyclo $\beta$-lactam derivatives (17, Scheme 7) from the bifunctional heteronorborene $\mathbf{1 6}$ in either water or methanol [42]. It was shown that both solvents gave similar results with regard to the yield (43-76\% vs. 50-96\%), whereas the diastereoselectivity was somewhat improved in water $(12-72 \%$ vs 4->99\%), in which the use of aliphatic aldehydes showed improved diastereoselectivity in this reaction. The highest diastereoselectivity was obtained with pivaldehyde 18 (100:0).

In 2010, Szakonyi et al. further extended their Ugi 4C-3CR-approach with enantiopure monoterpene-based $\beta$-amino acids [43] (19, Scheme 8), giving 22 as major isomer [44]. The stereoselectivity for $\mathbf{2 2}$ was explained by the steric effects of the dimethyl bridge that might prefer a $R e$-attack of the isocyanide. Compared to methanol, again the reaction in water proved to be faster. However, a solvent-free approach also resulted in the desired $\beta$-lactams with similar results in yield, diastereoselectivity and time.

Besides bicyclic systems, Ugi 4C-3CRs towards monocyclic $\beta$-lactams are also described in both organic and aqueous media. Pirrung et al. published a library of 32 different $\beta$-lactams from four $\beta$-amino acids $\mathbf{2 4}$, four different aldehydes and two isonitriles (Scheme 9) [41,45]. The reaction was performed in water at ambient temperature and yielded the desired products in good yields (71-89\%), however, without diastereoselectivity (dr 1:1).

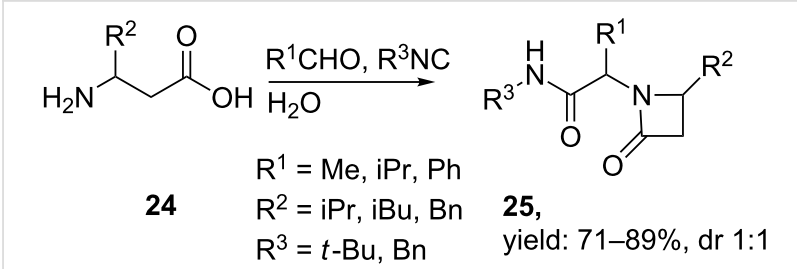

Scheme 9: General MCR for $\beta$-lactams in water.

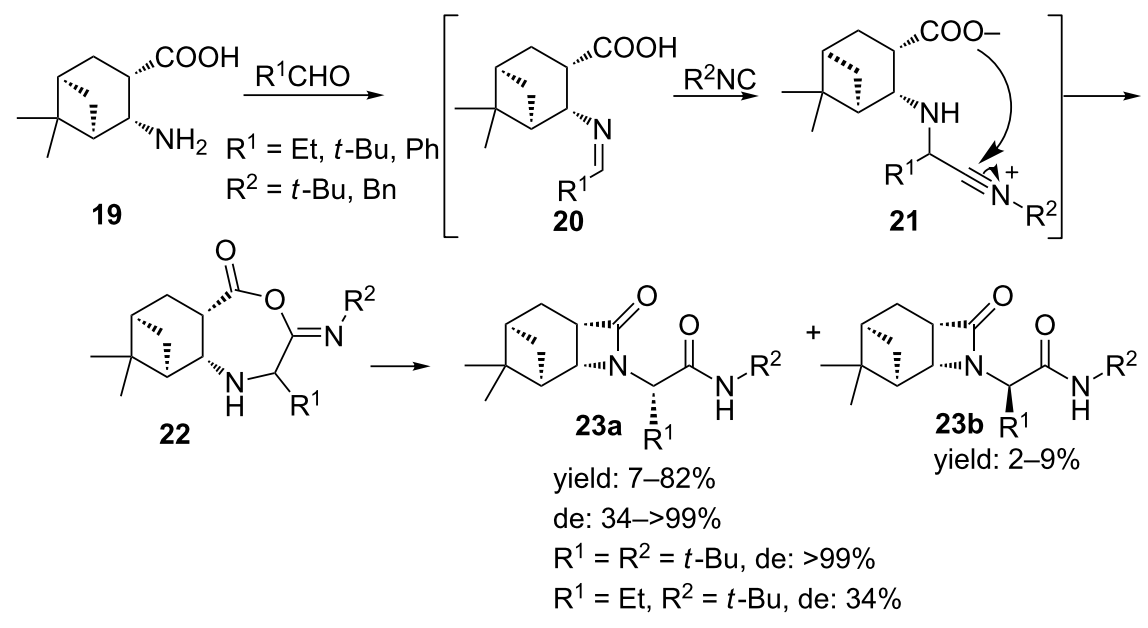

Scheme 8: Ugi MCR between an enantiopure monoterpene based $\beta$-amino acid, aldehyde and isocyanide resulting in bicyclic $\beta$-lactams. 


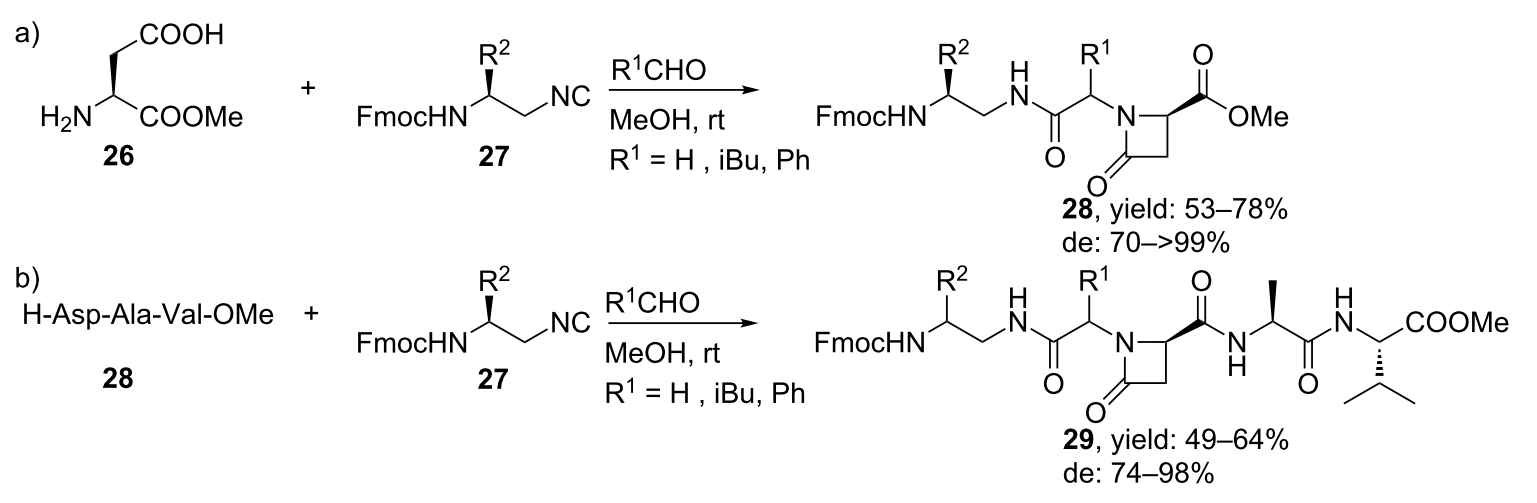

Scheme 10: a) Ugi reaction for $\beta$-lactam-linked peptidomimetics. b) Varying the $\beta$-amino acid resulted in $\beta$-lactam-linked peptidomimetic structures.

To improve the diastereoselectivity, the group of Sureshbabu utilized chiral $N^{\beta}$-Fmoc-amino alkyl isocyanides (obtained from $N^{\beta}$-Fmoc-amino acids) and $L$-aspartic acid $\alpha$-methyl esters as Ugi-substrates (Scheme 10) [46]. The resulting $\beta$-lactam-linked peptidomimetics were obtained in good yields (53-78\%) with high diastereoselectivities (70-99\%). In a variation, they also performed the reaction with $L$-aspartic acid $\alpha$-peptide esters yielding endo- $\beta$-lactam mimics 29 in good yields (49-64\%, de 74-98\%).

\section{Five-membered ring constraints}

In natural peptides, the cyclic proteinogenic amino acid proline has stabilizing and turn-inducing properties determining the secondary and teriary structure and conformation of peptides $[7,47,48]$. Moreover, their influence on an altered cis/trans ratio of the amide bond has provided in-depth insights in conformation and receptor binding [49]. Thus, the specific properties of proline play a crucial role to determine the biological activity of peptides and peptidomimetics, [50] and research towards such peptidic structures containing proline-analogues has received much attention [48]. In this part, multicomponent reactions to access pyrrolidines and other five-membered derivatives such as $\gamma$-lactams, oxazoles, thiazoles and triazoles incorporated into peptide structures will be described.

\section{Pyrrolidines}

2-substituted pyrrolidine-based dipeptide mimics were obtained from an Ugi-4CR followed by a Pd-catalyzed $\mathrm{S}_{\mathrm{n}} 2$ cyclization as described by Banfi et al. [51]. Herein, the Ugi reaction provided a small library of acyclic products (Scheme 11), in which the isocyanide input $\mathbf{3 0}$ was derived from the corresponding amine via an $N$-formylation/dehydration sequence [52]. An additional palladium-catalyzed cyclization gave the pyrrolidine mimics 32 in excellent yields and modest to good selectivities (de 8-78\%). In addition, the mild conditions tolerate a wide range of Ugi-substrates, resulting in a broad range of different pyrrolidine mimics 32 .

A more straightforward method [53] includes a single JoulliéUgi 3CR using previously described alkyl substituted cyclic imines [54] giving the cyclic constraint peptides $\mathbf{3 6}$ and $\mathbf{3 7}$ (Scheme 12). In this work, no limitations regarding the type of isocyanide inputs were observed. Several alkyl-, aryl- and estersubstituted isocyanides gave the desired products. On the other

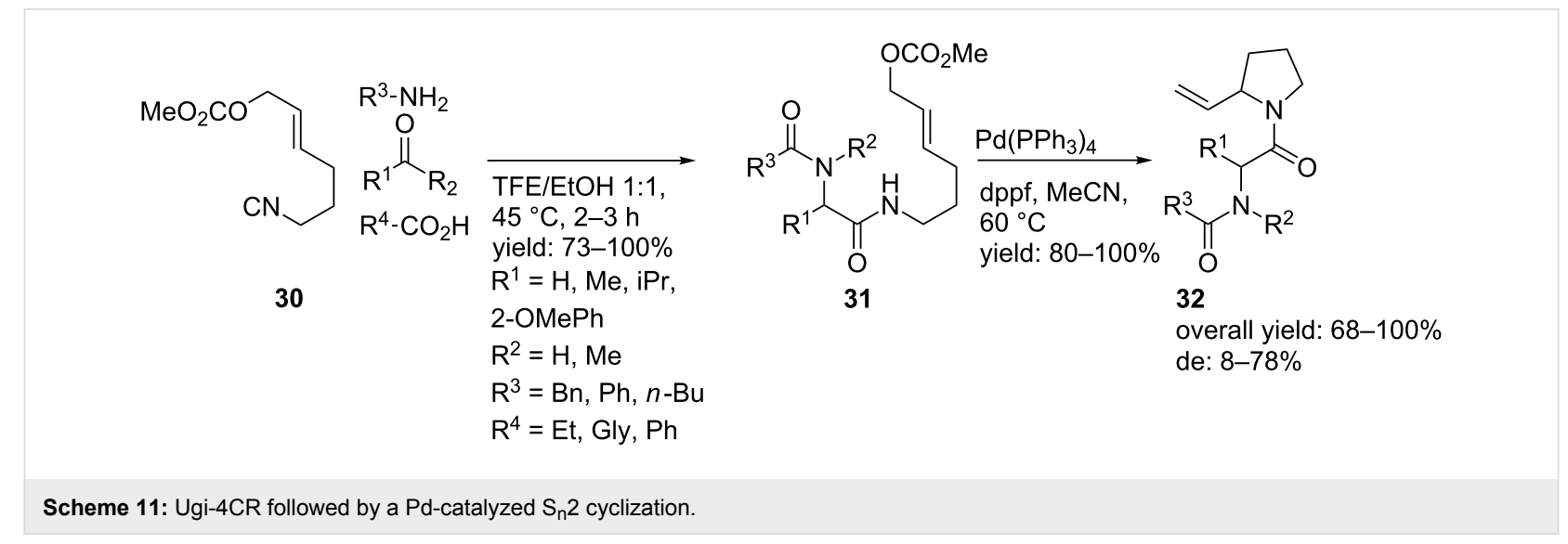




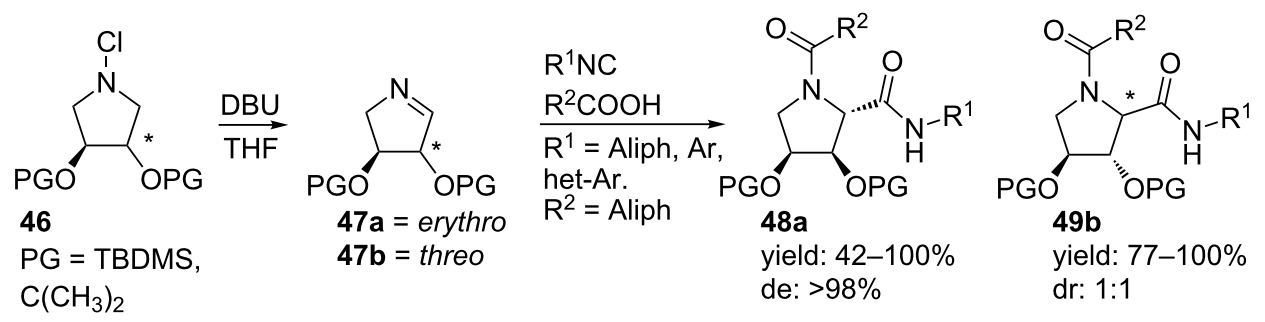

Scheme 15: Dihydroxyproline derivatives from an Ugi reaction.

oxazepinediones 41 and pyrrolodiazepinediones $\mathbf{4 3}$. The latter could be used as inhibitor for aminopeptidase P. In addition, incorporation of convertible isocyanides gave access to bicyclic compound 45 [13].

A one pot synthesis towards hydroxylated pyrrolidines was published by the group of Chapman (Scheme 15) [58]. Hydroxyproline derivatives have been reported as proline peptidase inhibitors [47]. The authors performed a Joullié-Ugi reaction with either the erythritol or the threitol imine $47 \mathbf{a}, \mathbf{b}$ and afforded both isomers $48 \mathrm{a}$ and $\mathbf{4 9 b}$, respectively, in moderate to excellent yields. The reaction with the erythro isomer resulted in a single diastereomer $48 \mathbf{a}$ whereas no selectivity was observed for the threo isomer.

Based on this diastereoselective MCR, the group of Banfi developed an Ugi-Joullié 3-CR with carboxylic acids, chiral bicyclic imines and chiral isocyanides (Scheme 16) [59]. The chiral isocyanides were prepared following an organocatalytic phase-transfer Mannich-type reaction [59], whereas the chiral imines 52a,b were obtained from a bio-catalytic protocol [60]. In particular, the rigid bicyclic imines are powerful starting points and they provide the Ugi-products 53a,b in high yields and mainly as trans-isomers (de $>88 \%$ ), without racemization. As an extension, two other enantiopure isocyanides were combined with a variety of carboxylic acids furnishing a small library of bicyclic dipeptide mimics (55a-d, Scheme 17) in good yields and in high diastereomeric excess (de 70-96\%) [60]. It is worth noting that deprotection of the acetal-group allows modulation of rigidity and polarity of the final molecules.

Our group reported a highly diastereoselective Ugi-MCR towards 3,4-alkyl-substituted prolyl mimics by reacting several isocyanides and carboxylic acids with optically pure 3,4-cissubstituted imines 57 (ee 94-97\%, Scheme 18) [61]. The chiral imines were derived from a biocatalytic oxidation of mesopyrrolidines 56 using monoamine oxidase N (MAO-N) [62]. The Ugi-products were exclusively obtained as single transisomers in high yields (71-83\%, de 84-86\% and ee 94-97\%).

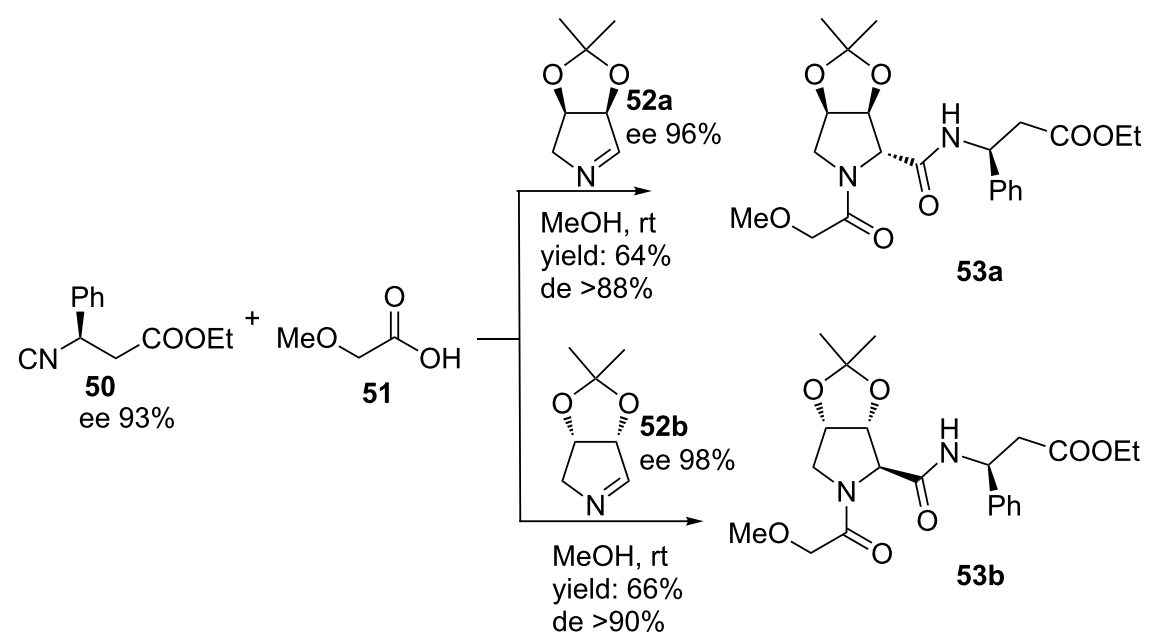




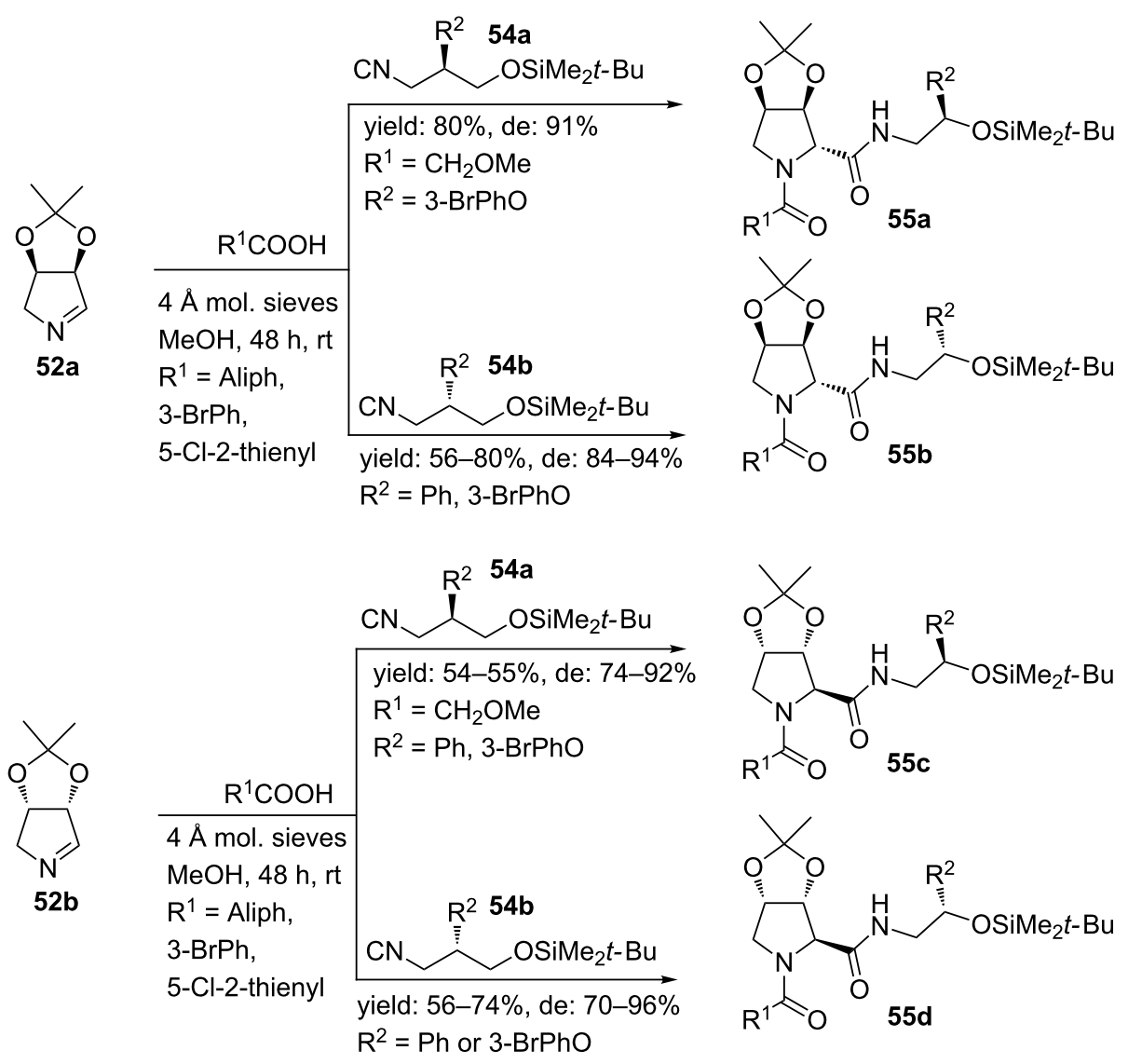

Scheme 17: Similar Ugi reaction as in Scheme 16 but with different acids and two chiral isocyanides.
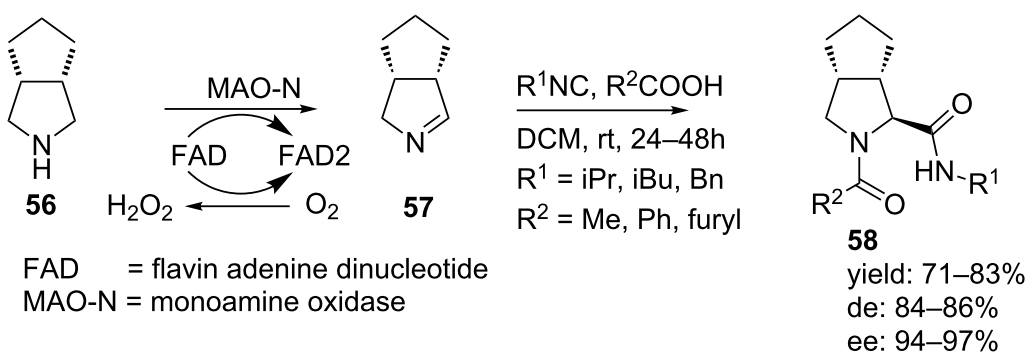

Scheme 18: Highly diastereoselective synthesis of pyrrolidine-dipeptoids via a MAO-N/MCR-procedure.

It is noteworthy that these enantiopure imines can be used in a MCR-based approach to access telaprevir, a known protease inhibitor of hepatitis C (Scheme 19) [63]. The key steps in this route are a Passerini 3-CR to afford the isocyanide substrate $\mathbf{6 1}$ and a subsequent Ugi 3-CR/oxidation protocoll to provide the final compound in a much shorter and more straightforward route compared to earlier described syntheses (11 vs. 24 steps). The bicyclic imine $\mathbf{5 7}$ was obtained via the MAO-N desym- metrizaton described above, whereas a peptide-coupling between L-cyclohexylglycine methyl ester pyrazinecarboxylic acid followed by a saponification afforded the carboxylic acid 62. Moreover, for the isocyanide component, the Dess-Martin oxidation of $\mathbf{6 0}$ and the subsequent Passerini reaction could be performed in one-pot, since the former reaction produces acetic acid as byproduct. Addition of cyclopropyl isocyanide followed by dehydration of the Passerini-product furnished the 


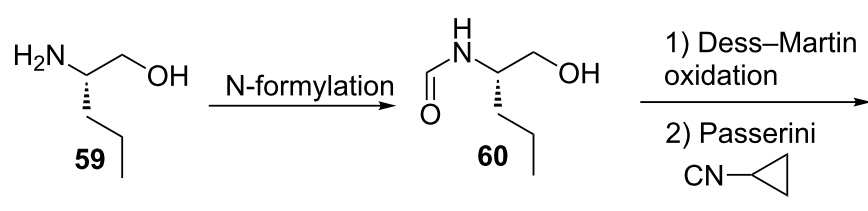

3) dehydration<smiles>CC(=O)OC(CCBr)C(=O)NC1CC1</smiles>

yield: $52 \%$<smiles>COCCCCCC(C)(C)OC</smiles><smiles></smiles>

1) Ugi with 61 and 62

2) Dess-martin oxidation yield: $80 \%$

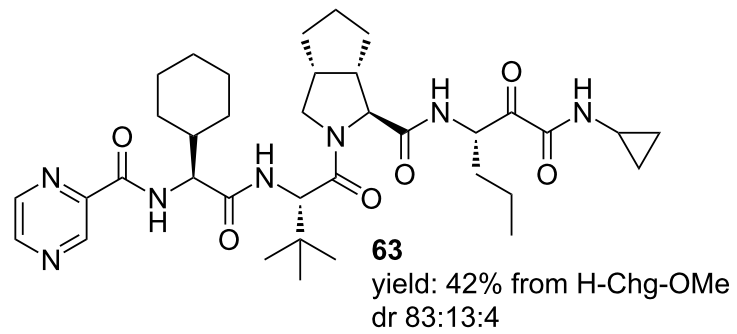

Scheme 19: MAO-N/MCR-approach towards the hepatitis $C$ drug telaprevir.

third Ugi-component 61. The subsequent Ugi 3-CR of 61, 62 and 57 followed by a final oxidation resulted in $\mathbf{6 3}$ (42\% from H-Chg-OMe, dr 84:13:4).

Even better selectivities were observed using the more sterically hindred 64 (Scheme 20) [61] in a similar MAO-N/MCR combination. In this way, dipeptide mimics $\mathbf{6 6}$ were obtained in good yields (75-83\%), however, now with very high diastereomeric ( $>98 \%)$ and enantiomeric excesses $(>99 \%)$.

\section{Y-lactams}

The $\gamma$-lactam unit is an important dipeptide pharmacophore since it can induce $\beta$-turns. A well-known example was described by Freidinger in 1980, who successfully developed a $\gamma$-lactam $\beta$-turn mimic of the luteinizing hormone-releasing hormone (LHRH) almost nine times more potent than the original hormone [64]. Since then, these "Freidinger lactams" have been used in numerous pharmaceutical and biological active compounds. For example, they are found in compounds used for the treatment of epilepsy $[65,66]$, HIV $[67,68]$, and depression [69]. Multicomponent reactions towards $\gamma$-lactam peptidomimetics were earlier described by Ugi [70], Mjalli [71] and Harriman [72]. However, in the last decade two other groups, independently, published Ugi-MCRs towards these cyclic dipeptide isosteres. Hulme et al. reported an Ugi-Deprotection-Cyclization strategy using resin-bound convertible isonitrile $\mathbf{6 7}$ to provide primary and secondary $\gamma$-lactams $\mathbf{7 0}$ in high purities over five steps (Scheme 21) [73]. As an extension,

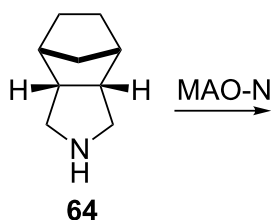

64

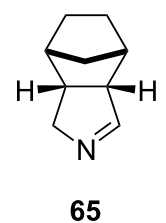

65

\section{$\underset{\mathrm{RCM}, \mathrm{rt}, 24-48 \mathrm{~h}}{\stackrel{\mathrm{R}^{1} \mathrm{NC}, \mathrm{R}^{2} \mathrm{COOH}}{\longrightarrow}}$}

$\mathrm{R}^{1}=\mathrm{iPr}, \mathrm{iBu}, \mathrm{Bn}$

$\mathrm{R}^{2}=\mathrm{Me}, \mathrm{Ph}$, furyl

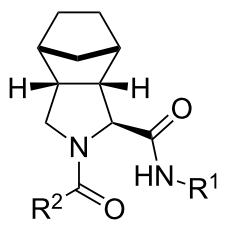

66

yield: $75-83 \%$

de: $>98 \%$

ee: $>99 \%$ 


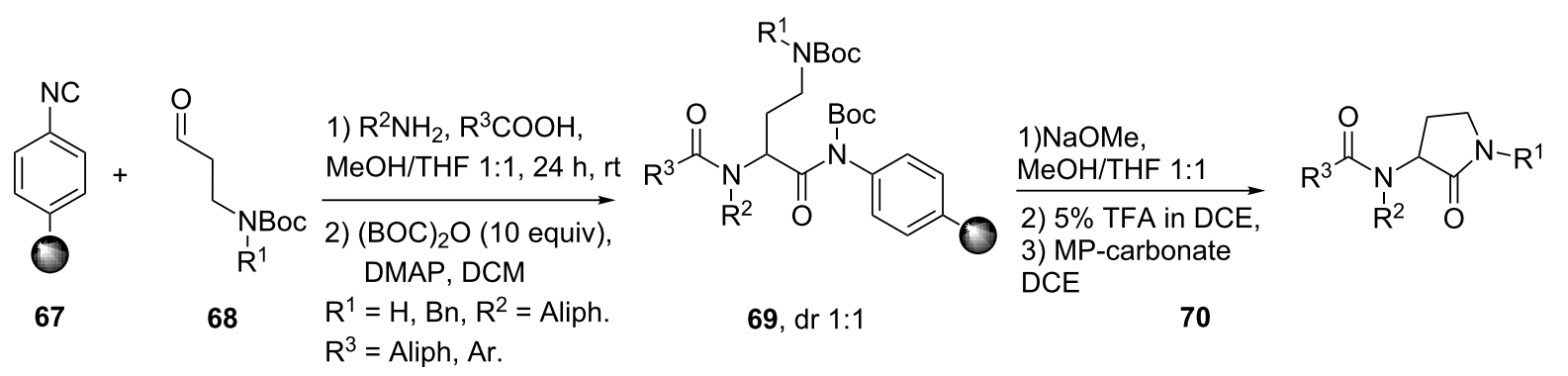

Scheme 21: Synthesis of $y$-lactams via an UDC-sequence.

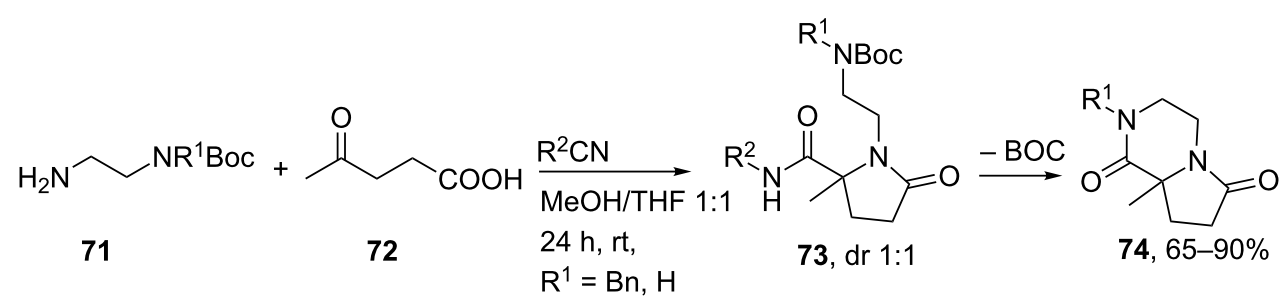

Scheme 22: Utilizing bifunctional groups to provide bicyclic $\gamma$-lactam-ketopiperazines.

they also performed the reaction sequence with bifunctional building blocks 71 and 72, in which subsequent $N$-Boc-deprotection of $\mathbf{7 2}$ provided bicyclic $\gamma$-lactam-ketopiperazines $\mathbf{7 4}$ (Scheme 22).

Krelaus et al. described the one-pot synthesis of both $\gamma$ - and $\delta$-lactams from an Ugi 4C-3CR (Scheme 23) [74]. Screening a variety of isocyanides resulted in a small library of $\gamma$-lactams $\mathbf{7 7} \mathbf{a}$ and $\delta$-lactams $\mathbf{7 7} \mathbf{b}$, in which the former were obtained in higher yields probably due to a more favourable six-membered transition state in the Mumm-rearrangement. Moreover, the nucleophilicity of the isocyanide used also seems important.
Thus, isocyano butane provided the $\gamma$-lactams in high yields (81-93\%), whereas more acidic ethyl 2-isocyano acetate showed less efficient conversion (7-13\%). The stereoselectivity of the process was also studied, however, even with two chiral inputs no stereoinduction was observed for the newly formed stereocenter (dr 1:1). As an extension, the authors performed the Ugi reaction with allyl amine $\mathbf{7 9}$ and olefinic amino acids $\mathbf{7 8}$ (derived from pyroglutamic acid), that, after a following ring-closure-metathesis (RCM) with Grubb's catalyst, resulted in bicyclic lactams $\mathbf{( 8 1}, 46 \%$ over the two steps, Scheme 24). In addition, an even shorter route by utilizing three olefinic Ugi-substrates was also reported. Herein,

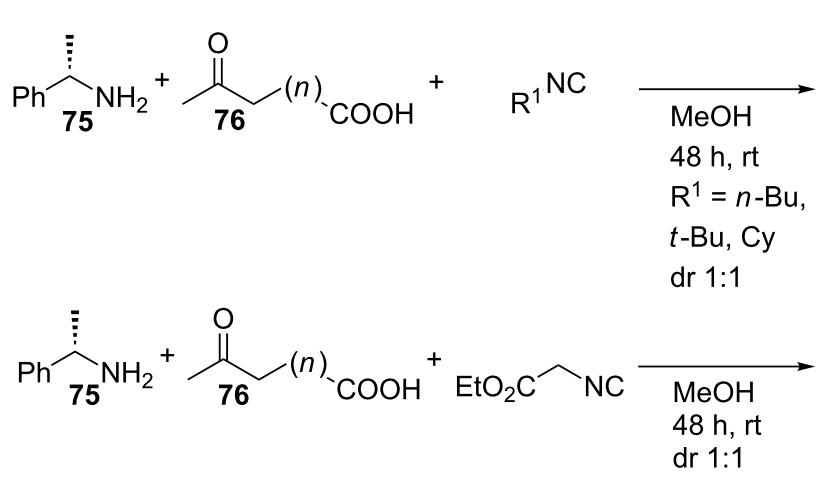<smiles>[R1]NC(=O)C1(C)[TeH]CC(=O)N1[C@H](C)c1ccccc1</smiles>

77a $n=1$, yield: $81-93 \%$

$77 \mathrm{~b} n=2$, yield: $46-59 \%$<smiles>CCOC(=O)CNC(=O)C1(C)CCC(=O)N1C(C)c1ccccc1</smiles>

77c $n=1$, yield: $7-12 \%$

$77 \mathrm{~d} n=2$, yield: $4-13 \%$ 


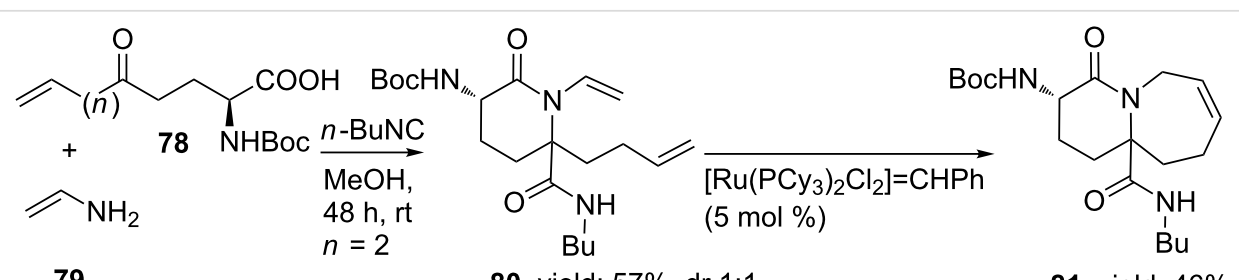

79

$\mathbf{8 0}$, yield: $57 \%$, dr $1: 1$

81, yield: $46 \%$<smiles>C=CCN(C(=O)/C=C/c1ccccc1)C(CC=C)(CC=C)C(=O)NCc1ccccc1</smiles>

82

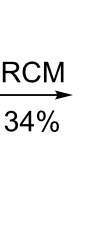

$34 \%$

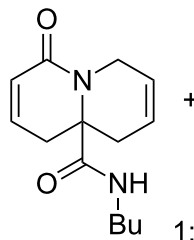

83a<smiles></smiles>

83b

Scheme 24: The sequential Ugi/RCM with olefinic substrates provided bicyclic lactams.

the ring closing step included a double RCM and resulted in an equal amount of both products 83a and 83b (ratio 1:1) $[75,76]$.

\section{Triazoles}

The replacement of amide bonds by 1,2,3-triazoles, especially the 1,4-disubstituted isomer, provided a wide variety of biological active peptidomimetics. Peptidomimetics containing these triazole cores can serve as blood components [77], anticancer medications [78], inhibitors of cysteine [79] and HIV-1 proteases [80-82]. The relative planarity of 1,2,3-triazoles, the strong dipole moment $(\sim 5 \mathrm{D})$ and the ability to both donate and accept hydrogen bonds indicate the physicochemical similarities with amide bonds (Scheme 25), however, they are inert towards oxidation, hydrolysis and enzymatic degradation [88]. Several studies have revealed the bio-similarity of triazoles with amide bonds. For example, X-ray studies towards triazole based-mimics of the HIV-1 protease inhibitor amprenavir showed an equivalent binding mode with the protease active site as compared to the amide-bond inhibitor $[81,83,84]$.

Multicomponent reactions towards amide isosteres often involve an Ugi reaction followed by a Click reaction, in which two of the Ugi-inputs either contain an alkyne or an azide moiety. A well-known example of the latter reaction is the
Copper(I) catalyzed azide-alkyne cycloaddition (CuAAC) between acetylenes and azides (Scheme 25) [85]. Advantages of this reaction are the kinetic stability of both functional groups under a range of different conditions. Also, the triazole products can be formed in both organic and aqueous solvents and by using the $\mathrm{Cu}(\mathrm{I})$-catalyst which induces regioselective formation of the 1,4-isomer over the 1,5-isomer [85].

In 2010, Nenajdenko et al. described an Ugi/Click-approach using chiral isocyanoazides, which in turn were derived from L-amino alcohols [85]. The Ugi-products were obtained in good yields, with high diastereoselectivity (de $>99 \%$ ). A follow-up Click reaction using $10 \mathrm{~mol} \% \mathrm{CuIP}(\mathrm{OEt})_{3}$ and phenyl propargyl ether as the alkyne provided triazole-peptidomimetics 85 in $70-80 \%$ yield (Scheme 26 ).

In a follow-up publication the same authors reported the development of tetrapeptides bearing $\alpha-\mathrm{CF}_{3}-\alpha$-amino and $\alpha-\mathrm{CF}_{3}-\alpha$ amino phosphonate cores (Scheme 27) [86]. Fluorinated compounds may enhance the biological properties of target molecules and especially $\mathrm{CF}_{3}$-containing amino acids have demonstrated to be hydrolytically more stable as compared to the native amino acids [87]. In addition, the insertion of $\alpha$-amino phosphonates to peptides has shown enhanced antibacterial, antivirus and anticancer activities [88]. The Ugi reaction

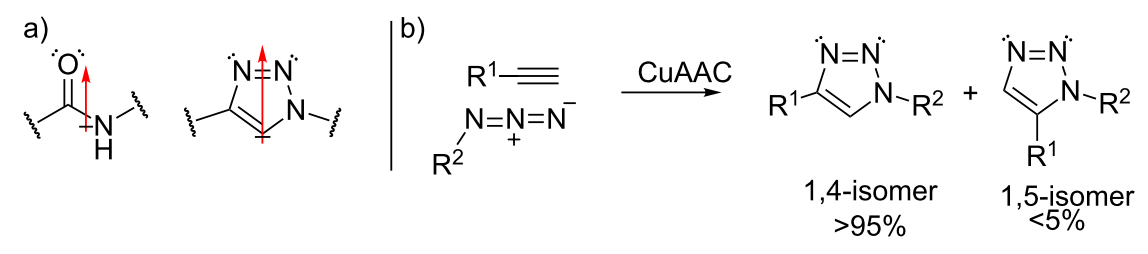

Scheme 25: a) The structural and dipole similarities of the triazole unit with the amide bond. b) The copper-catalyzed Click reaction. 


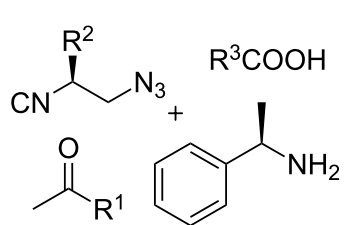

$\mathrm{MeOH}, 12 \mathrm{~h}, \mathrm{rt}$

yield: $48-93 \%$

$\mathrm{R}^{2}=\mathrm{H}$ or Aliph.

$\mathrm{R}^{3}=\mathrm{Ph}, \mathrm{CH}_{2} \mathrm{NHBoc}$<smiles>[c-]1ccccc1</smiles>

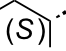<smiles>[R]C(CN)NC(=O)C([R])(C)N1CCCCC1C</smiles>

84a, $R^{1}=H, d r 1: 1$

84b, $R^{1}=\mathrm{Me}$, de $>99 \%$

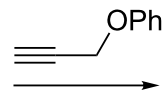

$10 \mathrm{~mol} \%$

CulP(OEt $)_{3}$

$\mathrm{EtOH}$

$3 \mathrm{~h}, 60^{\circ} \mathrm{C}$

yield: $70-88 \%$<smiles>[R]C(=O)N([C@@H](C)c1ccccc1)C([R1])(C)C(=O)NC([R])CI</smiles>

85, yield: $36-82 \%$

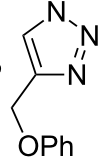

Scheme 26: The Ugi/Click sequence provided triazole based peptidomimetics.

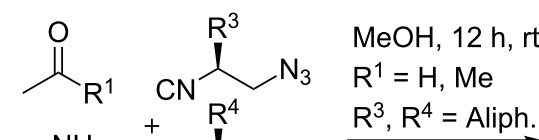

$\mathrm{R}^{2} \mathrm{NH}_{\mathrm{BocHN}}^{+} \stackrel{\mathrm{R}}{4}_{\mathrm{COOH}}$

$\mathrm{R}^{2}=\mathrm{DMB}$,

$\mathrm{PMB}$

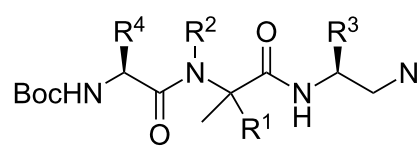

84a, $R^{1}=H$ dr 1:1

84b, $R^{1}=$ Me de $>99 \%$

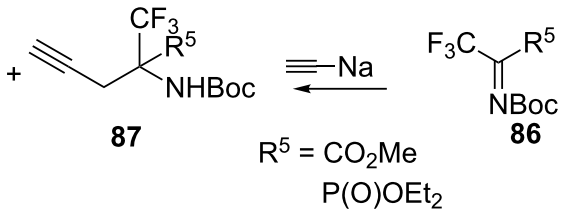

$\mathrm{CuSO}_{4} \cdot 5 \mathrm{H}_{2} \mathrm{O}(5 \%)$,

sodium ascorbate $(30 \%)$

$t-\mathrm{BuOH} / \mathrm{H}_{2} \mathrm{O}(1: 1)$,

$40-90{ }^{\circ} \mathrm{C}, 2-5 \mathrm{~h}$.

yield: $57-97 \%$

dr 1:1

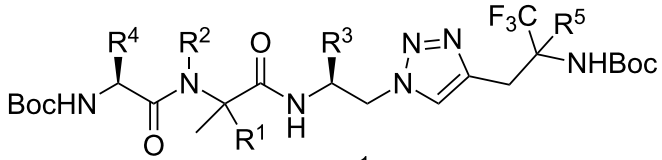

$88 a, R^{1}=H$

$88 b, R^{1}=M e$

Scheme 27: The Ugi/Click reaction as described by Nanajdenko.

provided the azide moieties $84 \mathbf{a}$ or $84 \mathbf{b}$, whereas a reaction between sodium acetylide and imines of general structure $\mathbf{8 6}$ afforded the alkyne derivatives $[89,90]$. A subsequent Click reaction gave the final triazole-mimics $(\mathbf{8 8 a}$ or $\mathbf{8 8 b})$ in good to excellent yields (57-97\%).
A less common approach was reported by Pramitha and Bahulayan [91]. Herein, the Ugi reaction was performed with chloroacetic acid, tert-butyl isocyanide and different aldehydes and amines yielding chloro-Ugi products 89 (Scheme 28). A subsequent substitution with sodium azide followed by the

$$
\begin{aligned}
& \underset{\mathrm{NC}}{\stackrel{\substack{\mathrm{DCM}, 72 \mathrm{~h}, \mathrm{rt} \\
\text { yield: } 64-95 \%}}{\mathrm{R}^{1} \mathrm{CHO}, \mathrm{R}^{2} \mathrm{NH}_{2}}} \\
& \begin{array}{l|l}
\text { yield: } 64-95 \% & \mathrm{NaN}_{3}, \mathrm{~K}_{2} \mathrm{CO}_{3} \\
\mathrm{R}^{1}=\mathrm{Ar} &
\end{array} \\
& \mathrm{R}^{2}=n-\mathrm{Bu} \\
& \text { DMF, } 4 \mathrm{~h}, \mathrm{rt} \\
& \mathrm{Bn}, 4-\mathrm{Br}-\mathrm{Ph}
\end{aligned}
$$<smiles>[C+]#CCOC(=O)c1cc2ccccc2oc1=O</smiles>

91<smiles>[R]C(C(=O)NC(C)(C)C)N([R])C(=O)CN</smiles>

90
$\mathrm{CuSO}_{4} \cdot 5 \mathrm{H}_{2} \mathrm{O}$, Sod.ascorbate yield: $98-100 \%$<smiles>[R]C(C(=O)NC(C)(C)C)N([R])C(=O)Cn1cc(COC(=O)c2cc3ccccc3oc2=O)nn1</smiles>

Scheme 28: The Ugi/Click-approach by Pramitha and Bahulayan. 
Click reaction resulted in the triazole-linked peptidomimetics 92.

Recently, Niu et al. reported an Ugi/Click method to obtain peptidomimetics that have triazole units at the terminal, center and/or at the side chain position [92]. Terminal triazoles were obtained via an Ugi reaction of 4-azidobenzoic acid and different isocyanides, aldehydes and amines (Scheme 29). No limitations for the amine substrate were observed, whereas electron-withdrawing groups in the aldehyde decrease the yield compared to electron donating groups. For practical reasons, the authors used $\mathrm{Cu}(\mathrm{OAc})_{2} /$ vitamin $\mathrm{C} / \mathrm{Et}_{3} \mathrm{~N}$ as $\mathrm{Cu}^{\mathrm{II}}$-complex, in which vitamin $\mathrm{C}$ functioned as reducing agent.

Side-chain triazoles were obtained from 4-azidobenzaldehyde in $48-62 \%$ yield, whereas incorporation of both 4 -azidobenzalde- hyde and 4-azidobenzoic acid provided mimics containing both a triazole unit in the side chain as in the terminal part (43\%). More interestingly, the authors also described an Ugi/Clickcombination in which both Click-substrates were obtained from an Ugi reaction. The subsequent Click cycloaddition provided the triazole linker 97 in $36 \%$ overall yield (Scheme 30). The authors also considered the possibility to perform these three steps simultaneously in one-pot, however, as isocyanides are also good ligands to transition metals, the Ugi products were only obtained in low yield (19\%) without observing any triazole product.

Even more interestingly was the copper-free procedure published by the group of Cai, especially since copper was found in some cases to be toxic to bacterial and mammalian cells [93]. Through a sequential Ugi 4-CR and a three-compo-

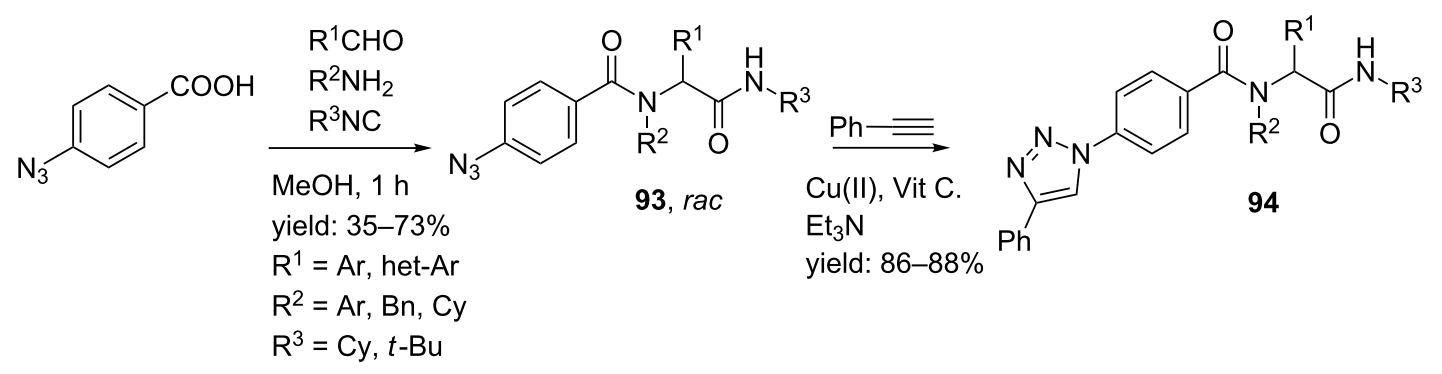

Scheme 29: The Ugi/Click-combination by Niu et al.

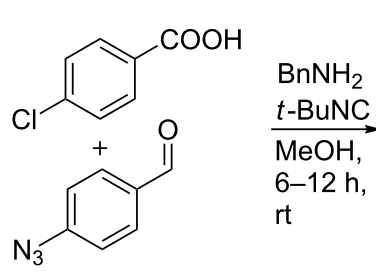<smiles>CC(C)(C)NC(=O)C(c1ccc(N)cc1)N(Cc1ccccc1)C(=O)c1ccc(Cl)cc1</smiles><smiles>C#CCN(C(=O)c1ccc(Cl)cc1)C(C(=O)NC(C)(C)C)C(C)C</smiles>

$\mathrm{Cu}(\mathrm{OAc})_{2}$, sodium ascorbate, $\mathrm{Et}_{3} \mathrm{~N}$

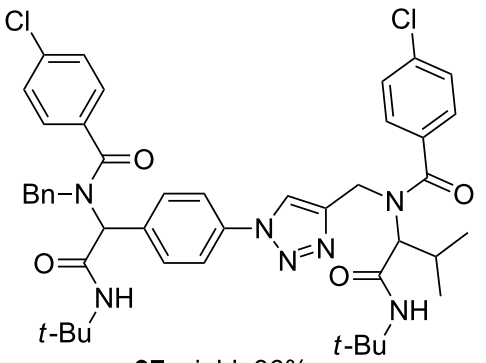

97, yield: $36 \%$
iPrCHO $t$-BuNC<smiles>C#CC[NH2+][CH-]Cc1ccc(Cl)cc1</smiles>

Scheme 30: Triazole linked peptidomimetics obtained from two separate MCRs and a sequential Click reaction. 

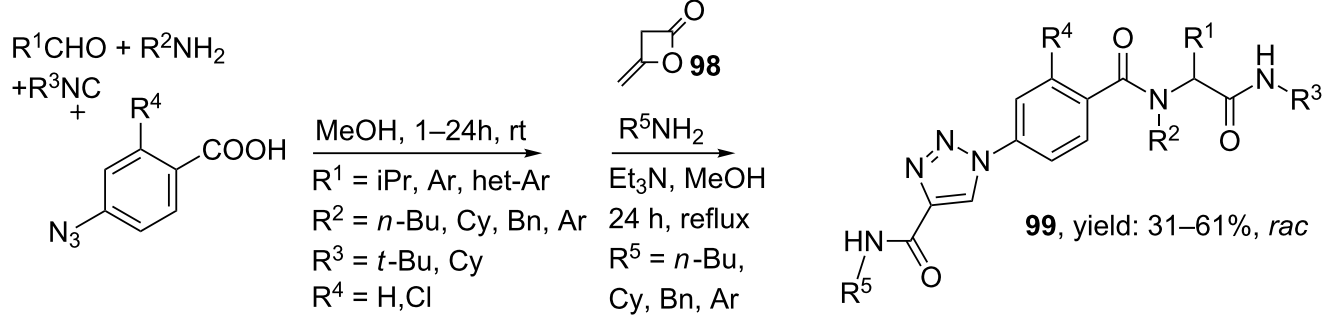

Scheme 31: Copper-free synthesis of triazoles via two MCRs in one-pot.

nent cycloaddition they exclusively prepared 1,4-disubstituted triazoles (99, Scheme 31). Thus, the Ugi 4-CR produced the azide precursor that further reacted in the subsequent 3-CR with diketene 98 and a wide variety of primary amines to afford the triazole linker. The scope of the Ugi reaction was investigated with several aliphatic and aromatic aldehydes and amines and gave the Ugi-products in good yields (34-61\%). Moreover, the scope of sequential cycloaddition was also explored with several aliphatic and aromatic amines, in which the more electron-rich inputs gave the higher yields. In a variation, first the triazole-unit was formed followed by the Ugi MCR. However this resulted in lower yields compared to the initial sequence (33-39\% vs. $31-61 \%$ ).

\section{Pyrazoles and pyrazolones}

The group of Krasavin prepared both pyrazole- as well as pyrazolone-containing peptidomimetics via a sequential hydrazinoUgi/Paal-Knorr condensation [94]. In their first approach, pyrazoles were obtained in good yields, however, with a limited scope of the condensation substrates (Scheme 32). Therefore, an intramolecular Paal-Knorr condensation of 104, derived from an Ugi reaction of bifunctional hydrazine 103 (Scheme 33), under basic conditions was considered. Surprisingly, use of a base did not cleave the trifluoroacetyl group but instead deprotonation of the methylene group was found, yielding pyrrazol-3ones 107. The authors assumed that the cyclization proceeds via an $\mathrm{N}-\mathrm{C}$ acyl migration of the trifluoroacetyl group, based on the<smiles>[R]NC(=O)C([R])N(NC(=O)OCc1ccccc1)C(=O)C(F)(F)F</smiles>

1) $10 \%$ aq. $\mathrm{K}_{2} \mathrm{CO}_{3}$

or

1) $\mathrm{HCl}$, dioxane

2) $\mathrm{EtOH}$, reflux 18-20h

$\mathrm{R}^{3^{\mathrm{O}}} \mathrm{CN}$<smiles>[R]NC(=O)C([R])n1nc(C)cc1N</smiles>

102a $R^{3}=t-B u$, yield: $44 \%$

102b $\mathrm{R}^{3}=1$-adamantyl, yield: $52 \%$

Scheme 32: The sequential Ugi/Paal-Knorr reaction to afford pyrazoles.

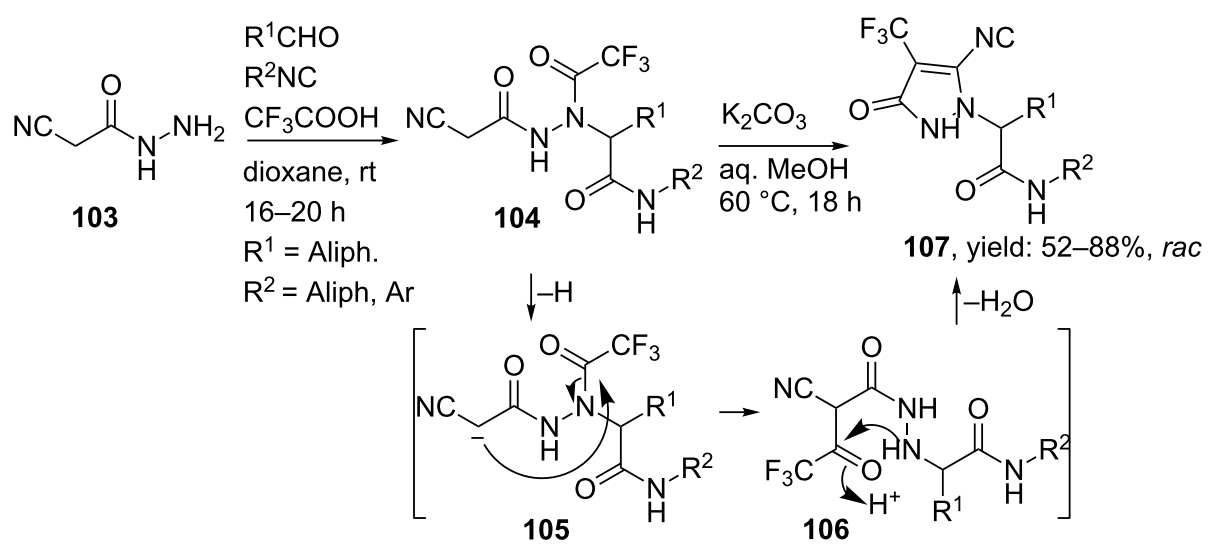




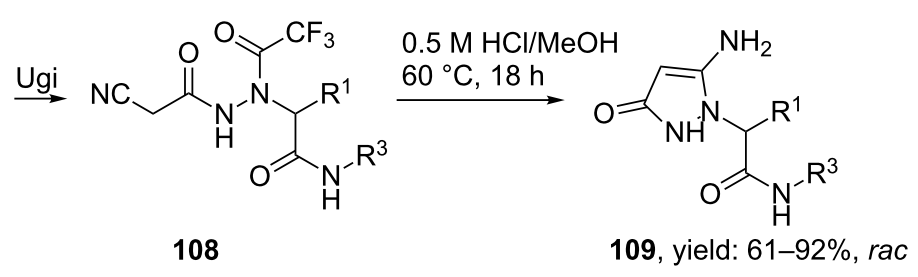

Scheme 34: Similar cyclization performed under acidic conditions provided pyrazolones without the trifluoroacetyl group.

labile character of the latter moiety (Scheme 33). In contrast, acid-promoted cyclization cleaved the trifluoroacetyl group and revealed the initially expected compound $\mathbf{1 0 9}$ (Scheme 34).

\section{Thiazoles}

In several natural products, the thiazole ring can be found as a backbone linker, probably resulting from easy cyclization/oxidation of cysteine residues. These compounds show interesting antifungal and antibiotic [95,96], algicidal [97], and antitumor $[98,99]$ biological activities. In addition, thiazole-based pharmaceuticals are also used as anti-prion agents (neurodegenerative disorders) [100]. Dömling and co-workers were the first that reported an Ugi-based synthesis of 2,4-disubstituted thiazoles (Scheme 35) [101,102]. The procedure involved a condensation of isocyanoacrylate $\mathbf{1 1 0}$ (derived from a known protocol by Schöllkopf) [103], thiocarboxylic acid, a variety of aliphatic amines and several aliphatic and aromatic oxo-components, furnishing the thiazoles $\mathbf{1 1 5}$ as racemic mixtures in moderate to excellent yields (37-82\%). Based on the fact that the Ugi-product tautomerizes, the authors proposed a plausible mechanism, in which tautomer 113 undergoes cyclization via an intramolecular Michael reaction to give intermediate 114. The next step involves cleavage of the dimethylamine group to afford the thiazole structures $\mathbf{1 1 5}$.

In 2003, the same group also described a solid-phase approach with either thioacetic acid or thiobenzoic acid to obtain the 2-acylaminomethylthiazoles [104]. Deprotection of the resin onto the amide, resulted in compound 117 (Scheme 36).

As an extension, Dömling and co-workers designed thiazolebased dipeptide mimics with an additional $\beta$-lactam moiety at-

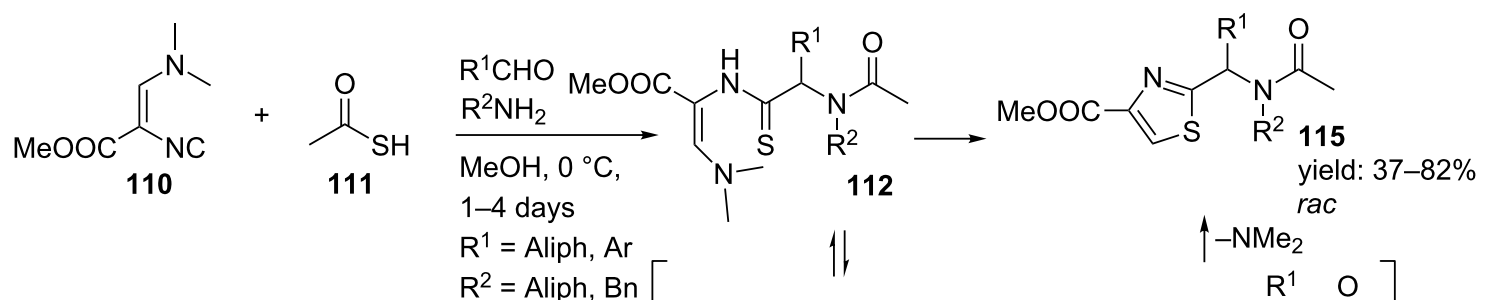
$\mathrm{R}^{2}=$ Aliph, $\mathrm{Bn}$

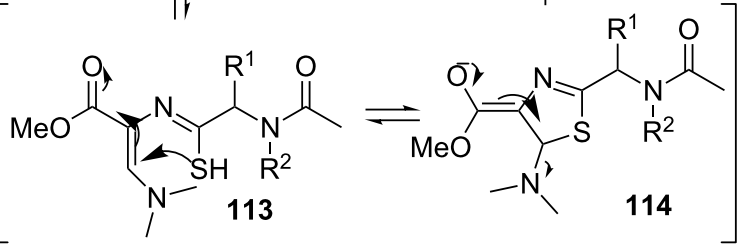
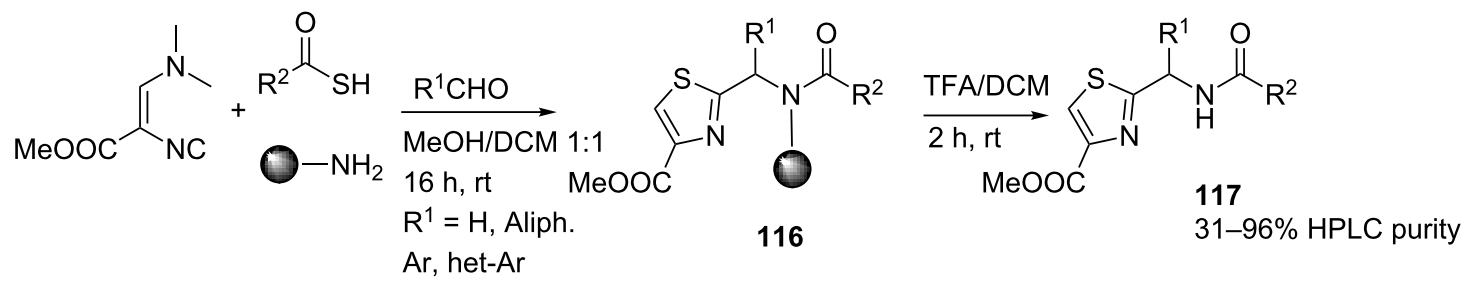


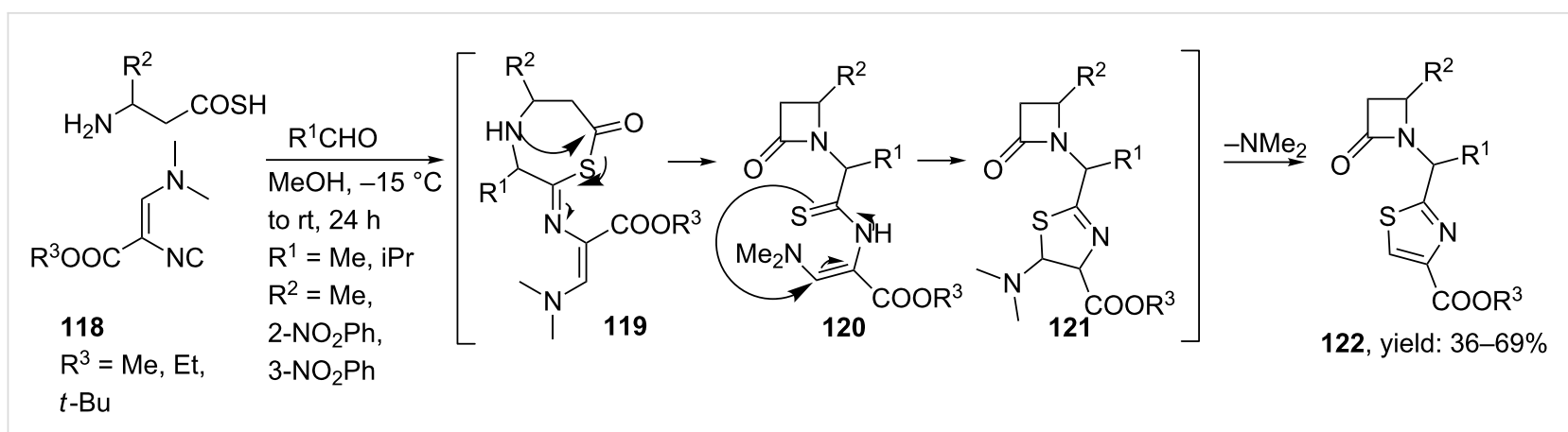

Scheme 37: Reaction mechanism of formation of thiazole peptidomimetics containing an additional $\beta$-lactam moiety.

tached to the scaffold. These compounds could find application as potent antibiotics, protease inhibitors or as cholesterol absorption modifiers (Scheme 37) [18]. In this particular reaction, the scaffolds were obtained by reacting the complex isocyanide 118 with different aldehydes and $\beta$-amino thiocarboxylic acids, in which the latter component was obtained from $Z$-protected $\beta$-amino acids via a cyclic anhydride in two steps [105]. Most likely this reaction proceeds via a 7-membered Ugiintermediate that after an intramolecular acylation results in $\beta$-lactam intermediate 120. A subsequent Michael-type addition followed by dimethylamine absorption then affords the observed thiazoles (((1-thiazole-2-yl)methyl)azetidin-2-ones) in moderate to good yields (36-69\%).

In contrast, Thompson et al. described the synthesis of 2,4disubstituted 5-aminothiazoles via a sequential Ugi/deprotection/thionation/cyclization strategy, in which both $\mathrm{R}^{1}$ and $\mathrm{R}^{2}$-positions could be easily varied (Scheme 38 ) [106,107]. They derived the linear dipeptide from an Ugi 4-CR involving the Walborsky reagent 123 (1,1,3,3-tetramethylbutyl isocyanide) as a cleavable isocyanide input, 2,4-dimethoxybenzylamine $124\left(\mathrm{DMB}-\mathrm{NH}_{2}\right)$, different aldehydes and carboxylic acids [106]. Subsequent TFA-treatment provided the precursor 125 that via a follow-up reaction with Lawesson's reagent and an intramolecular cyclization gave access to the thiazole derivative 126. A second TFA-cleavage of the $N$-(1,1,3,3-tetramethylbutyl) group resulted in the 5-aminothiazole peptidomimetics 127 in sufficient overall yields (5-13\%).

In a variation, the authors designed an ammonia-based Ugi reaction that avoids the use of protected amines (Scheme 38) [107]. It was shown that this protecting-group-free protocol tolerates a great variety of different isocyanides and also allows acid sensitive substrates. In particular, the use of isocyanide $\mathbf{1 2 8}$ gave access to 5-aminothiazoles $\mathbf{1 2 7}$ after deprotection of the DMB-group (Scheme 39).

Kazmaier and Persch studied a versatile thio-Ugi MCR towards 2,5-disubstituted thiazoles (Scheme 40). The authors first obtained the Ugi-products by reacting thiobenzoic acid,

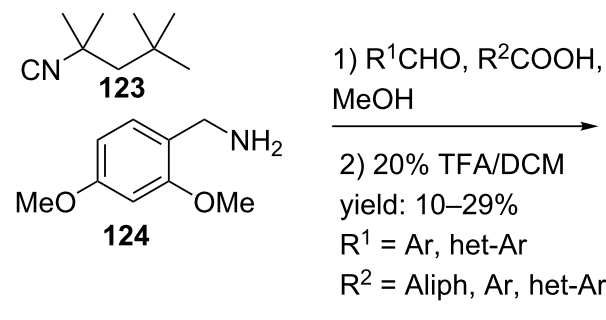

\begin{tabular}{l} 
1) $\mathrm{R}^{1} \mathrm{CHO}, \mathrm{R}^{2} \mathrm{COOH}$ \\
$\mathrm{MeOH}$ \\
\hline 2) $20 \%$ TFA/DCM \\
yield: $10-29 \%$ \\
$\mathrm{R}^{1}=\mathrm{Ar}$, het-Ar \\
$\mathrm{R}^{2}=$ Aliph, Ar, het-A
\end{tabular}
TFE, rt, 18 h, yield: $24-64 \%$

$\mathrm{R}^{1}=\mathrm{Ar}$, het-Ar

$\mathrm{R}^{2}, \mathrm{R}^{3}=$ Aliph, $\mathrm{Ar}$, het-Ar $\stackrel{\mathrm{NH}_{3}}{+}+\mathrm{R}^{1} \mathrm{CHO}+\mathrm{R}^{2} \mathrm{COOH}+$
$\mathrm{R}^{3} \mathrm{NC}$

Lawesson's reagent xylene, reflux, $1 \mathrm{~h}$ yield: $23-65 \%$<smiles>[R]Nc1sc([R2])nc1[R10]</smiles> 


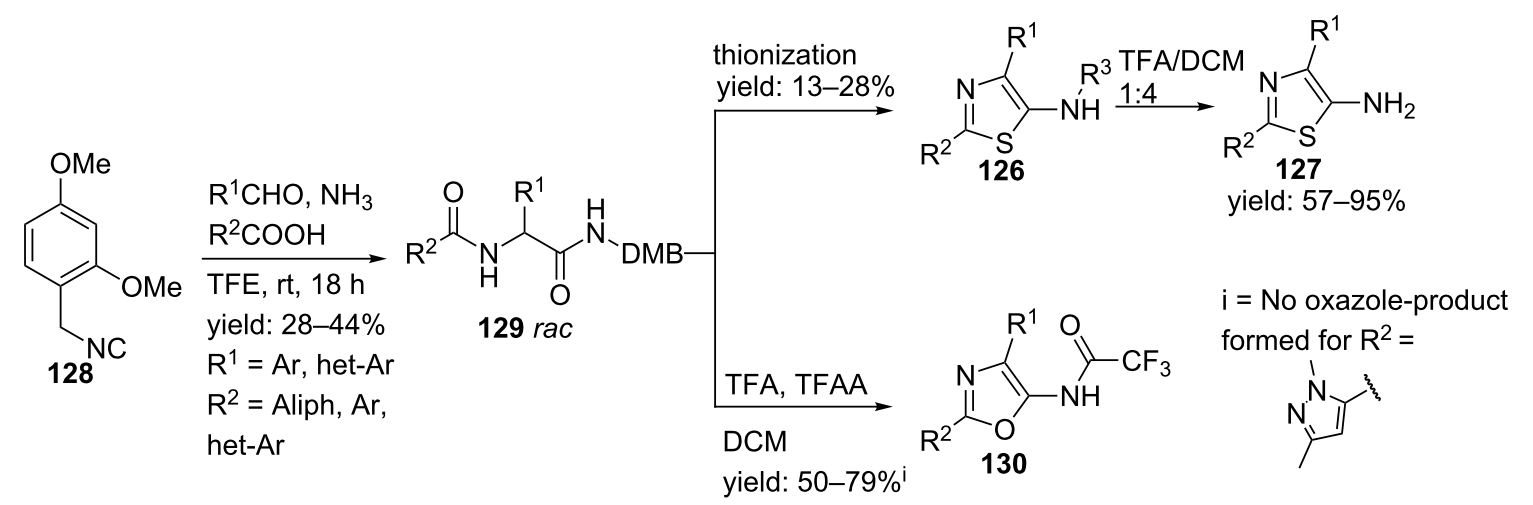

Scheme 39: Performing the Ugi reaction with DMB-protected isocyanide gave access to either oxazoles or thiazoles.

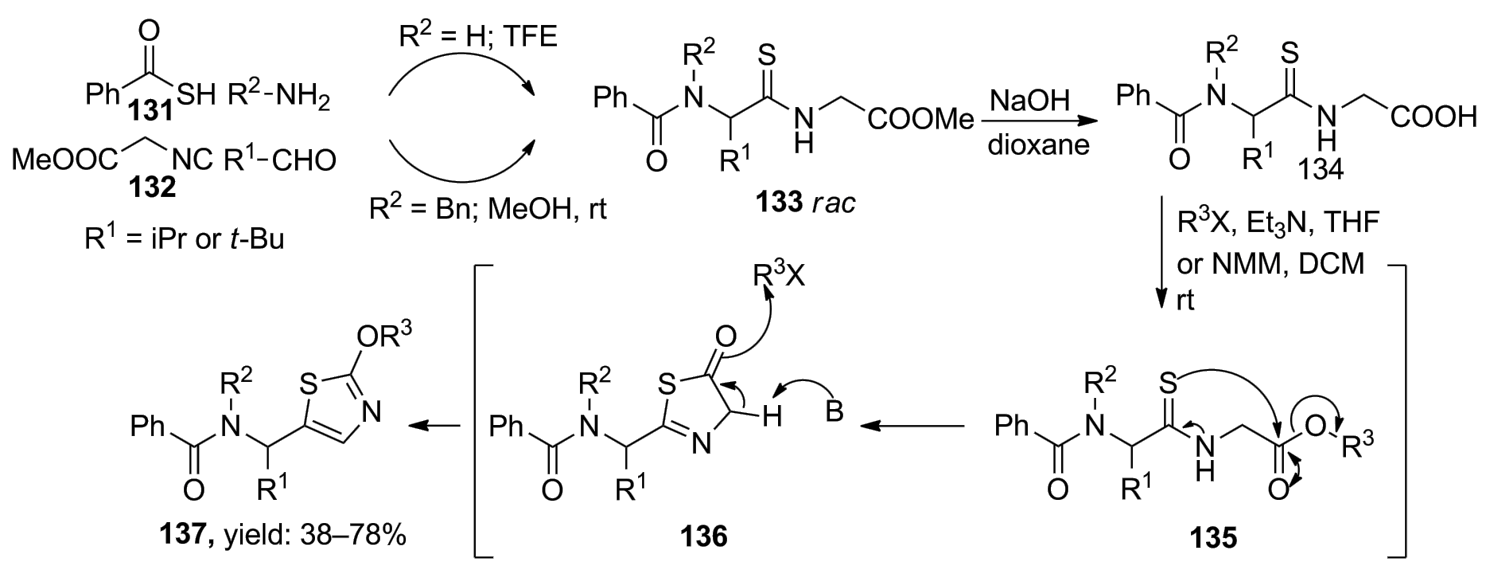

Scheme 40: Ugi/cyclization-approach towards 2,5-disubstituted thiazoles. The Ugi reaction was performed with different benzylamines or ammonia.

isocyanoacetate, two aliphatic aldehydes (iPr, $t$-Bu) and benzylamines/ammonia in either methanol (for benzylamines) or trifluoroethanol (for ammonia) [108]. Then, subsequent hydrolysis of the methylester followed by activation via acid chlorides or triflates gave the 5-substituted thiazoles (38-78\%), probably via a thiazolone intermediate. It is noteworthy that the triflate-thiazoles can be further elongated via cross coupling reactions, resulting in even higher functionalized 5-substituted or non-functionalized thiazoles in good to excellent yields (51-95\%, Scheme 41) [108].

In 2009, the group of Dömling reported an Ugi-approach towards the synthesis of Bacillamide C (Scheme 42) [109]. (R)Bacillamide $\mathrm{C}$ is a natural product with algicidal and antibacterial properties [97]. It was shown that a stereoselective reaction between Schöllkopf's isocyanide, acetaldehyde, thioacetic acid and 4-methoxy-phenylethylamine (also as chiral auxiliary) provided the corresponding Ugi product 138 in $60 \%$ yield ( $\mathrm{dr}$ $1: 1)$. Chiral separation and deprotection in TFA resulted in compound 139 in $70 \%$ yield, after which saponification followed by an amide coupling with tryptamine and CDI afforded the final $(R)$-bacillamide $\mathrm{C}$ in $6 \%$ yield over three steps (ee $94 \%)$.

\section{Oxazoles}

The oxazole unit has been applied in different bioactive marine natural products [110]. The group of Zhu reported a Ugi 3-CR to a small library of 2,4,5-trisubstituted oxazole-containing peptide-like structures from bifunctional $\alpha$-isocyanoacetamides (Scheme 43) [111,112]. A plausible mechanism for this reaction involves the formation of $\mathbf{1 4 1}$, that after tautomerization, cyclizes to the oxazole product $\mathbf{1 4 3}$. It is noteworthy, that this reaction proceeds without the addition of a carboxylic acid because amino-oxazoles are unstable under acidic conditions. In total, six different aldehydes, twelve amines and three isocyanides yielded the corresponding desired oxazole mimics 143 in good yields (60-96\%), however, the products were obtained as racemates even when the reaction was performed 


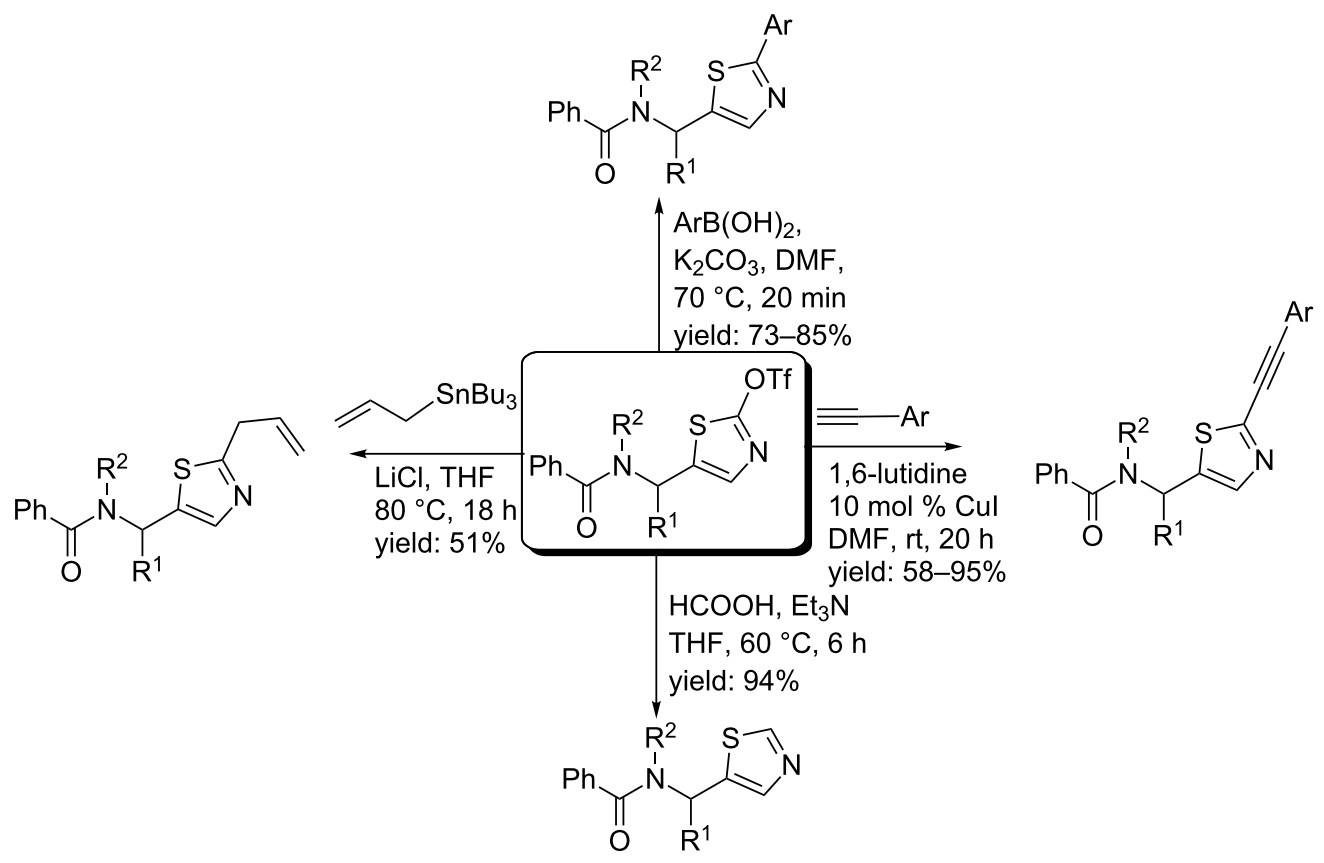

Scheme 41: Further derivatization of the thiazole scaffold.
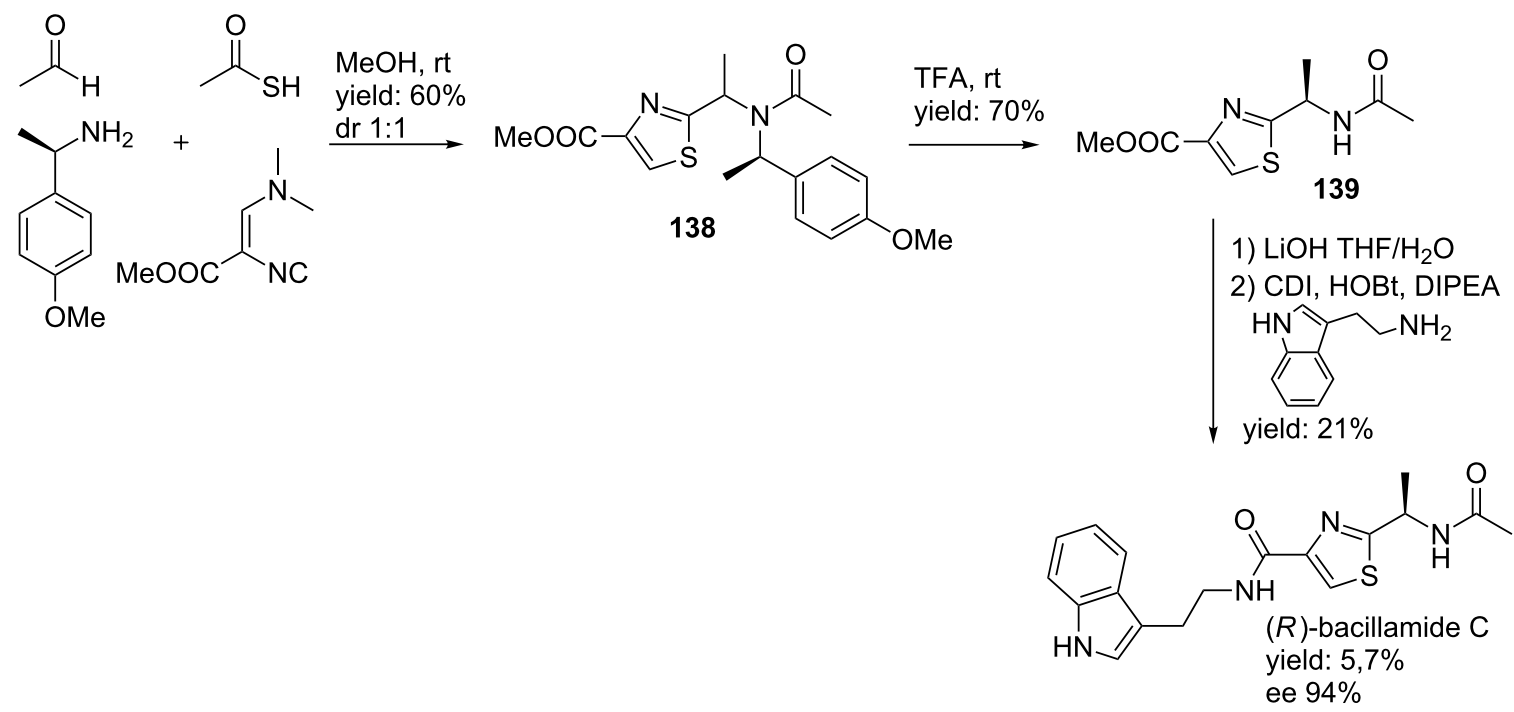

Scheme 42: Three-step procedure towards the natural product bacillamide C.

with chiral isocyanides. Some diastereoselectivity was only observed when the methyl ester of $(S)$-proline was used as an amine input (de $42 \%$, Scheme 43 ). As an extension, the authors also performed the Ugi reaction in (the non-polar solvent) toluene and ammonium chloride as proton source (for the imine) at evaluated temperatures to provide the oxazoles in $52-73 \%$ yield (Scheme 43 ). It is noteworthy that during this latter approach no Passerini products or side-products with $\mathrm{NH}_{3}$ (from ammonium chloride) were observed.

In contrast, Shaw et al. [113] reported another convenient approach in which a sequential Ugi 4-CR followed by a Robinson-Gabriel reaction resulted in the desired oxazoles (Scheme 44). Herein, dimethoxybenzylamine, several 
a)<smiles>[R]C(N)C(=O)N1CCOCC1</smiles>

140,

$\mathrm{R}^{3}=\mathrm{Bn}, \mathrm{Ph}, \mathrm{iPr}$

b)<smiles>[R]C(C)C(=O)N1CCOCC1</smiles>

140,

$\mathrm{R}^{3}=\mathrm{Bn}, \mathrm{Ph}, \mathrm{iPr}$
$\underset{\mathrm{ReOH}}{\stackrel{1}{ } \mathrm{HO}, \mathrm{R}^{2} \mathrm{NH}_{2}}$
$50^{\circ} \mathrm{C}, 4 \mathrm{~h}$

yield: $52-96 \%$

$\mathrm{R}^{1}=$ Aliph, $\mathrm{Ar}$

$\mathrm{R}^{2}=$ Aliph, Bn,

morpholine<smiles>[R]CNC([R])c1nc([R3])c(N2CCOCC2)o1</smiles>

$\mathrm{R}^{1} \mathrm{CHO}, \mathrm{R}^{2} \mathrm{NH}_{2}$

toluene, $\mathrm{NH}_{4} \mathrm{Cl}$ $60{ }^{\circ} \mathrm{C}$

yield: $52-73 \%$<smiles>[R]NC([R])c1nc([R3])c(N2CCOCC2)o1</smiles>

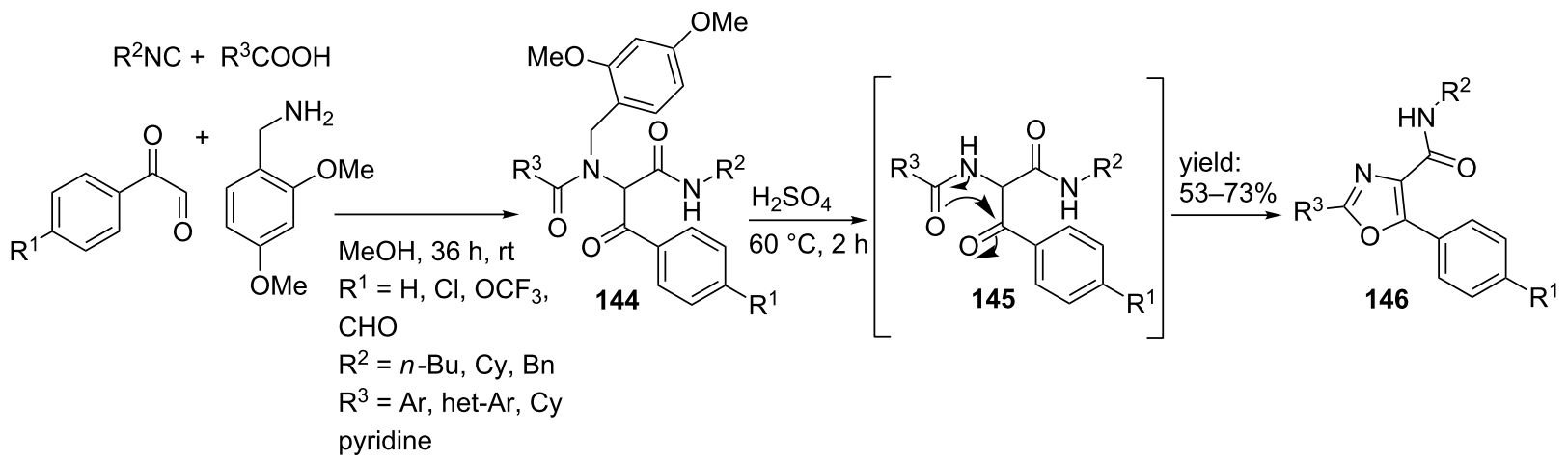

Scheme 44: Ugi-based synthesis of oxazole-containing peptidomimetics.

isocyanides, aryl-glyoxals and (hetero)-aryl carboxylic acids afforded the desired corresponding Ugi-products 144 in reasonable to good yields (42-65\%). Subsequent exposure to concentrated sulfuric acid at $60{ }^{\circ} \mathrm{C}$ deprotected and cyclized the linear products towards the oxazole derivatives $\mathbf{1 4 6}$ in yields up to $73 \%$.

\section{Tetrazoles}

In medicinal chemistry, tetrazoles are often used as carboxylic acid bio-isosteres due to their comparable acidity [114] However, studies towards 1,5-disubstituted tetrazoles have shown that these heterocycles also show geometrical properties similar to cis-amide bonds [115]. Therefore, they have been incorporated as constrained cis-amide bond isosteres in several bio-active compounds such as inhibitors of cyclooxygenase-2 (COX-2) [116], hepatitis C NS3 proteases [117], HIV-1 proteases [111,112,117], the CB1 receptor of cannabinoid and fatty acid amide hydrolase [114,118-121].
In this context, Hulme and co-workers described a Passerini multicomponent approach towards cis-constrained norstatine mimics, a class of HIV-1 protease inhibitors with a tetrazole core (Scheme 45) [122]. They showed that a TMSN 3 -modified Passerini 3-CR gave easy access to tetrazole building blocks that, after $N$-Boc-deprotection, could be coupled with polymerbound tetrafluorophenol-esters. Subsequent heating provided the desired $N$-coupled Norstatine peptidomimetics 149 (HPLC purities: $30-74 \%$ ), in which additional scavenging of the unreacted amines with polystyrene-based isocyanate (PS-NCO) improved the purities of the final products $(69-84 \%)$. It is noteworthy that the use of $\mathrm{TMSN}_{3}$ has several advantages, as it is less toxic and explosive than commercial derivatives and the byproduct (methoxytrimethylsilane) is easily evaporated.

Based on this Passerini reaction, the group of Zhu developed an enantioselective approach using hydrazoic acid as the azide source and [(salen) $\left.\mathrm{Al}^{\mathrm{III}} \mathrm{Me}\right]$ as the catalyst [123]. A variety of 


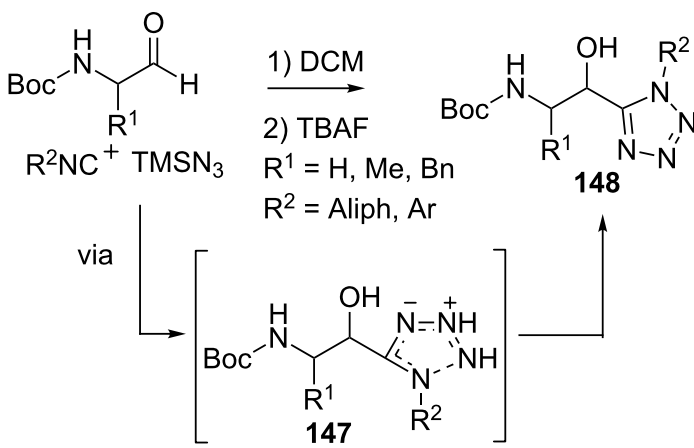

2) $\underset{T F P^{-}-X^{-R^{3}}}{\stackrel{T F A / D C M}{\longrightarrow}}$

3) PS-NCO

$\mathrm{X}=\mathrm{CO}$ or $\mathrm{SO}_{2}$

$\mathrm{R}^{3}=$ Aliph, $\mathrm{Ar}$<smiles>[R][X]NC([R])C([R])c1nnnn1[R]</smiles>

149, yield: $69-84 \%$

Scheme 45: $\mathrm{TMNS}_{3}$ based Ugi reaction for peptidomimics containing a tetrazole.

aliphatic aldehydes and both aliphatic and aromatic isocyanides were tolerated in their approach and resulted in a library of tetrazoles 150 with excellent yields and high enantiomeric excesses (51-97\%). For this enantioselectivity, the authors proposed a mechanism as shown in Scheme 46. In addition, from their study it became clear that the azide moiety is directly transferred from $\mathrm{HN}_{3}$ and not from the Al-bound azide, since no product was formed in the absence of $\mathrm{HN}_{3}$.

5 -substituted tetrazoles could also be obtained from an Ugi 4-CR between aldehydes, amines and $\mathrm{TMSN}_{3}$ and cleavable isocyanides as was described by Mayer et al. [124] Cleavable isocyanides consist of acidic protons at the $\beta$-position and can be obtained for example from $\beta$-amino acids. During the Ugi reaction, the tetrazole moiety is obtained from a sigmatropic rearrangement (Scheme 47). Subsequent base-treatment enables $\beta$-elimination, which is driven by mesomeric stabilization of the triazole ring, resulting in the desired 5-substituted tetrazoles $\mathbf{1 5 4}$ in moderate to good yields with three points of diversity.

Alternatively, 5-substituted tetrazoles can be obtained via an Ugi-reaction between a (Rink) resin bound isocyanide, $\mathrm{TMSN}_{3}$, several aldehydes and amines [125]. The final tetrazoles $\mathbf{1 5 6}$ were obtained from TFA cleavage (Scheme 48).

In a combined approach, Gunawan et al. also described such an Ugi-azide reaction to develop $\gamma / \delta / \varepsilon$-lactam tetrazoles [126,127]. Depending on the keto-ester or acid used, an Ugi reaction with different primary amines, isocyanides and $\mathrm{TMSN}_{3}$ followed by subsequent cyclization gave either $\gamma$-, $\delta$ - or $\varepsilon$-lactam tetrazoles (Scheme 49). Herein, cyclization for the $\gamma$-lactam derivatives was performed under acidic conditions, while CDI was used as cyclization agent in the $\delta$-lactam formation and $\mathrm{SOCl}_{2}$ was required for the $\varepsilon$-lactam tetrazoles. All multicomponent reactions were performed in $\mathrm{MeOH}$ at room temperature and the final tetrazoles $\mathbf{1 5 8 a - c}$ were obtained in moderate to good yields.

\section{Six-membered ring constraints \\ Pipecolic acid}

In the previous section we discussed some important conformational properties of proline derivatives playing an important role in controlling peptide and protein secondary structures.

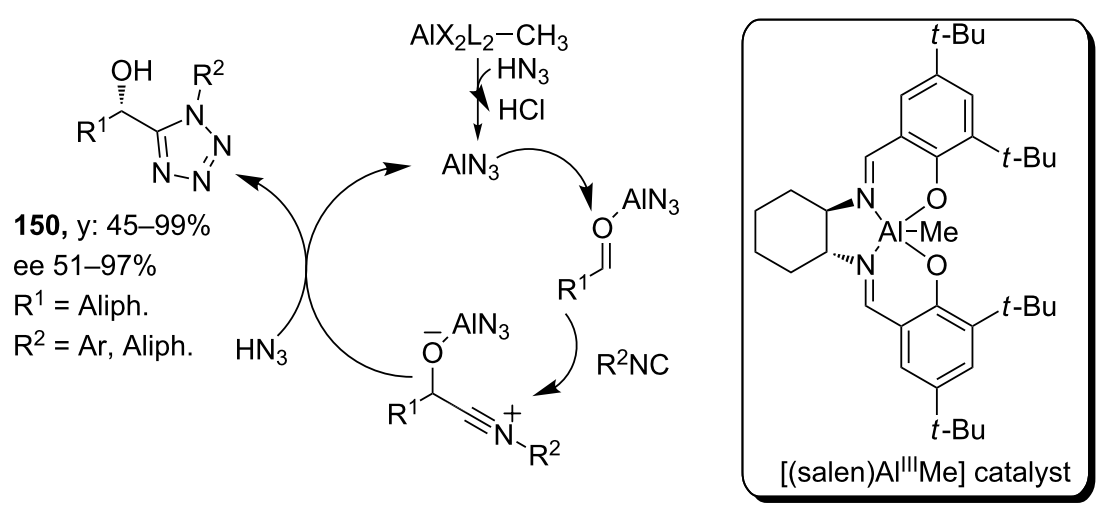

Scheme 46: Catalytic cycle of the enantioselective Passerini reaction towards tetrazole-based peptidomimetics. 


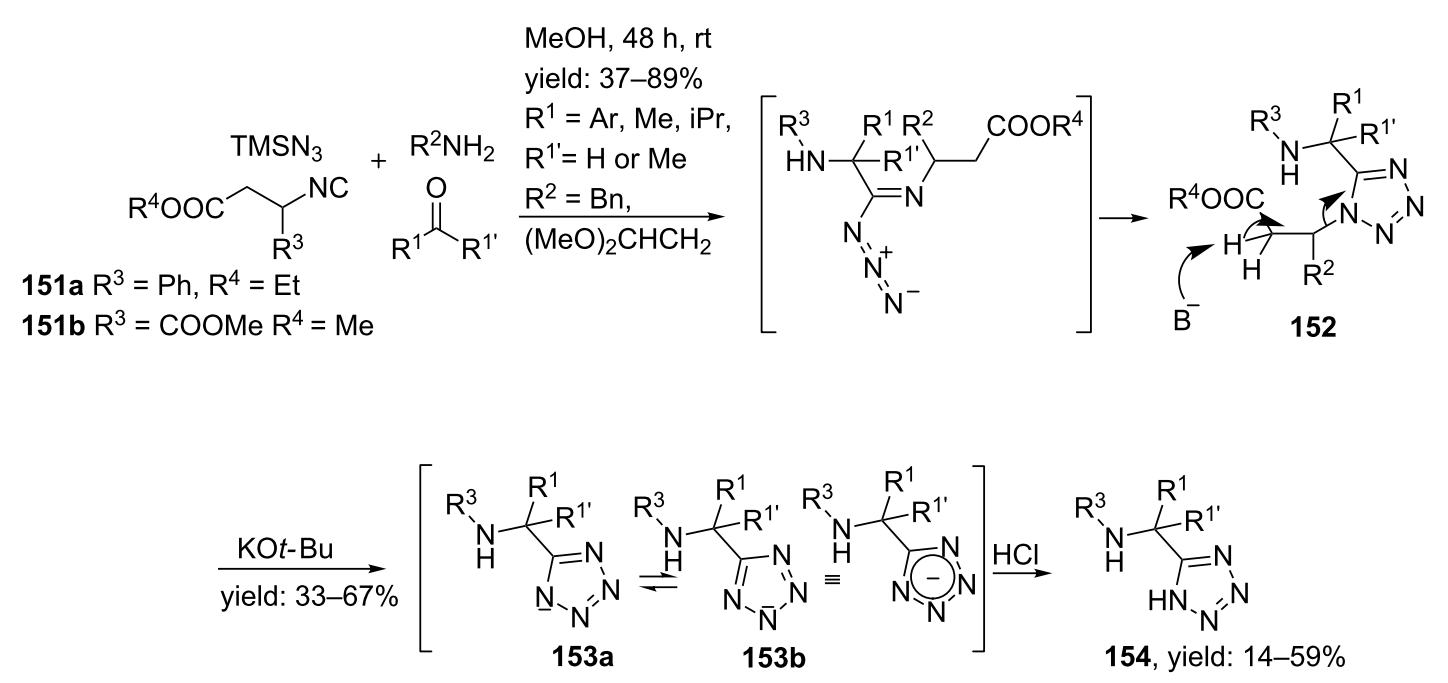

Scheme 47: Tetrazole-based peptidomimetics via an Ugi reaction and a subsequent sigmatropic rearrangement.
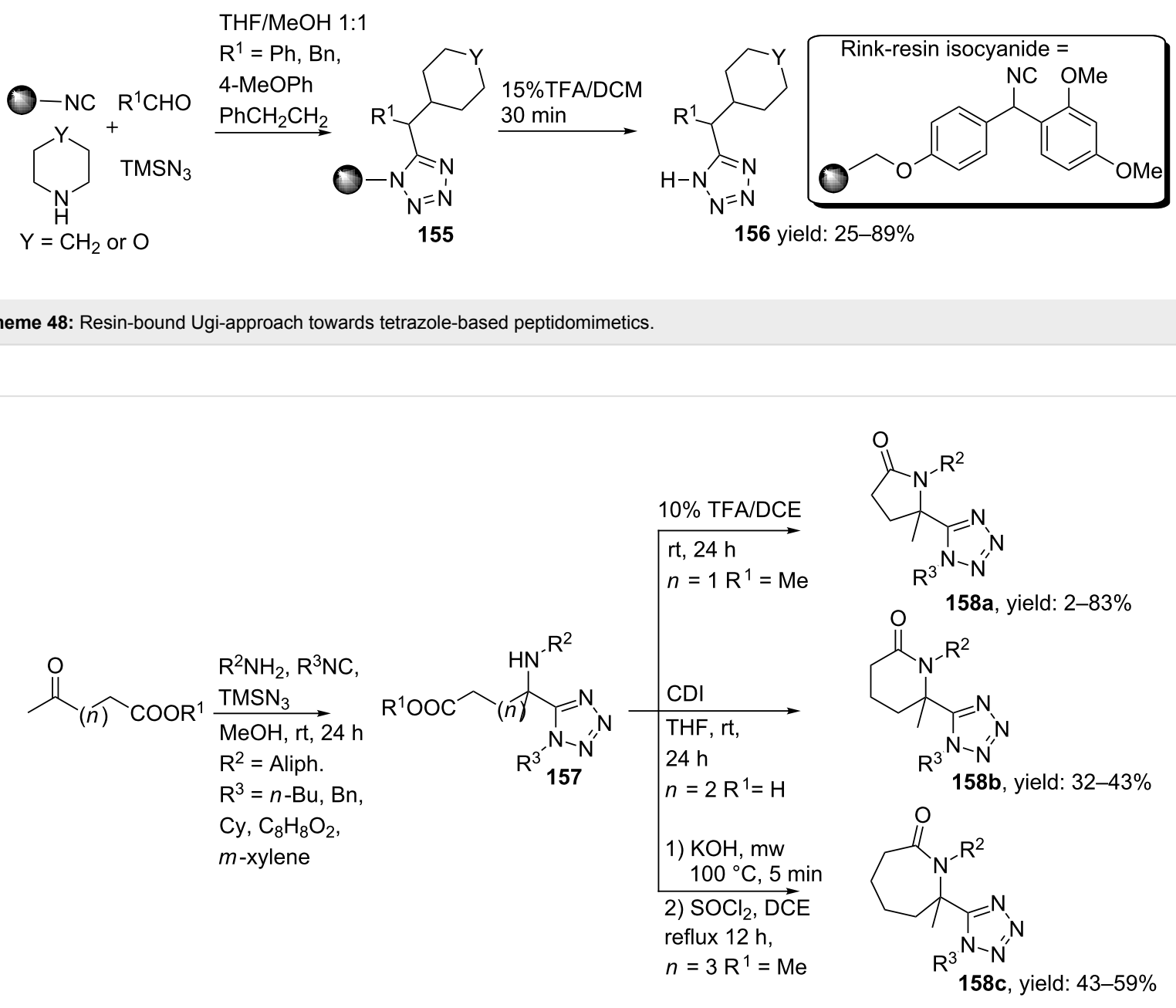
Replacement of the proline residue by its six-membered analogue, pipecolic acid, has provided valuable insights in peptide folding and bioactive conformations [128,129]. In particular, pipecolic acid derivatives often find their application as $\beta$-turn mimetics [130], and are therefore included in several pharmaceutical compounds such as antipsychotics, anticonvulsants, local anaesthetics or analgesics [131]. An interesting diastereoselective multicomponent approach towards such sixmembered pipecolic acid-based analogues was described by Maison et al. [128] Although this work is closely related to earlier work of Dömling and Ugi [129], it is an interesting extension of the original protocol. Maison investigated 3- and 6-substituted pipecolic acid analogues $159 \mathbf{a}-\mathbf{b}$ via a reaction with achiral and chiral imines, methyl-2-isocyanoacetate and $N$-Boc-protected glycine (Scheme 50). It was shown that the products were obtained in excellent yields and in high diastereoselectivity when chiral imines were employed (159b, de $>95 \%$ ).
The group of van Boom and Overkleeft reported pipecolic amides via a Staudinger-Aza-Wittig/Ugi sequence (SAWU 3CR, Scheme 51) [132]. First the Staudinger reaction between an orthogonally protected carbohydrate-derived azido-acetal and trimethylphosphine yielded the necessary cyclic imine, which then was exposed to benzoic acid and different isocyanides. The resulting Ugi-bisamides 163 were obtained in moderate to good yields $(22-78 \%)$, in which the more sterically demanding isocyanides gave the best results. In addition, the Ugi-products were obtained as single diastereomers with a trans-configuration. They argue that the isocyanide and acid substrates react at the least hindered side of the imine.

\section{2,5-Diketopiperazines}

Diketopiperazines (DKPs) are the smallest class of naturally occurring cyclic peptides containing a six-membered core ringsystem. Such DKPs were shown to possess several interesting medicinally relevant properties such as antifungal

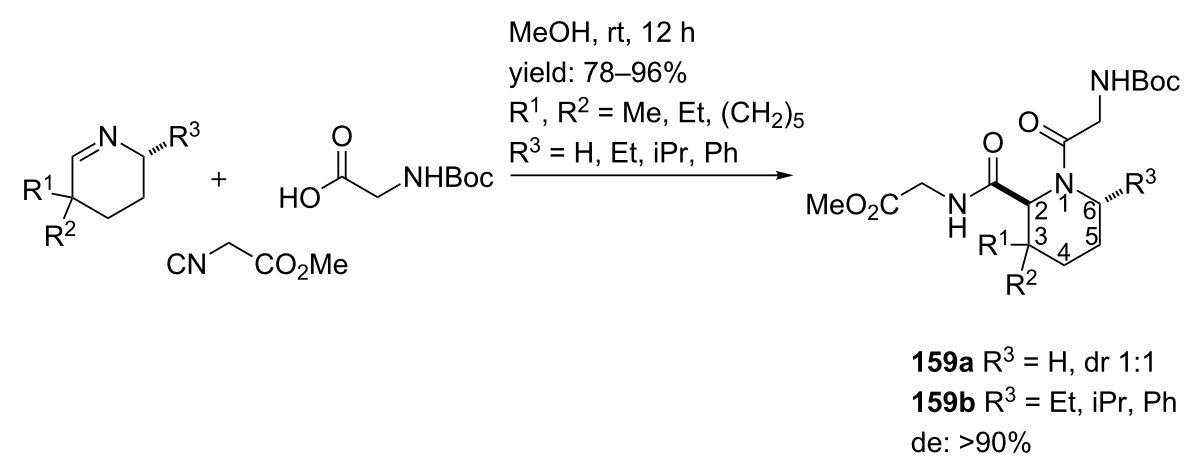

Scheme 50: Ugi-3CR to pipecolic acid-based peptidomimetics.

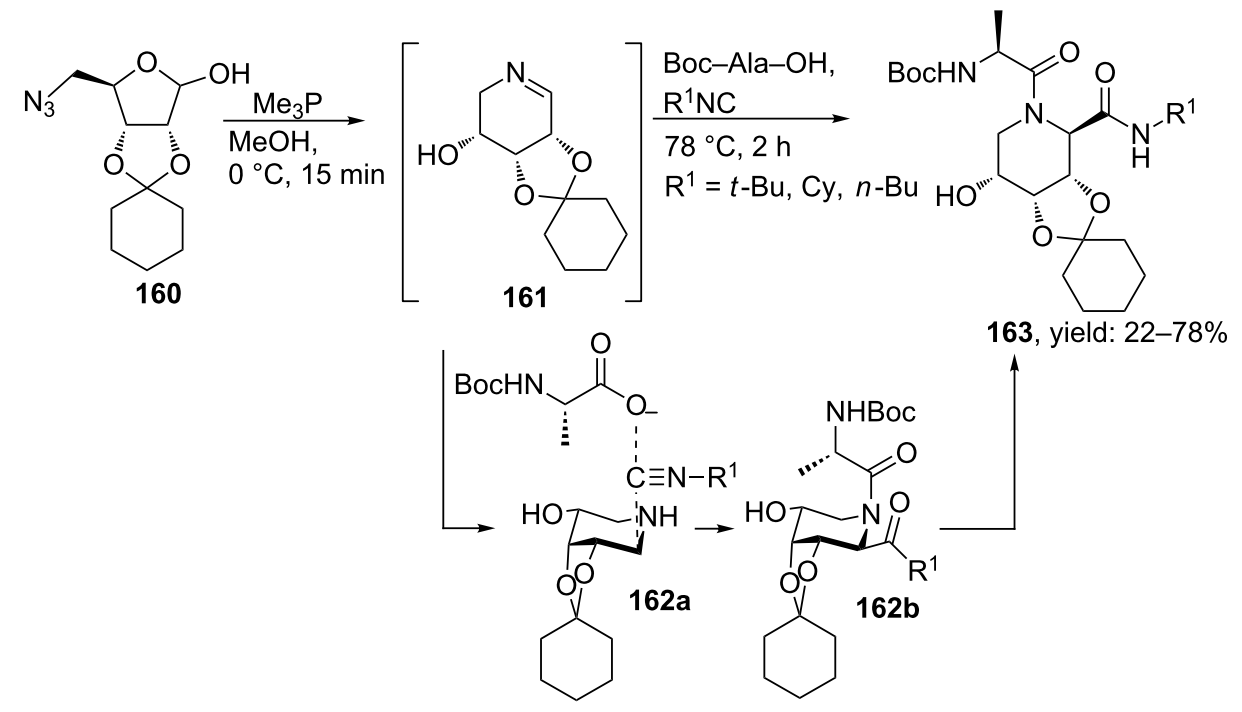

Scheme 51: Staudinger-Aza-Wittig/Ugi-approach towards pipecolic acid peptidomimetics. 
$[133,134]$, antibacterial [135], and antitumor activity [136,137] but are also used to introduce for example a bitter taste in e.g. beer, cacao and coffee [138-140]. The DKPs occur in three different isomers, in which the position of one oxo-group is different at the piperazine-ring [26]. The 2,5-diketopiperazines are most relevant due to the structural similarity with peptides (Figure 1).<smiles>[R]C1[R19]C([R])C([R])NC1=O</smiles><smiles></smiles><smiles>[R][R1]1=C([R])C(=O)N([R6])C(=O)C1[R]</smiles>

Figure 1: The three structural isomers of diketopiperazines. The 2,5DKP isomer is most common.

The DKP core shows properties for enhanced interaction with biological targets such as metabolic stability, conformational rigidity and the scaffold can both donate and accept hydrogen bonds. Furthermore, diversity can be introduced at four positions (N1, N4, C3 and C6). An important feature of DKPs is that they are able to induce secondary structures such as $\beta$-turns, $\beta$-hairpins in $\beta$-sheets and $\alpha$-helices [141]. Therefore, DKPs are often used as peptidomimetic building blocks. A more detailed review of diketopiperazines is published by Borthwick and Piarulli [141,142].

Standard multicomponent reactions towards DKPs have the disadvantage that cyclization of the linear dipeptide unit is difficult. Instead of relatively easy ester cyclizations, the Ugi-product contains a C-terminal amide that is more difficult to cyclize. Therefore, Ugi MCRs towards diketopiperazines require subsequent post-condensation modifications such as Ugi-deprotection-cyclizations (UDC), Ugi-activation-cyclizations (UAC) or the combination of both (UDAC). Hulme et al.
$[143,144]$ was the first who reported a library of DKPs via a solution phase UDC approach as shown in Scheme 52. An Ugi reaction of Armstrong's convertible isocyanide, a variety of aldehydes and amines and bifunctional amino acid 164 in methanol afforded the corresponding linear Ugi-products $\mathbf{1 6 5}$ in good yields (72-92\%). Subsequent $N$-Boc deprotection and activation of the isocyanide amide in acidic environment allowed cyclization to the diketopiperazines scaffolds 166 (overall 14-51\%). As alternative, the authors reported an Ugi reaction with ethylglyoxalate as bifunctional component since in certain cases the convertible isocyanide performed sub-optimal in the cyclization [145]. Via this procedure dipeptide 167 was obtained, that after TFA- treatment in dichloroethane (DCE) resulted in the desired DKPs products $\mathbf{1 6 8}$ in good to excellent yields $(53-72 \%)$.

Solvent effects of the Ugi reaction under microwave irradiation were considered by Santra and Andreana (Scheme 53) [146]. Protic solvents such as water gave rise to either 2.5-diketopiperazines 170 via an aza-Micheal reaction or 2-azaspiro-[4,5]deca6,9-diene-3,8-diones (171) via a 5-exo-Michael addition, whereas DCM as solvent induced an intramolecular thiophene Diels-Alder reaction yielding tricyclic lactam 173.

In an alternative approach an Ugi-protocol employing a resinbound carbonate-based convertible isocyanide 174 (CCI) was reported [147]. A wide variety of aldehydes, primary amines and carboxylic acids were tolerated resulting in a library of 80 different linear dipeptides. Cleavage from the carbonate resin with $\mathrm{KO} t$-Bu afforded compound $\mathbf{1 7 6}$ which was converted to the methyl ester 177 using NaOMe (Scheme 54). Subsequent TFA-treatment resulted in the desired diketopiperazines 178.

The group of Wessjohann reported a small library of DKPs using the acidic-labile convertible isocyanide 179 [148] in combination with readily available primary amines, aldehydes and $N$-Boc-protected amino acids [140]. It was shown that treat-

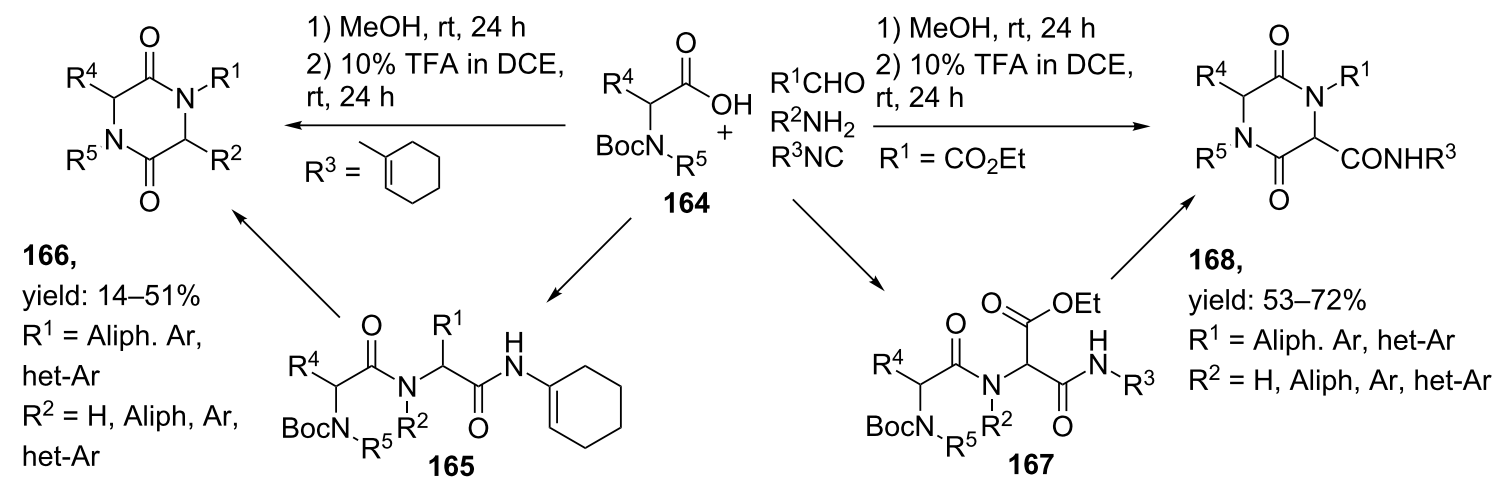

Scheme 52: UDC-approach to obtain 2,5-DKPs, either using Armstrong's isocyanide or via ethylglyoxalate. 
a)

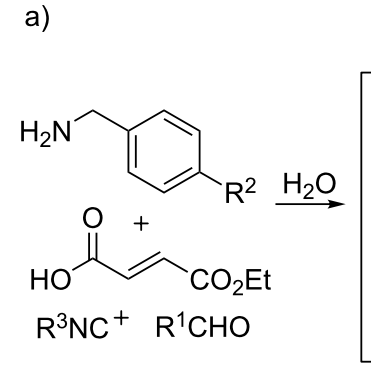

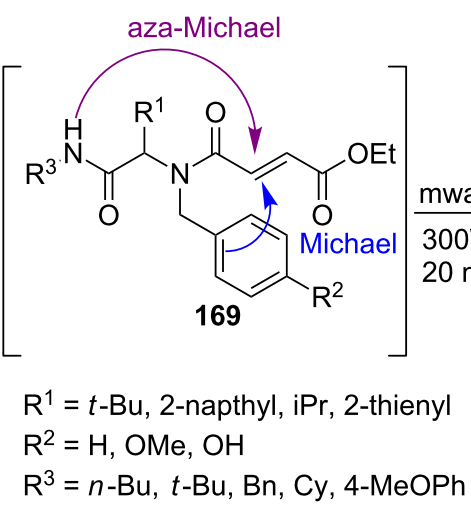

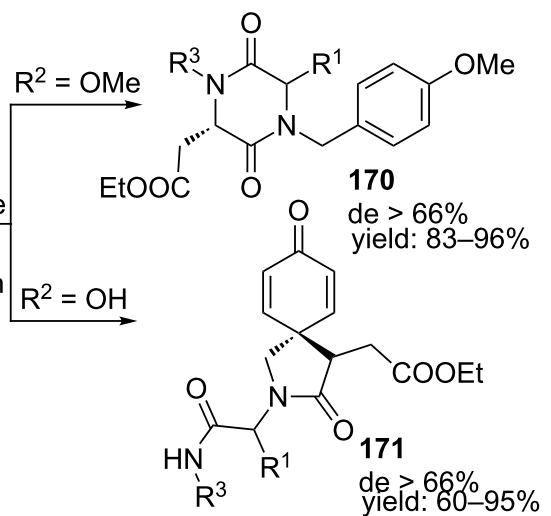<smiles>N#Cc1c(CO)cccc1OCCOC(=O)C=CC(=O)O</smiles>
$\mathrm{Bn}-\mathrm{NC}$
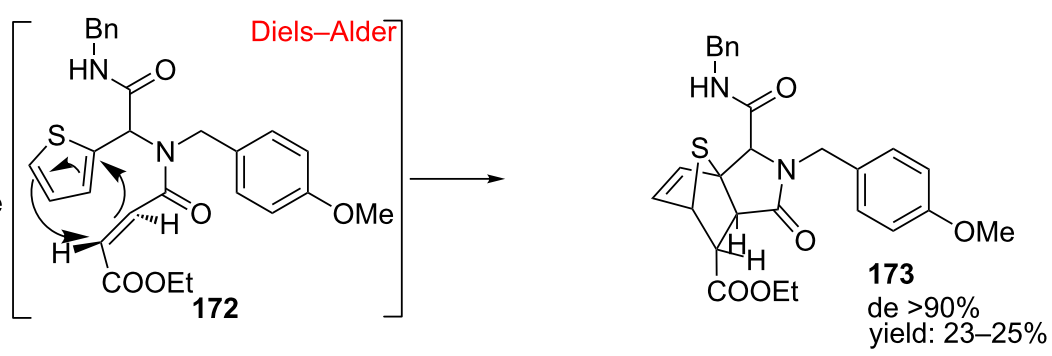

Scheme 53: a) Ugi reaction in water gave either 2,5-DKP structures or spiro compounds. b) The Ugi reaction in DCM gave tricyclic lactams.

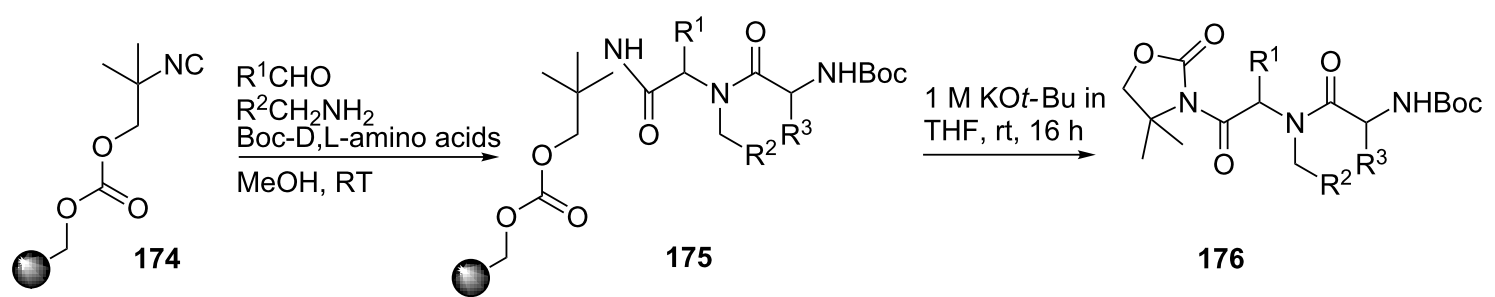

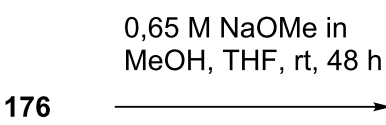

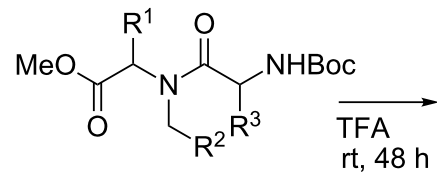

177<smiles>[R2]CN1C(=O)C([R])NC(=O)C1[R]</smiles>

178 purities: $68-88 \%$

Scheme 54: Solid-phase approach towards diketopiperazines.

ment of the Ugi-adduct 180 with acid both cleaved the $N$-Bocprotecting group and activated the nitrile amide. Subsequent addition of a base induced cyclization and resulted in the DKPscaffolds (182, Scheme 55). In total seven compounds were synthesized based on this UDAC-protocol with yields varying from 56 to $79 \%$.

Recently, another UDC-based synthesis of DKP scaffolds using the cheaper and commercial available $n$-butylisocyanide as convertible component was reported [149]. The scaffolds were obtained in good yields in a 1:1 diastereomeric ratio. However, microwave heating was required to induce cyclization (Scheme 56).

In addition the UDC-approach was also used for a small library of orally active diketopiperazines active against the oxytocin receptor [150,151]. Rapid access towards these antagonists is highly desirable since inhibition of this receptor delays preterm labour in newborns [152]. The UDC-approach started with an Ugi reaction of aryl aldehydes, isonitriles, D-leucine methyl 

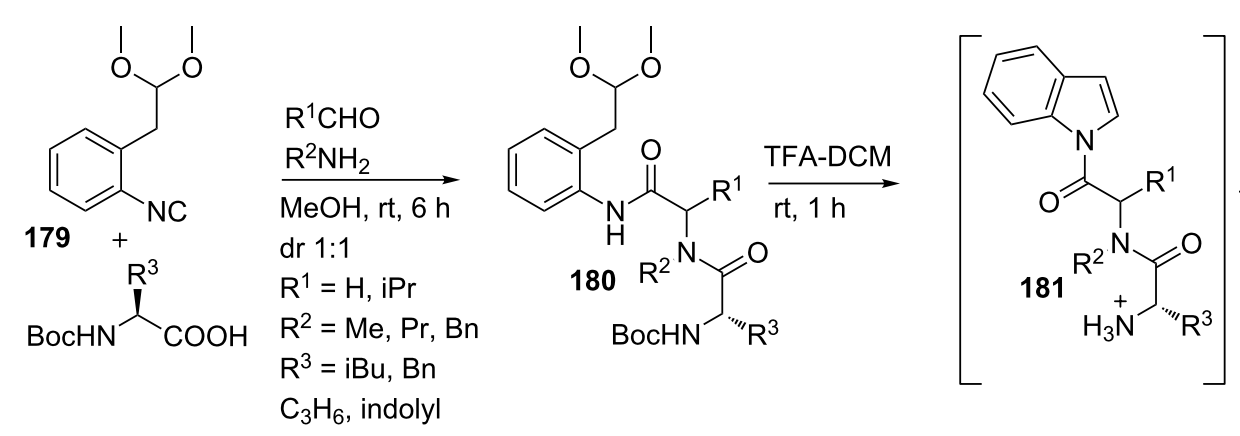

$10 \%$ aq. $\underset{\mathrm{NaHCO} 3}{\longrightarrow}$ DCM RT, $3 \mathrm{~h}$<smiles></smiles>

Scheme 55: UDAC-approach towards DKPs.

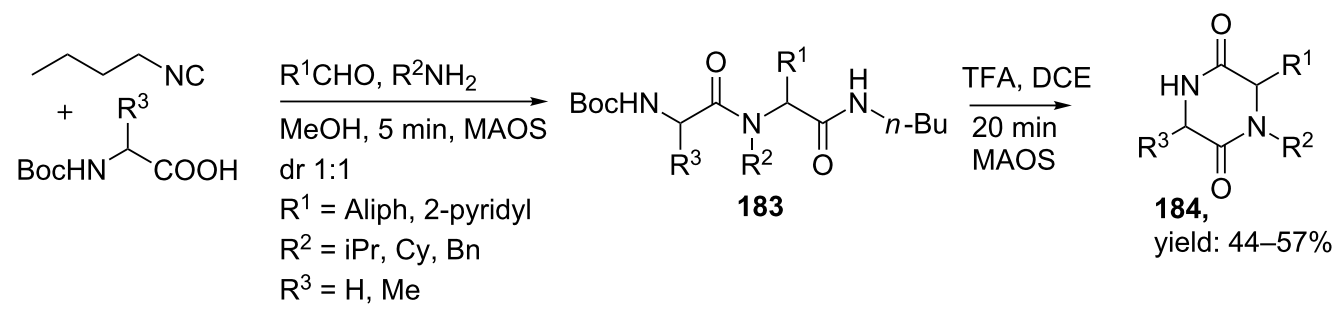

Scheme 56: The intermediate amide is activated as leaving group by acid and microwave assisted organic synthesis (MAOS)

ester and $N$-Boc-D-indanylglycine (derived from the benzhydrylimine of $N$-Boc-glycine, ee $>99 \%$ ) in methanol and afforded linear dipeptide 188 (Scheme 57). Subsequent treatment with TFA followed by base catalyzed cyclization provided both $(3 R, 6 R, 7 R)$ - and $(3 R, 6 R, 7 S)$-isomers, in favour of the latter (dr 1:3). However, the minor $R R R$-isomers $\mathbf{1 8 9}$ showed to have the highest potency and were obtained in yields up to $21 \%$.

In a variation, improved stereoselective reaction for the $R R R$ isomer 189 was observed. After an Ugi 4C-3-CR of benzalde-
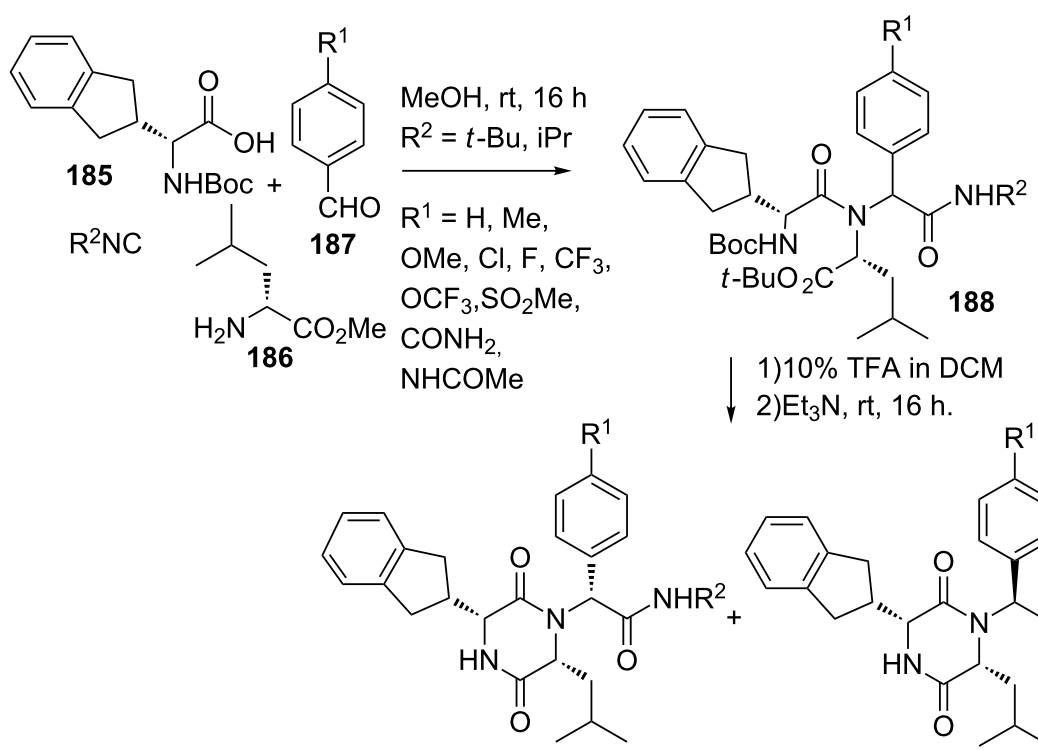

2) ${ }_{3} \mathrm{~N}, \mathrm{rt}, 16 \mathrm{~h}$

189, yield: $3-21 \%$ dr $1: 3$

Scheme 57: UDC-procedure towards active oxytocin inhibitors. 

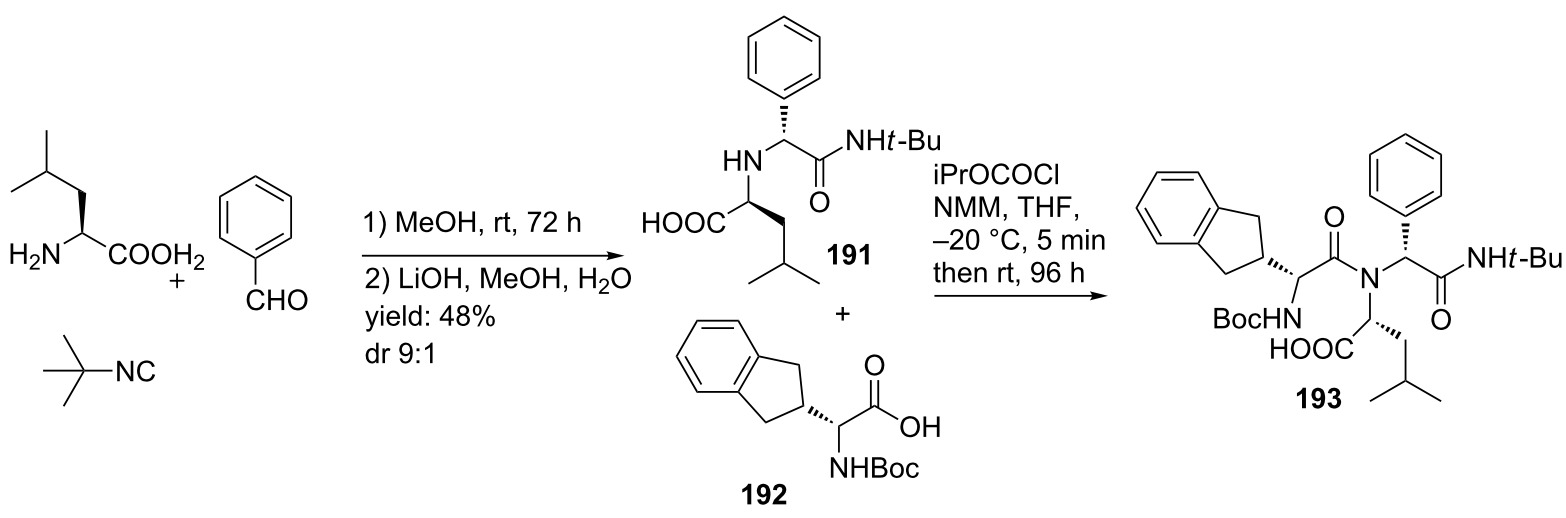

192

193

1) $4 \mathrm{~N} \mathrm{HCl}$ in

$\underset{18 \mathrm{~h}}{\stackrel{\text { dioxane, } \mathrm{rt}, 3 \mathrm{hCl}}{\mathrm{MeOH}}, \mathrm{rt}}$,
$\mathrm{MeO}$

yield: $47 \%$<smiles>CCCCNC(=O)[C@@H](c1ccccc1)N1C(=O)[C@@H](C2Cc3ccccc3C2)NC(=O)[C@H]1CC(C)C</smiles>

Scheme 58: An improved stereoselective MCR-approach towards the oxytocin inhibitor.

hyde, L-leucine, $t$-butylisonitrile in methanol followed by subsequent hydrolysis of the ester the $R S$-acid 191 was formed in $48 \%$ yield (Scheme 58) [153]. The acid was then combined with the in situ-formed anhydride derivative of $(R)$-Boc-indanyl glycine (192) and subsequent cyclization resulted in $\mathbf{1 8 7}$ in $47 \%$ yield. It is noteworthy that via this particular route, the configuration of the leucyl amide is inverted during the coupling reaction, whereas the chirality of phenyl glycine and the indanyl glycine are retained.

A less common approach was developed by Marcaccini and co-workers [154]. They obtained 2,5-DKPs in high yields by reacting 2-chloroacetic acid 194 with different aromatic amines, isocyanides and aldehydes in methanol followed by cyclization in ethanolic $\mathrm{KOH}$ under ultrasonic conditions (Scheme 59).

\section{Bicyclic diketopiperazines}

The development of bicyclic diketopiperazines has received special interest since these scaffolds force the molecule into a similar conformation as the type I $\beta$-turn in native peptides $[142,155]$. Therefore, $\beta$-turn mimetics based on this bicyclic core can reveal important information about the biologically active conformation of the native peptide $[69,155]$. $\beta$-Turns are characterized as any tetrapeptide sequence which is stabilized by an intramolecular $\mathrm{H}$-bond between residue $i$ and $i+3$ forming a pseudo-ten-membered ring $[10,156]$. The distance between the $\alpha$-carbons of these two residues is $\leq 7 \AA$ (Figure 2) [157].

There are two different types of $\beta$-turn mimetics possible, external and internal mimics [159]. The former includes turninducing-scaffolds that in most cases replace the $i+1$ and $i+2$

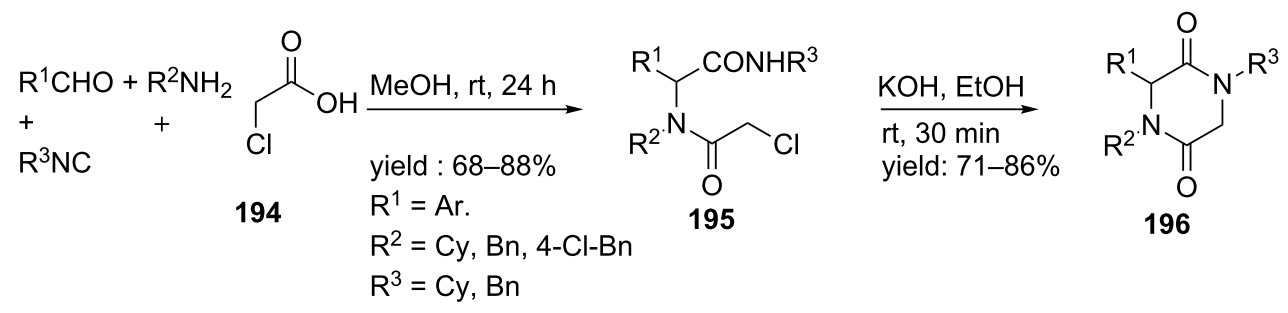




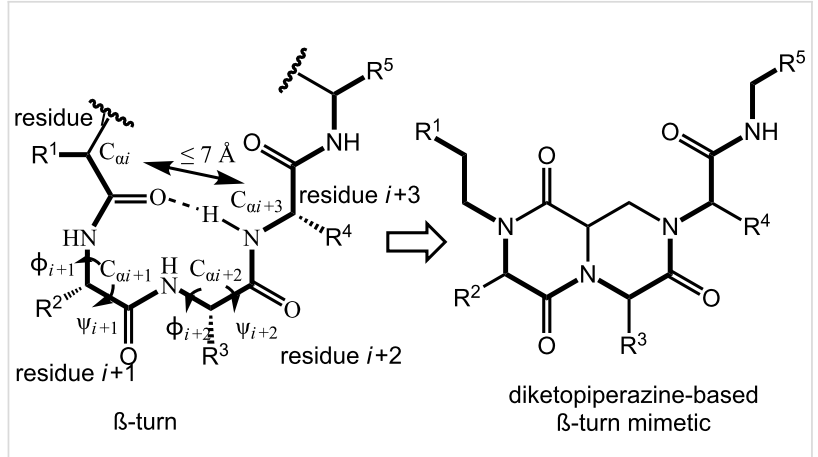

Figure 2: Spatial similarities between a natural $\beta$-turn conformation and a DKP based $\beta$-turn mimetic [158].

residues and have their rigidifying moiety lying outside the hydrogen bonded ring. Examples are lactams and dihydropyridimidinones .In contrast, internal mimics have their rigidifying part lying in the pseudo-ten-membered ring. Examples are bicyclic scaffolds such as diketopiperazines. A multicomponent approach to these latter scaffolds is described by Golebiowski et al. (Scheme 60) $[156,160]$. Herein, the Ugi reaction involving resin-bound amine 198 and an excess of $R$-(+)-2-bromoalkyl acid 199, isocyanide and aldehyde ( 5 equiv) afforded the linear dipeptide 200 that after acidic Boc-removal and base-catalyzed $\mathrm{S}_{\mathrm{n}} 2$-cyclization was converted to the monocyclic ketopiper- azine 201. The authors coupled this modified Ugi-adduct to different $N$-Boc-amino acids, in which TFA treatment and subsequent cyclization in acetic acid furnished the bicyclic diketopiperazines 203. During the Ugi reaction, inversion of configuration was observed at the $\mathrm{R}^{3}$-position (from bromine displacement by a $\mathrm{S}_{\mathrm{n}} 2$-mechanism), whereas the stereochemistry at the central bridging carbon originates from the chirality of diaminopropionic acid, derived from either L- or D-asparagine. The scope of the Ugi reaction includes several aliphatic and aromatic aldehydes, in which the former gave higher conversions. However, only a limited set of isocyanides were tolerated in this approach.

\section{Other bicyclic derivatives}

As an alternative to (bicyclic) DKPs, the group of Silvani reported a tetracyclic tetrahydro- $\beta$-carboline (THBC)-based turn-mimic via an Ugi/Pictet-Spengler combination [16]. The Ugi reaction provided two diastereomers (205a,b, dr 1:1), both in $25 \%$ yield by reacting $N$-diprotected-2-aminoacetaldehyde (used for the first time in an Ugi-like reaction), $\mathrm{N}$-protected tryptophan derived isocyanide 204, aminoacetaldehyde diethyl acetal and acetic acid (Scheme 61). The subsequent Pictet-Spengler reaction provided three steroisomers 206a,c. To investigate the turn-properties, the authors converted the products to the corresponding carboxamide $N$-acetyl analogues via a

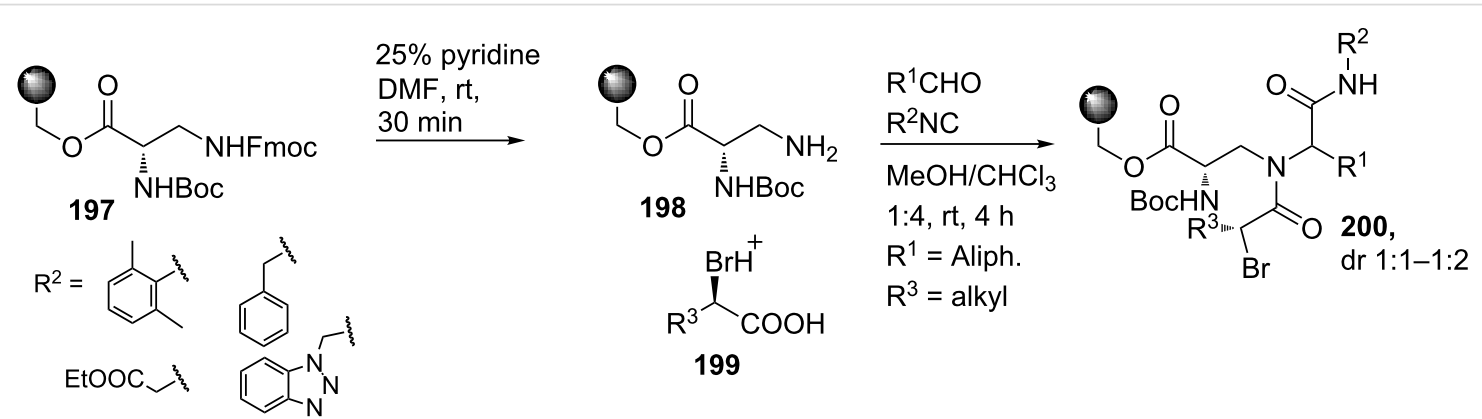

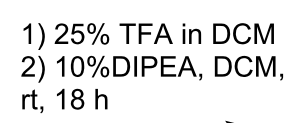<smiles>[R1]NC(=O)C([R1])N1CC(C(=O)OC[O-])NC([R3])C1=O</smiles>

201

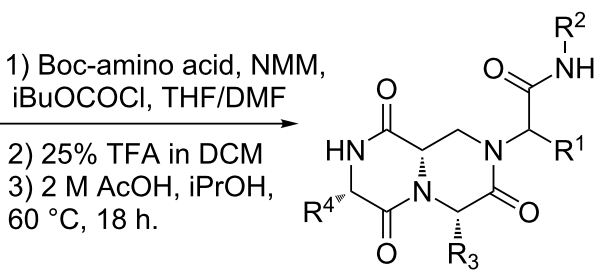

203, purities: $24-88 \%$ onic acid and Merrifield's hydroxymethyl resin under Mitsunobu conditions, followed by a standard Fmoc deprotection. 


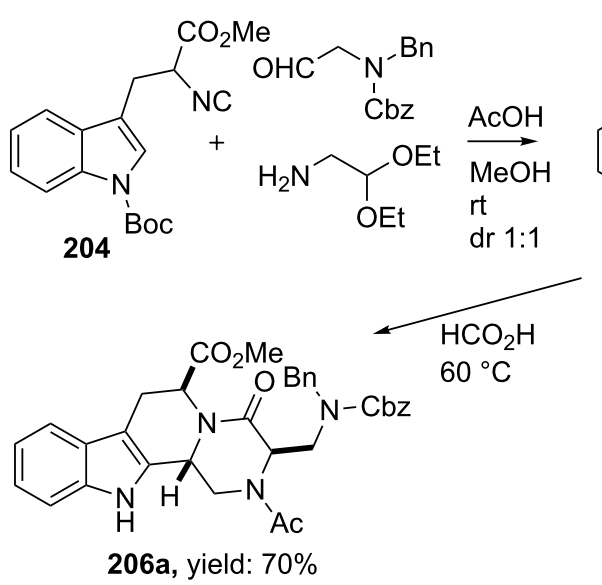

1) aq. $\mathrm{LiOH} 0,5 \mathrm{M}, 0^{\circ} \mathrm{C}$, EtOH 2) $\mathrm{MeNH}_{2}$, TBTU, DIPEA, DCM yield: $30 \%$

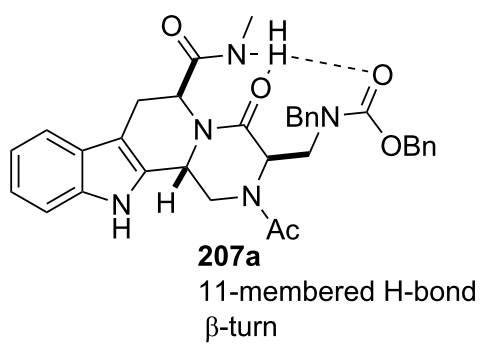<smiles>CCOC(CNC(CN(Cc1ccccc1)C(=O)OCc1ccccc1)C(=O)NC(Cc1cn(C(C)(C)C)c2ccccc12)C(=O)OCc1ccccc1)OCC</smiles>

205a, yield: $25 \%$<smiles>CCOC(CNC(=O)[C@@H](CN(Cc1ccccc1)C(C)=O)NC(=O)[O-])Cc1cn(C(C)=O)c2ccccc12</smiles>

205b, yield: $25 \%$ $170{ }^{\circ} \mathrm{C}$

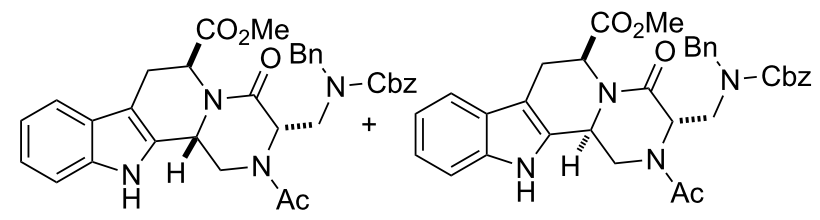
206b, yield: $40 \%$

206c, yield: $30 \%$

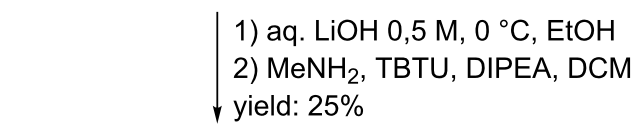<smiles>CNC(=O)[C@@H]1Cc2c([nH]c3ccccc23)[C@@H]2CN(C(C)C)[C@H](CNC(=O)OCc3ccccc3)C(=O)N12</smiles>

207b,c

7-membered $\mathrm{H}$-bond $\gamma$-turn

Scheme 61: Ugi-based synthesis of $\beta$-turn and $\gamma$-turn mimetics.

hydrolysis and subsequent condensation with $\mathrm{MeNH}_{2}$. Both NMR and modelling studies confirmed the formation of a $\beta$-turn like conformation for the cis-isomer 207a and $\gamma$-turns for the trans-isomers $\mathbf{2 0 7 b}, \mathbf{c}$.

\section{3,4-Dihydropyridin-2-ones}

Another interesting class of 6-membered heterocyclic rings that can be used in peptidomimetics is the 3,4-dihydropyridin-2-one. Conformationally, dihydropyridin-2-ones can be compared to dihydropyridines (DHP), which in turn have shown potential as calcium channel modulators $[161,162]$. Furthermore, these scaffolds have structural similarities with Freidinger lactams (Figure 3) [161,162].

In 2007, our group reported the synthesis of 3,4-dihydropyridin2 -ones via a double MCR approach $[163,164]$. The first MCR provided the 3,4-dihydropyridin-2-one core by reacting phosphonate 208 with various nitriles, aldehydes and $\alpha$-aryl isocyanoacetates. This particular 4-CR involves a Horner-Wadsworth-Emmons (HWE) reaction, in which first the phosphonate is deprotonated [125]. Subsequent addition to the nitrile-component resulted in the ketimine intermediate 209a,b which is more nucleophilic at carbon than at nitrogen<smiles>[R]C1=CC([R])C([N]C)C(=O)N1</smiles><smiles>[R]C1=CC(c2ccccc2)CCN1</smiles>

isocyanide-based 3,4-dihydropyridin-2-one dihydropyridine Freidinger lactam

Figure 3: Isocyanide substituted 3,4-dihydropyridin-2-ones, dihydropyridines and the Freidinger lactams. Bio-active calcium channel modulators, the dihydropyridines should contain an axial phenyl substituent at the C4-center adopting a boat conformation.

and reacts with the aldehyde, generating an in situ 1-azadiene intermediate 210. A subsequent Michael attack by the isocyanide $\alpha$-carbon atom, followed by a lactonization resulted in the core structure containing an isocyanide moiety (212, Scheme 62).

Variation of all substrates except the phosphonate proved the possible formation of the isonitrile-functionalized 3,4-dihydropyridin-2-ones in good yields, in which aromatic isocyanoacetates exclusively gave the cis-diastereomer. In addition, aliphatic isocyanoacetates only show a preference for the cis- 


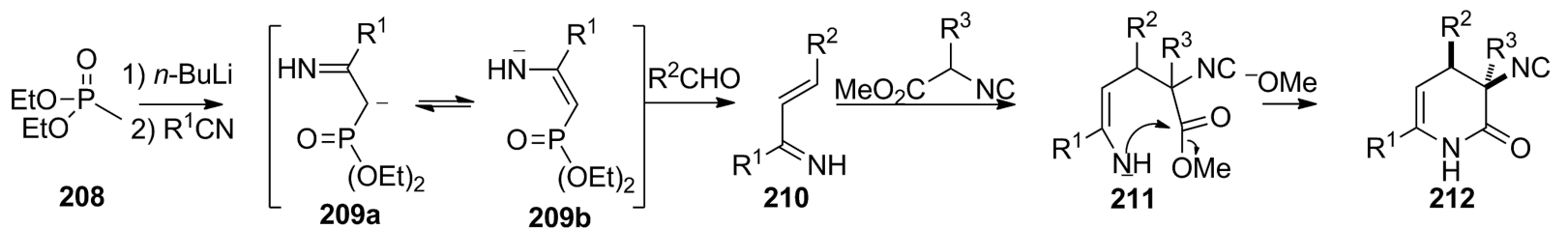

Scheme 62: The mechanism of the 4-CR towards 3,4-dihydropyridine-2-ones 212.

diastereomer if the cyclization step was performed at higher temperatures [12]. We argued that epimerization (of the C4-center) to the more thermodynamically stable isomer was the reason for this. More interestingly, the isocyanide moiety did not react and was left intact during the initial 1-azadienebased multicomponent reaction. This opened the way for an additional Passerini 3-CR (Scheme 63), in which a wide variety of aldehydes/ketones and acids successfully reacted with the isocyanide to obtain depsipeptides 213 in overall yields of $28-74 \%$ (dr 1:1). In a variation, we combined both MCRs to a one-pot 6-CR, and obtained the depsipeptides in comparable yields as the two-step procedure.

Moreover, the structural similarities of C3-substituted 3,4-dihydropyridin-2-ones with Freidinger lactams inspired our group to investigate possible turn properties of this restricted core element [10]. Since modelling studies confirmed that these scaffolds can adopt type IV $\beta$-turn structures, we developed constrained tetra/penta (depsi) peptides via a quick MCR-alkylation-MCR approach. It is noteworthy that both the Passerini and the Ugi reaction could be applied as second MCR, providing the cyclic constrained peptide-like structures in good yields (Scheme 64). As an extension, we also incorporated $N$-protected amino acids as acid input in order to provide penta(depsi)peptides 216 and 217. Unfortunately, based on spectroscopic analyzes (X-ray crystallography and ${ }^{1} \mathrm{H}$ NMR) none of these penta or tetra mimics adopted a true $\beta$-turn conformation. Nevertheless, these scaffolds consist of rigidifying properties and can be used as conformationally constrained building blocks in the design of peptidomimetics.

\section{Triazines}

Aza- and urea-based peptidomimetics have shown to be useful peptide isosteres in several therapeutic applications [166-168]. In addition, their cyclic constraints such as 1,2,4-triazines can induce peptide-turns and according to literature 1,2,4-triazines are active as selective herbicides [169], HIV-protease inhibitors [170] and anti-cancer agents [171-173]. However, multicomponent reactions towards them are scarce. The group of Torroba and Marcacinni reported an interesting Ugi 3-CR/cyclization approach towards pseudopeptidic 6-oxo-[1,2,4]-triazines (Scheme 65) [174]. The linear Ugi-adducts 219 were obtained from a reaction between phenylglyoxalic acid, several isocyanides and semicarbazone $\mathbf{2 1 8}$ as imine component, in

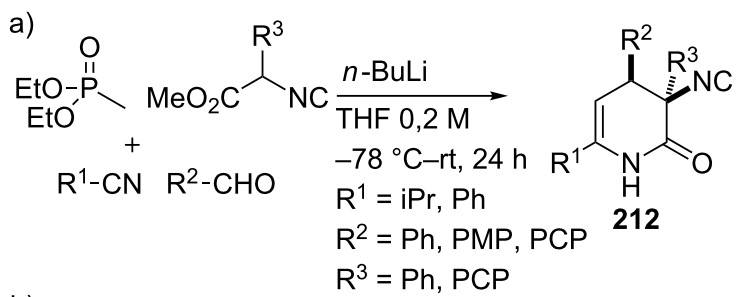

b)

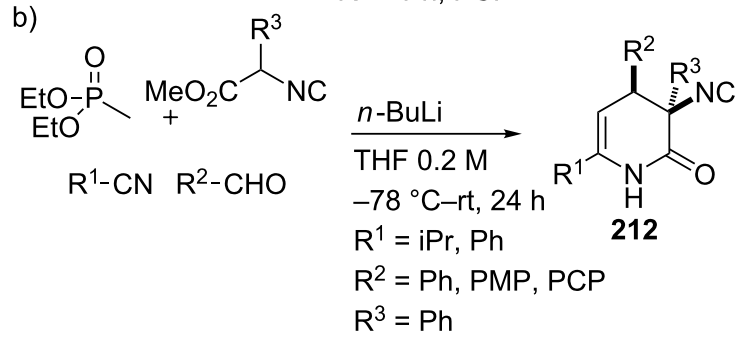

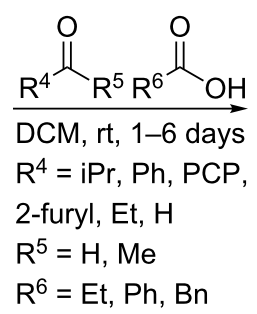<smiles>[R]C(=O)OC([R])([R])C(=O)NC1([R1])C(=O)NC([R])=CC1[R]</smiles>

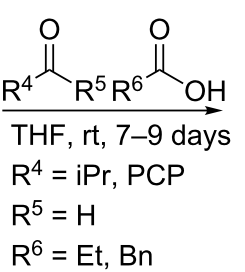<smiles>[R]C(=O)OC([R3])([R])C(=O)NC1([R1])C(=O)NC([R])=CC1[R]</smiles>
yield: $36-48 \%$ $\mathrm{R}^{6}=\mathrm{Et}, \mathrm{Bn}$ 


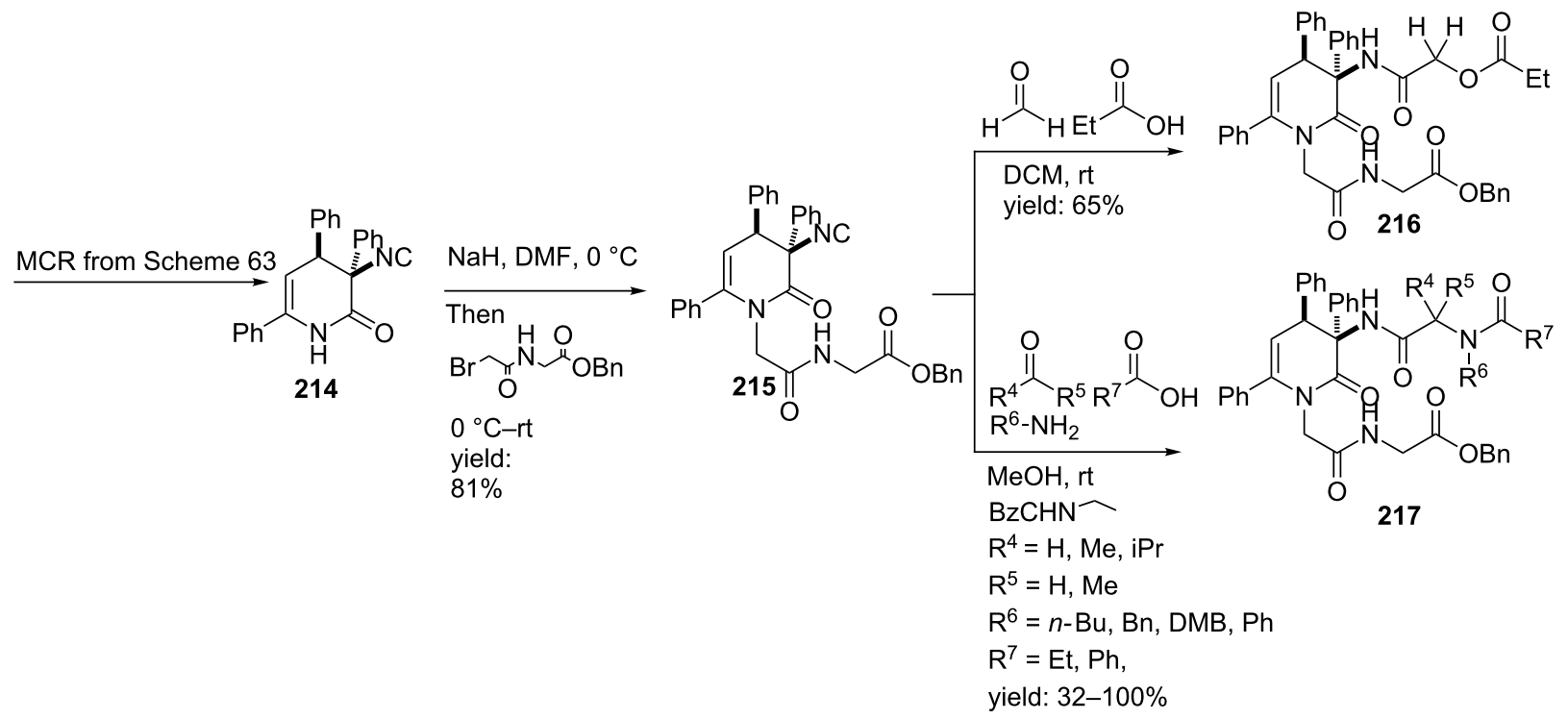

Scheme 64: The MCR-alkylation-MCR procedure to obtain either tetrapeptoids or depsipeptides.
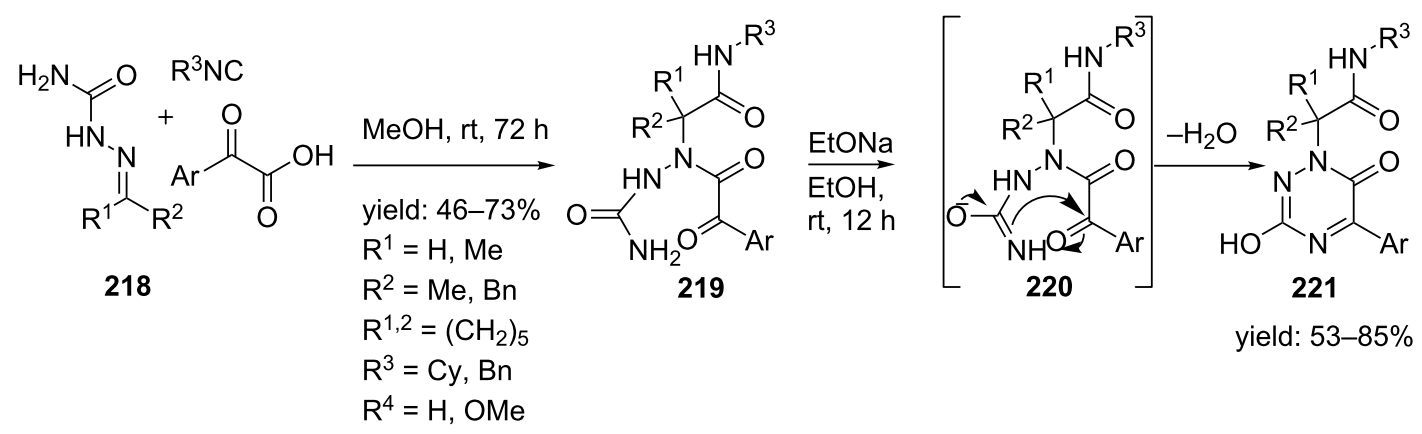

Scheme 65: U-3CR/cyclization employing semicarbazone as imine component gave triazine based peptidomimetics.

which the incorporation of the latter was not reported before. Addition of sodium ethoxide in ethanol promoted cyclization and afforded the triazines 221 in good overall yields.

Our group published the synthesis of triazinane diones as novel cyclic urea derivatives via a 4-CR-alkylation-IMCR sequence [165,175-177]. The 4-CR involves the HWE reaction described above between a phosphonate, nitrile and aldehyde, in which the in situ-formed 1-azadiene is trapped by an isocyanate (instead of an isocyanoacetate) to afford the triazinane dione core (222, Scheme 66). For the scope of this reaction a wide range of aliphatic and (hetero)aromatic nitriles and aldehydes and several benzylic and aromatic isocyanates were tolerated, whereas for the phosphonate input only diethyl methyl- or

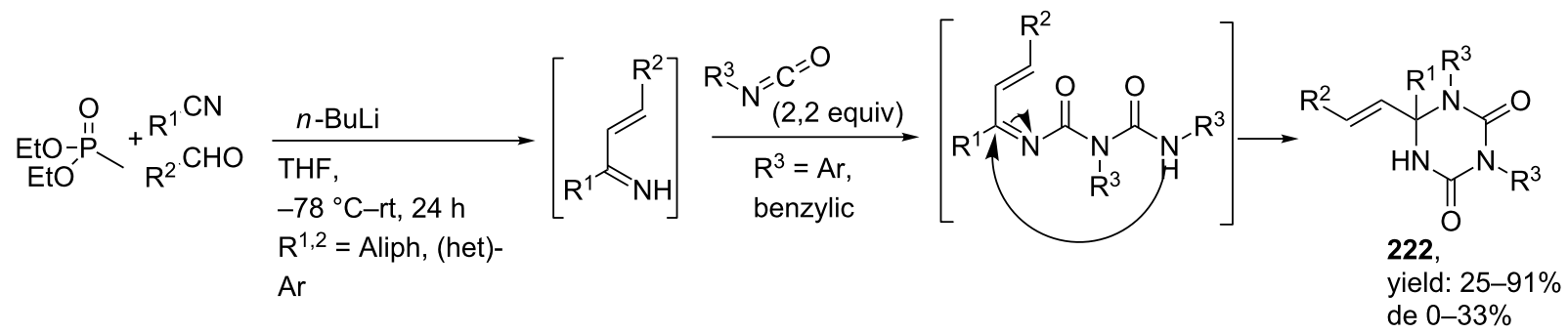


ethylphosphonate were compatible. From the results it became clear, that addition of 2,2 equivalents of the isocyanate was favourable for the reaction and increased the yield of $\mathbf{2 2 3}$ up to $91 \%$. A subsequent $N$-alkylation with tert-butyl 2-bromoacetate followed by deprotection of the tert-butyl group furnished the carboxylic acid 225 which could further react in an additional Ugi or Passerini reaction (Scheme 67). The Passerini reaction was performed with isobutyraldehyde, acid $\mathbf{2 2 5}$ and tert-butyl isocyanide to provide the depsipeptide-like product 226a in $62 \%$ yield, whereas the Ugi reaction was employed with the same substrates and benzyl- or allyl amine as fourth component to provide two peptidoyl triazinane diones $226 \mathbf{b}, \mathbf{c}$ in $43 \%$ and $75 \%$ yield for the last step, respectively [176].

\section{Other 6-membered ring constraints}

In addition to a range of MCR-based protocols available for the above discussed six-membered ring constraints, a few other types of (hetero) cyclic peptidomimetics containing a six membered ring have been reported. Among them, the thiomorpholin-3-one heterocycle is used in several therapeutic applications [178,179] and an Ugi-based MCR was reported by the group of Marcaccini (Scheme 68) [180]. In this work, monocyclic and bicyclic 5-oxothiomorpholine-3-carboxamides 228 were obtained in $76-85 \%$ yields ( $\mathrm{dr} 1: 1)$ by reacting bifunctional oxoacids 227, benzylamines and cyclohexyl isocyanides in methanol. Pyrrolidone-constrained peptidomimetics can be obtained via an Ugi/HWE sequence as describe by Dömling et

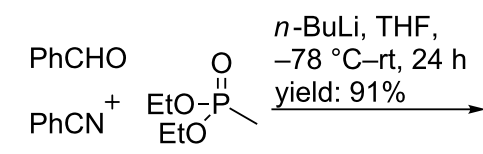

$\mathrm{PhNCO}$<smiles>[X]C(=O)CN1C(=O)N(c2ccccc2)C(=O)N(c2ccccc2)C1(/C=C/P)c1ccccc1</smiles>

226a, $X=O, \quad$ overall yield: $42 \%, \mathrm{dr} 1: 1$

226b, $X=N-B n$, overall yield: $51 \%$, dr $1: 1$

226c, $X=$ N-Allyl, overall yield: $29 \%$, dr 1:1

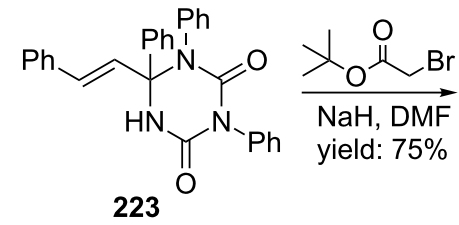<smiles>CC(C)(C)OC(=O)CN1C(=O)N(c2ccccc2)C(=O)N(c2ccccc2)C1(/C=C/c1ccccc1)c1ccccc1</smiles>

TFA/DCM

$\checkmark 1: 1$, quant.

Passerini: $t$-BuNC, $\mathrm{PrCHO}$, DCM, $17 \mathrm{~h}$, rt, yield: $62 \%$

Ugi: $\mathrm{BnNH}_{2}$ or allylNH $\mathrm{N}_{2}$, $t$-BuNC, iPrCHO

$\mathrm{MeOH}, 17 \mathrm{~h}$, rt yield: $43 \%$ for $N$-allyl yield: $75 \%$ for $N-B n$<smiles>O=C(O)CN1C(=O)N(c2ccccc2)C(=O)N(c2ccccc2)C1(P)/C=C/c1ccccc1</smiles>

a)<smiles>[R7]C(=O)C([R])SCC(=O)O</smiles>

b)<smiles>[R]C(=O)C([R])CC</smiles>
$\mathrm{HOOC}^{\mathrm{PO}(\mathrm{OEt})_{2}}$ 230

$$
\begin{aligned}
& \mathrm{R}^{3} \mathrm{NH}_{2}, \text { Cy-NC } \\
& \overrightarrow{\mathrm{MeOH}, \text { reflux, } 3 \mathrm{~h}} \\
& \mathrm{R}^{1}=\mathrm{Me} \\
& \mathrm{R}^{2}=\mathrm{H} \\
& \mathrm{R}^{1 / 2}=\left(\mathrm{CH}_{2}\right)_{4}
\end{aligned}
$$<smiles>[R]C1SCC(=O)N([R])C1([R])C(=O)NC1CCCCC1</smiles>

228, yield: $76-85 \%$ 
al. [181]. They obtained the linear Ugi-products 231 by reacting $\alpha$-keto aldehydes 229, phosphono acetic acid $\mathbf{2 3 0}$ and a variety of isocyanides and primary amines in methanol. The following HWE reaction was performed under basic conditions and furnished the 6-oxo-1,2,3,6-tetrahydro-pyridine-2-carboxylic acid amides 232 in modest to excellent yields (10-94\%).

\section{Seven membered ring constraints \\ Benzodiazepines}

Benzodiazepines (BDPs) represent an important class of small seven membered ring peptidomimetics. These BDPs demonstrate numerous therapeutic applications ranging from protease inhibitors against HIV [182] and malaria [183,184] to drugs with anticancer [185-187] or psychoactive properties [188]. In addition, the diazepinone ring also possesses turn and $\alpha$-helix inducing properties 8 [189-191]. Multicomponent approaches towards BDPs usually comprise an Ugi reaction along with several cyclization strategies. Hulme and co-workers reported an UDC strategy involving a $\mathrm{S}_{\mathrm{n}} \mathrm{Ar}$ cyclization (Scheme 69) [192]. The Ugi products herein were obtained in good yields by reacting 2-fluoro-5-nitrobenzoic acid $\mathbf{2 3 3}$ with $N$-Boc- $\alpha$-amino aldehydes 234 and several isocyanides and amines. Subsequent TFA treatment and cyclization induced by a proton scavenger revealed a library of 80 BDPs $(\mathbf{2 3 6}, 44-72 \%$, dr 2:1-3:1).
Banfi et al. published an Ugi/Mitsunobu combination towards sulfonamide-based BDPs, 240 which makes use of imines $\mathbf{2 3 8}$, isocyanides and acid 237 [193]. Herein, the imines were obtained from aldehydes and ethanolamine. The subsequent cyclization using standard Mitsunobu conditions furnished the BDPs in good overall yields (Scheme 70).

A microwave-mediated UDAC-procedure employing convertible isocyanides was also reported (Scheme 71) [194]. The usually non-convertible cyclohexylamino- and methylacetylamino isocyanides proved in this case ideally suited as convertible substrates. The Ugi-products were obtained by combining these isocyanides with a variety of aromatic aldehydes, bifunctional acids and both aliphatic and benzylic amines. Subsequent $N$-Boc-deprotection and microwave-assisted cyclization furnished a small library of BDPs (242, yields 31-97\%). In addition, it was also shown that fluoro-benzaldehydes allow further scaffold derivatization via a subsequent Suzuki coupling.

In a variation, Hulme et al. developed a similar approach utilizing two internal nucleophiles towards tetracyclic BDPs (Scheme 72) [195]. Deprotection of the Ugi-products activated the nitrile functionality and unmasked both amino-groups, in which microwave irradiation allowed a sequential double

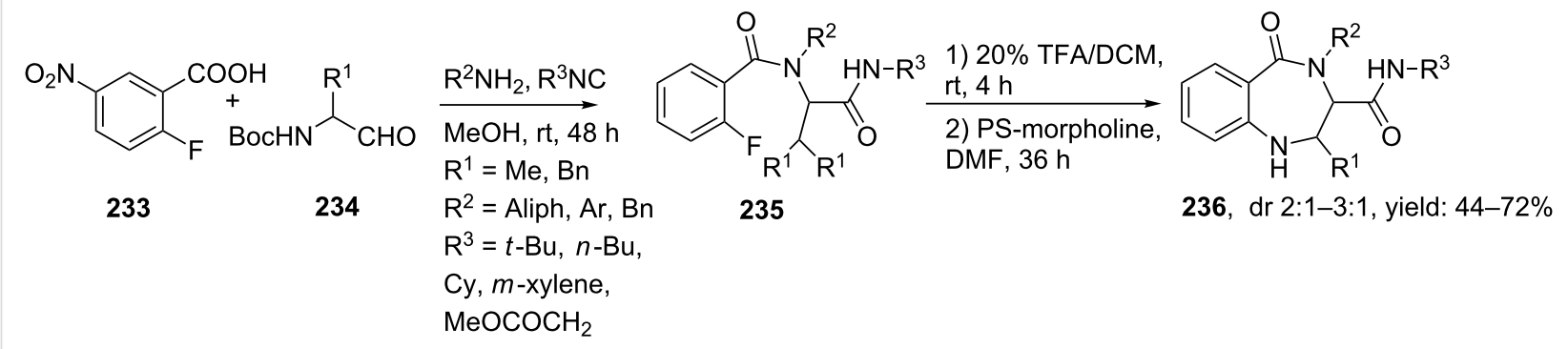

Scheme 69: UDC-approach for benzodiazepinones.

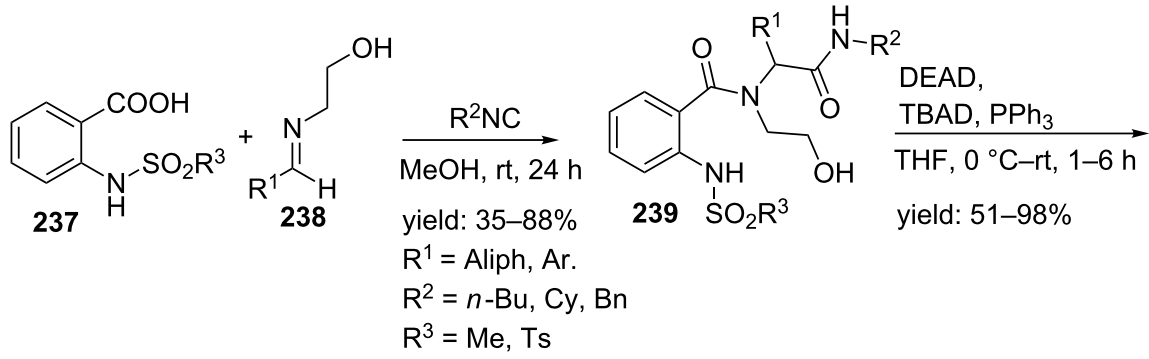<smiles>[R]NC(=O)C([R])N1CCNc2ccccc2C1=O</smiles>

$\mathrm{R}^{3} \mathrm{O}_{2} \stackrel{\prime}{\mathrm{S}} \quad 240$

overall yield: $25-75 \%$ 


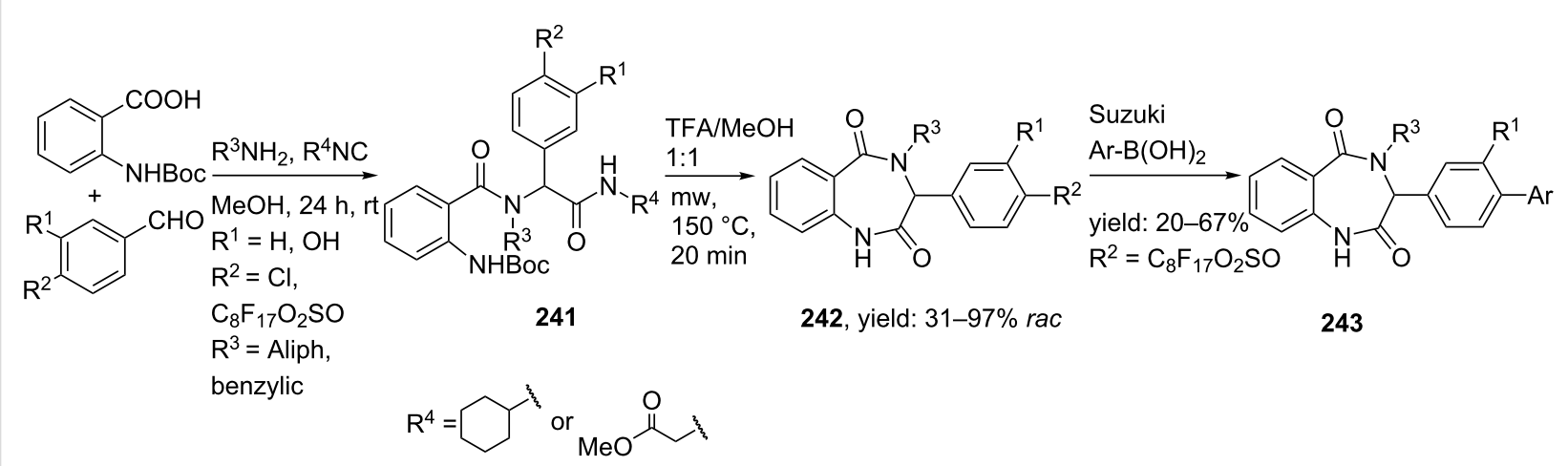

Scheme 71: A UDAC-approach to BDPs with convertible isocyanides. The corresponding amide is cleaved by microwave heating, thereby providing the 7-membered ring.

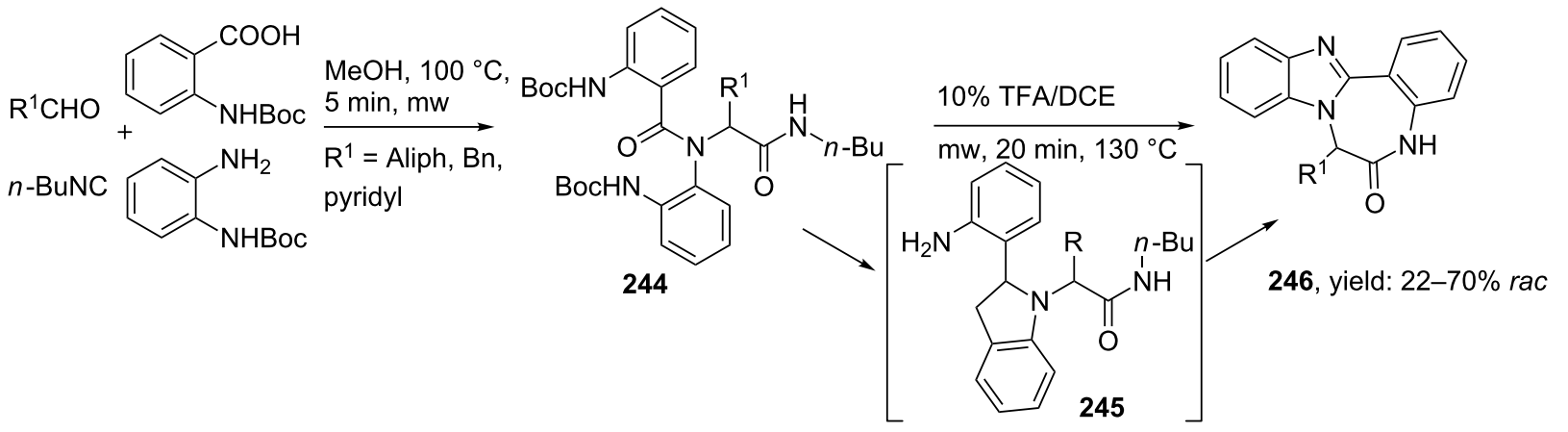

Scheme 72: microwave assisted post condensation Ugi reaction.

cyclization to the tetracyclic benzimidazole-benzodiazepines 246. During these cyclizations the authors observed that the order of cyclization was in favour of the benzimidazole, nonetheless after 20 minutes of irradiation all the intermediates were converted to the tetracyclic scaffolds in modest to high yields $(22-70 \%)$.

$\beta$-Turn mimetics of type $\mathbf{2 4 8}$ were developed by the groups of Marcaccini and Torroba [196] via an Ugi/Staudinger-AzaWittig sequence (Scheme 73). The Ugi reaction of arylglyoxals, para-substituted benzylamines, cyclohexyl isocyanide, and 2-azidobenzoic acid provided the linear dipeptides 247. Subsequent addition of triphenylphopshine induced a Staudinger-azaWittig cyclization and furnished the BDPs 248 in 37-77\% overall yields. From spectroscopic studies it became clear that these conformationally restricted peptidomimetics adopt type I, I', II and II' $\beta$-turn conformations.

In 2010, the same groups performed the Ugi reaction with $(S)$ 3-phenyl-2-azidopropionic acid (instead of 2-azidobenzoic acid) in order to control stereochemistry at the position of the aryl glycine moiety (Scheme 74) [197]. However, no stereoinduc-

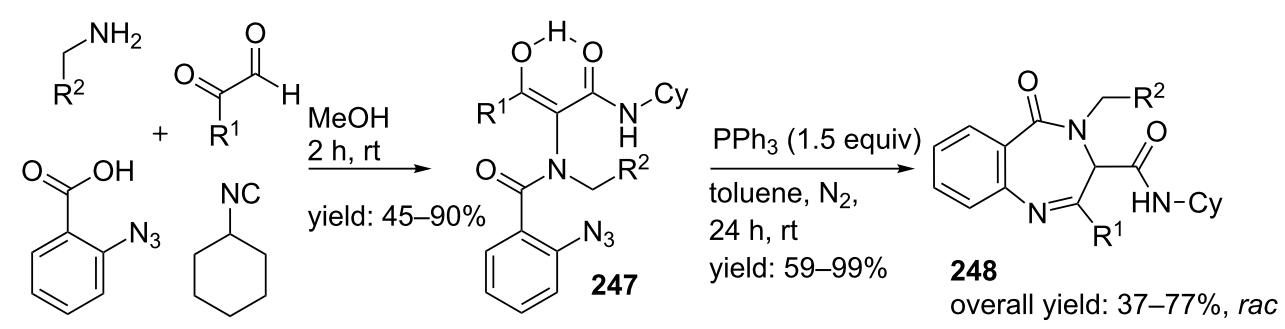


a)<smiles>Nc1ccccc1C(=O)c1ccccc1</smiles><smiles>N#[N+][C@@H](Cc1ccccc1)C(=O)O</smiles><smiles>[R1]c1ccc(C=O)cc1</smiles>

$\mathrm{MeOH}, \mathrm{rt}, 48 \mathrm{~h}$ yield: $57-75 \%$ $\mathrm{R}^{1}=\mathrm{Br}, \mathrm{Cl}, \mathrm{Me}$<smiles>[R]c1ccc(C(C(=O)NC2CCCCC2)N(C(=O)C(C#N)Cc2ccccc2)c2ccccc2C(=O)c2ccccc2)cc1</smiles>

249
$\mathrm{PPh}_{3}$ (1.5 equiv)

toluene, $\mathrm{N}_{2}$,

$24 \mathrm{~h}, \mathrm{rt}$ yield: $65-84 \%$<smiles></smiles>

overall yield: $37-59 \%$ dr $1: 1$

b)<smiles>[R]C(=O)C=O</smiles>

$\mathrm{R}^{2} \mathrm{NH}_{2}$

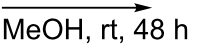
yield: $53-80 \%$ $\mathrm{R}^{1}=\mathrm{Ar}$ $\mathrm{R}^{2}=n-\mathrm{Bu}$, benzylic $\mathrm{R}^{3}=\mathrm{H}, \mathrm{Me}$, NHBoc<smiles>[R]/C(O)=C(\C(=O)NC1CCCCC1)N([R])C(=O)C([R])CN</smiles>

251

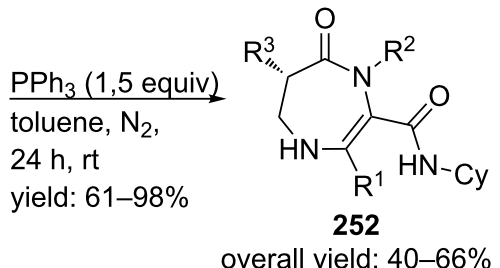

overall yield: $40-66 \%$

Scheme 74: Two Ugi/cyclization approaches utilizing chiral carboxylic acids. Reaction (a) provided the products in a diastereomeric mixture of 1:1, whereas reaction (b) yielded the products as single enantiomers.

tion was observed at this stereocenter and the BDPs $\mathbf{2 5 0}$ were obtained as mixtures of diastereomers (dr 1:1, 37-59\%). In the same report, they described an enantioselective Ugi/cyclization reaction in which monocyclic diazepinones $\mathbf{2 5 2}$ were obtained as single $S$-enantiomers (40-66\%). In this approach the Ugi reaction was performed with optically pure $(S)$-3-azidopropionic acids and 2-aminobenzophenone (Scheme 74).

\section{Other seven membered ring derivatives}

Dömling and co-workers reported a convenient route towards 1,4-thienodiazepine-2,5-diones [198]. Thiophenes can be synthesized via the Gewald 3-CR, providing 2-aminothio- phenes, which in turn have shown to be suitable derivatives of anthranilic acids (Scheme 75) [199,200]. This inspired the researchers to combine the Gewald 3-CR with a sequential Ugideprotection-cyclization in order to obtain 1,4-thienodiazepine2,5-diones. The Ugi reaction of 256, 257 and a variety of amines and isocyanides gave access to the linear dipeptides $\mathbf{2 5 8}$. Subsequent TFA-deprotection and cyclization catalyzed by the strong guanidine base triazabicyclodecene (TBD) afforded the 1,4-thienodiazepine-2,5-diones $\mathbf{2 5 9}$ in moderate to excellent overall yields (12-60\%, Scheme 76). Additional modelling studies showed that these mimics consist of $\alpha$-helix-inducing properties and that they can be used as potent tumor suppressors. In a variation, the authors shifted the (exo-) peptide chain

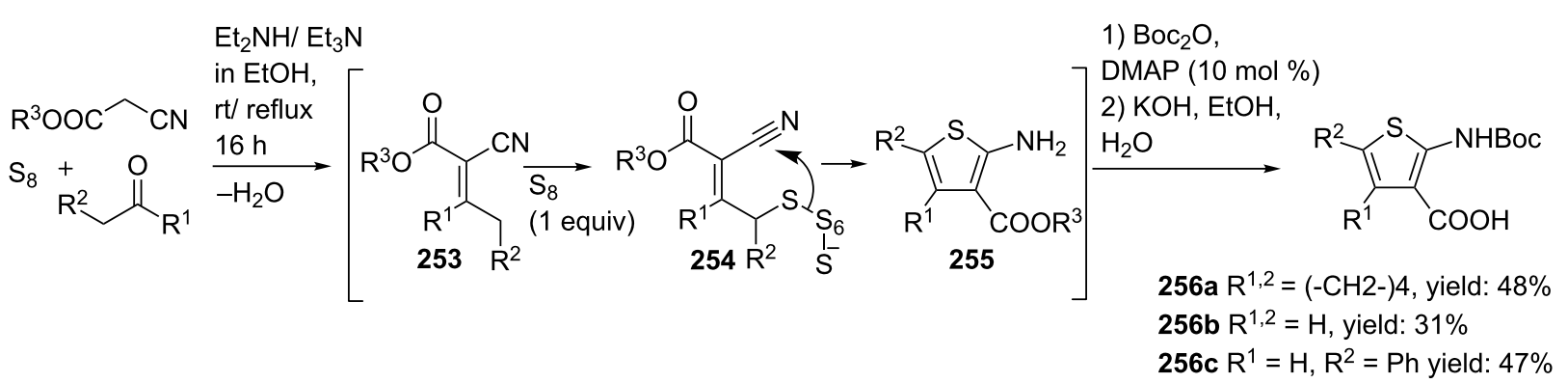

Scheme 75: The mechanism of the Gewald-3CR includes three base-catalysed steps involving first a Knoevnagel-Cope condensation between $\alpha$-methylene carbonyls and $\alpha$-activated acetonitriles, second an addition of sulfur to the $\alpha-\beta$-unsaturated intermediate and third a cyclization towards the 2-aminothiophene. 
a)

$$
\begin{array}{lll}
256 \mathrm{a}-\mathrm{C}+257 & \mathrm{MeOH}, \mathrm{rt}, 48 \mathrm{~h} \\
& \mathrm{R}_{\mathrm{R}} \mathrm{R}^{1,2}=\left(-\mathrm{CH}_{2}\right)_{4}, \\
& \mathrm{R}^{1}=\mathrm{H}, \mathrm{R}^{2}=\mathrm{H}, \mathrm{Ph} \\
& \mathrm{R}^{3}=\mathrm{Aliph}, \mathrm{Ar} \\
& & \begin{array}{l}
\text { benzylic } \\
\mathrm{R}^{4}=t-\mathrm{Bu}, \mathrm{Bn} \\
\text { cyclopropylmethyl }
\end{array}
\end{array}
$$

b)

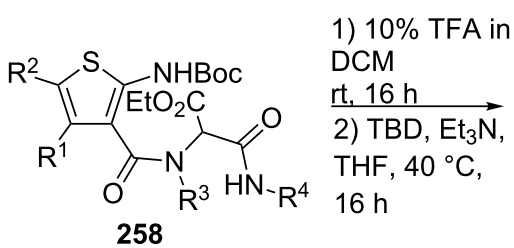<smiles>[R1]NC(=O)C1C(=O)Nc2sc([R])c([R])c2C(=O)N1[R3]</smiles>

259, yield: $12-60 \%$ rac

$$
\begin{aligned}
& \begin{aligned}
256 \mathbf{C O O H}+260 & \begin{array}{l}
\mathrm{R}^{1,2}=\left(-\mathrm{CH}_{2}\right)_{4} \\
\mathrm{R}^{4}=t-\mathrm{Bu}, \mathrm{Bn}
\end{array}
\end{aligned} \\
& \mathrm{R}^{5} \mathrm{CHO} \quad \mathrm{R}^{4} \mathrm{NC} \quad \text { cyclopropylmethyl } \\
& \mathrm{R}^{5}=\mathrm{H}, \mathrm{iBu}, \mathrm{Ar}, \mathrm{Bn}
\end{aligned}
$$

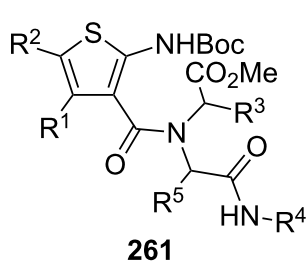
1) $10 \%$ TFA in
DCM $\mathrm{rt}, 16 \mathrm{~h}$
2) $\mathrm{TBD}, \mathrm{Et}_{3} \mathrm{~N}$, THF, $40^{\circ} \mathrm{C}$,

261<smiles>[R4]NC(=O)C([R3])N1C(=O)c2c(sc([R])c2[R])NC(=O)C1[R]</smiles>

262, yield: $13-46 \%$ rac

Scheme 76: Two structural 1,4-thienodiazepine-2,5-dione isomers by U-4CR/cyclization.

from carbon to the neighbouring nitrogen by performing the Ugi reaction with different amino esters as amine source (Scheme 76) [201].

Tetrazole-based diazepinones were obtained via a $\mathrm{TMSN}_{3}-$ modified UDC protocol reported by Hulme and co-workers (Scheme 77) [202]. A variety of secondary amines, $N$-Bocamino-aldehydes, and substituted methylisocyanoacetates were tolerated and provided the tetrazoles $\mathbf{2 6 3}$ in good yields. TFA treatment and the addition of a proton scavenger allowed cyclization and furnished the tetrazole-diazepine-ones $\mathbf{2 6 4}$ in $45-75 \%$ yield.

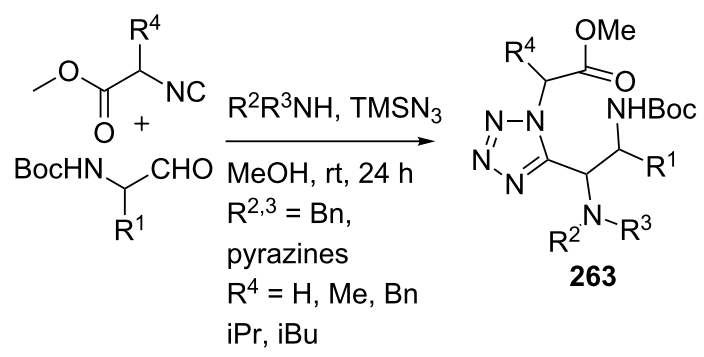

1) $10 \%$ TFA in DCM.

2) PS-DIPEA, DMF/ dioxane 1:1, reflux.

3) PS-NCO, PSTsNHNH THF/DCE, 1:1.

Tricyclic tetrazole-fused BDP derivatives were reported as well (Scheme 79) [204]. In this case an Ugi-Azide reaction using

\begin{abstract}
In a variation, Nayak and Batra reported an Ugi/hydrolysis/ coupling sequence starting from allyl isonitrile $\mathbf{2 6 6}$ that was synthesized from its corresponding primary allyl amine $\mathbf{2 6 5}$, which in turn was derived from Baylis-Hillsman acrylates [203]. The tetrazole-based Ugi adducts 267 were obtained in high to excellent yields (60-86\%), that via subsequent ester-hydrolysis and coupling with EDC and NMM resulted in the tetrazole-based BDPs 268 in overall yields of $47-67 \%$ (Scheme 78).
\end{abstract}




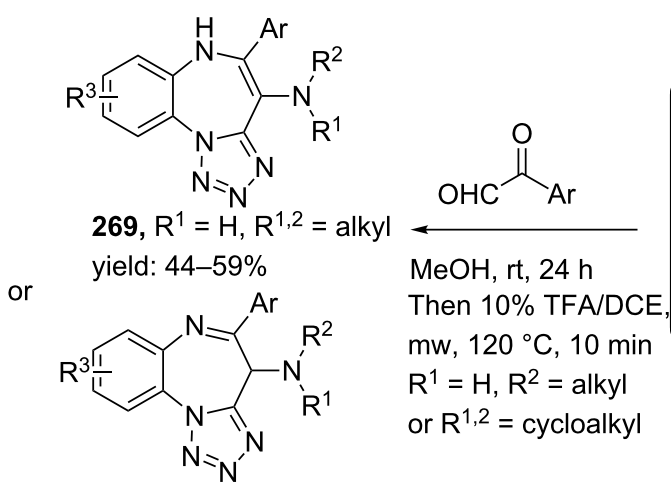

270, $\mathrm{R}^{1}=\mathrm{R}^{2}=$ alkyl yield: $23-59 \%$, rac

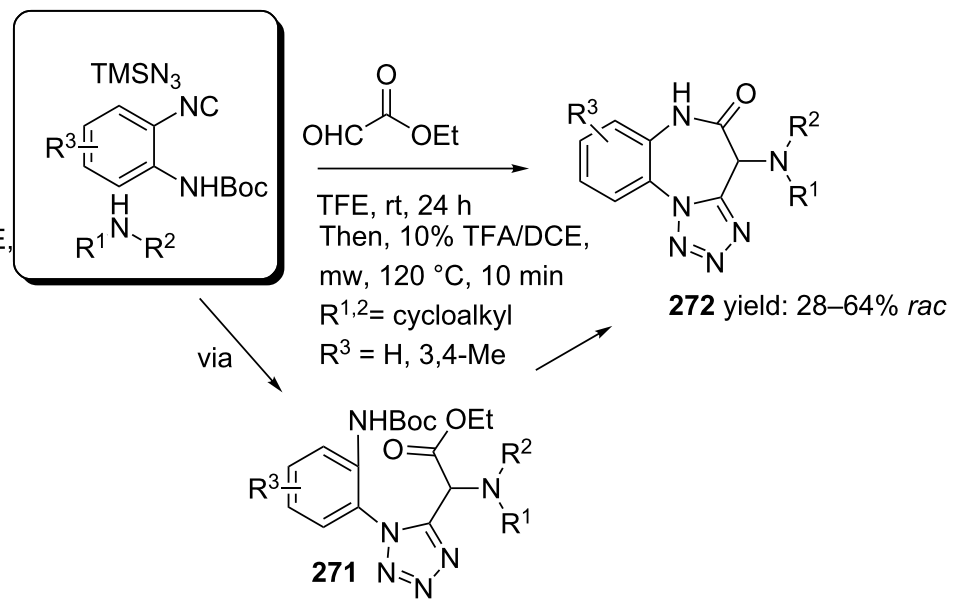

Scheme 79: MCR synthesis of three different tricyclic BPDs

amines with ethylglyoxalate, $\mathrm{TMSN}_{3}$ and bifunctional isocyanide in trifluoroethanol were employed to obtain 271. An additional Boc-cleavage and cyclization under microwave conditions afforded the benzotetrazolediazepinones 272. As an extension, the authors also performed the Ugi reaction with arylglyoxaldehydes together with either primary or secondary amines, in which the primary amines exclusively led to benzotetrazolodiazepines 269, whereas incorporation of secondary amines afforded either benzotetrazolodiazepines $\mathbf{2 6 9}$ or $\mathbf{2 7 0}$. However, these latter analogues are prone to hydrolysis and oxidation at room temperature.
Another important structural motif that can constrain peptides is the 1,4-oxazepine [205-208]. Only a few multicomponent approaches have been described towards 1,4-oxazepine analogues. For example, dihydro-1,4-benzoxazepines and dihydro-1,4-benzoxazepin-5-ones have been reported by Banfi et al. [209]. The dihydro-1,4-benzoxazepin-5-ones 276 were synthesized by either a sequential Ugi-Mitsunobu cyclization or employing a reversed version of the sequence (Mitsunobu-Ugi). Both procedures gave similar results, however, the latter one required an additional deprotection step (Scheme 80). In addition, the Mitsunobu reactions were performed with $\mathrm{PPh}_{3}$ and

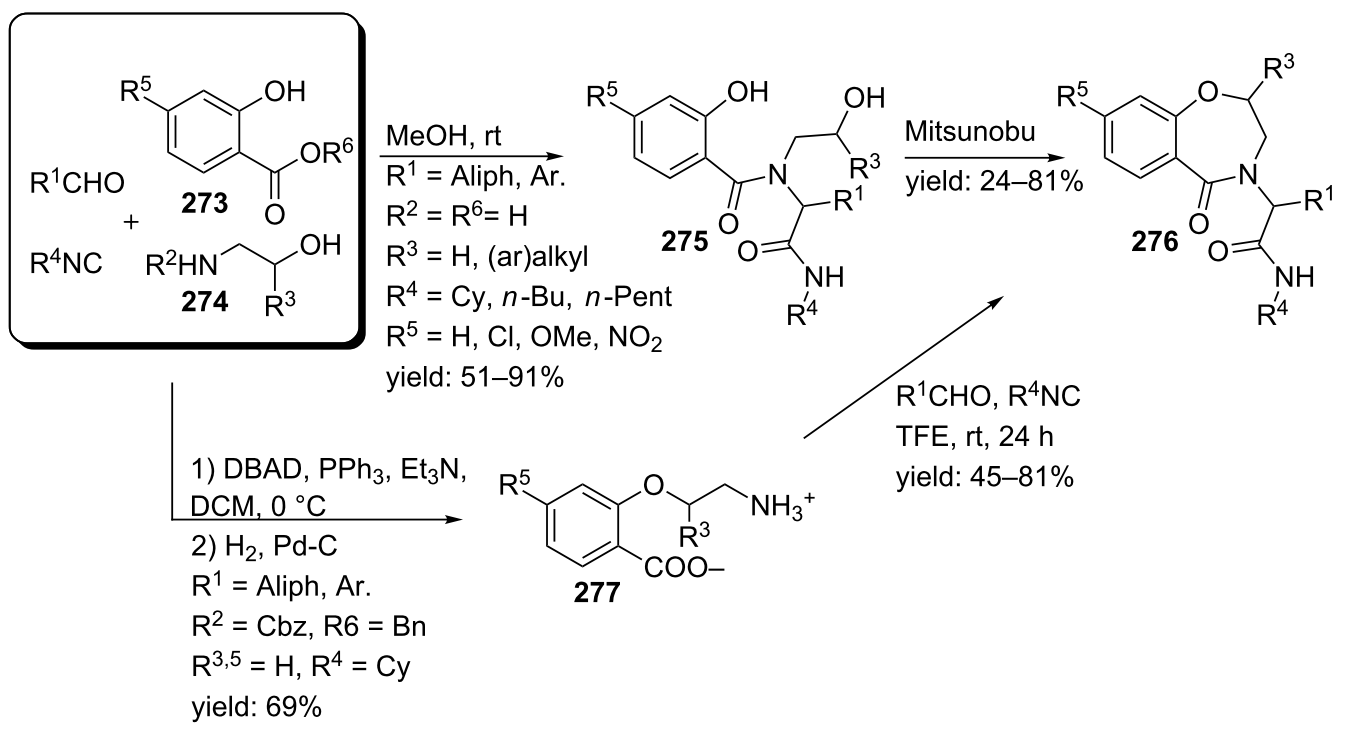




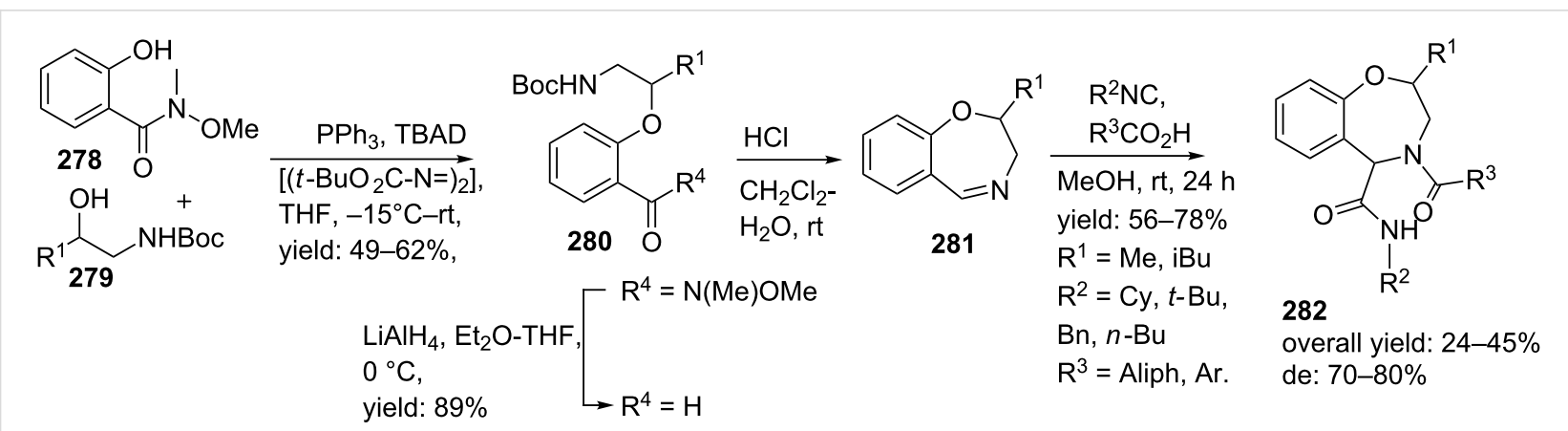

Scheme 81: Mitsunobu-Ugi-approach towards dihydro-1,4-benzoxazepines.

DBAD. The scope of the Ugi reaction tolerated a wide variety of isocyanides and aldehydes, affording the bicyclic scaffolds in good yields. Furthermore, additional modelling studies revealed that these mimics could induce $\alpha$-helix-conformations, when the $\mathrm{R}^{1}, \mathrm{R}^{3}, \mathrm{R}^{5}$ substituents contains (aryl)alkylchains [190].

In contrast, dihydro-1,4-benzoxazepines $\mathbf{2 8 2}$ (Scheme 81) could be obtained in four-steps by first performing the Mitsunobu reaction with racemic alcohols and the Weinreb hydroxamate 278. Subsequent reduction and deprotection resulted in the cyclic imines 281 [210]. Then an additional Joullié-Ugi reaction provided the final bicyclic mimics $\mathbf{2 8 2}$ in good to excellent yields, (24-45\%) with a preference for the cis-isomer. Steric arguments account for the observed selectivities.

Heteroaryl-fused 5-oxo-1,4-oxazepines have been reported by Ivachtchenko and co-workers (Scheme 82) [211]. The key substrate in their approach employs the bifunctional keto-acid 284, derived from hydroxy-substituted heteroaryl carboxylates $\mathbf{2 8 3}$, which in turn were commercially or synthetically available. In total a medium-sized library of 23 heteroaryl-derivatives $\mathbf{2 8 5}$ was developed using three different hetero-aryl keto-acids and a wide variety of amines (18-94\%).

\section{Nine-membered ring constraints}

Multicomponent reactions towards medium-sized cyclic peptidomimics (9-12 membered) usually involve two unsaturated components that can be cyclized via a post ring closing metathesis (RCM). Following this two-step sequence, Banfi and co-workers [212] reported a small library of nine-membered lactams with potential turn-properties (Scheme 83). The isocyanoacetate $\mathbf{2 8 6}$ and the (preformed) imine $\mathbf{2 8 7}$ provided the olefin moieties in the racemic Ugi-products. Subsequent treatment of these Ugi-products $\mathbf{2 8 8}$ with Grubb's catalyst (first generation) provided the cyclic constructs exclusively in the $Z$-conformation, along with several acyclic dimers as byproducts. Final saponification and decarboxylation, furnished the nine-membered lactams 289 in good yields (37-53\%, dr 3:2 for the $c i$-isomer). In order to investigate the turn-properties, the authors coupled the lactam $\left(\mathrm{R}^{1}=(\mathrm{Boc}) \mathrm{NHCH}_{2}\right)$ analogues with two glycine methylesters that after deprotection and a final peptide-coupling with BOP afforded the pentacyclic structure 290 as shown in Scheme 83. It is noteworthy that only the cisisomer was able to cyclize and was obtained in a reasonable overall yield (43\%). In addition, modelling and spectroscopic studies of the structures revealed that these bicyclic scaffolds can adopt a type II' $\beta$-turn motif, in which a hydrogen bond between residue $i$ and $i+3$ is formed [11].

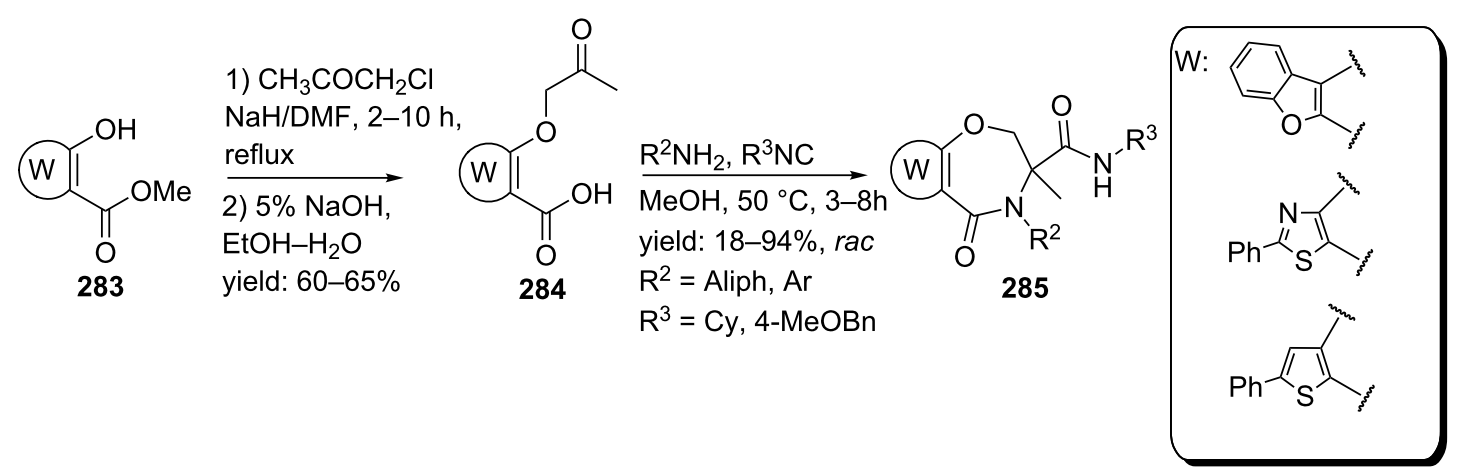


a)

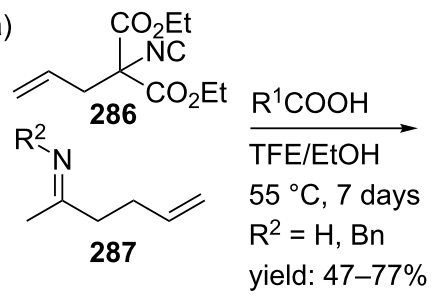<smiles>[R16]C(=O)OCC(CC=C)(NC(=O)C(C)(CCC=C)N([R])C([R16])=O)C(=O)OCC</smiles>

3) dioxane, reflux

$\mathrm{R} 1=\widehat{\mathrm{NHBoc}}$ $\int_{N H F m o c}^{\mathrm{CO}_{2} t-\mathrm{Bu}}$<smiles>[R1]C(=O)N([R1])C1(C)CC/C=C\CC(COCC)N1</smiles>

289

*yield: $37-53 \%$ dr $3: 2$ (cis)

b)<smiles>CCOC(CC)C1C/C=C\CCC(C)(N(Cc2ccccc2)C(=O)CN)C1=O</smiles>

BocHN

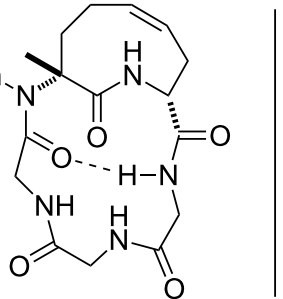

290 yield: $43 \%$

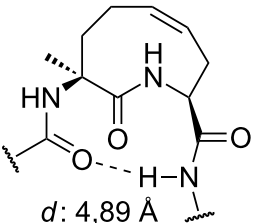

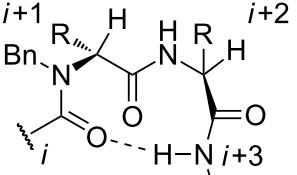

$d: 4,91 \AA$ in

type II' B-turn

modelling studies

Scheme 83: a) Ugi/RCM-approach towards nine-membered peptidomimetics b) Sequential peptide-coupling, deprotection, peptide coupling revealed the GGG-pentacyclic structure that adopts a $\beta$-turn conformation.

A second application extended the scope to cyclic RGD pentapeptides (Scheme 84). Peptides containing the RGDsequence (arginine-glycine-apartic acid) are of great pharmaceutical interest since this tripeptide sequence can be recognized by a special category of receptors, the so-called integrins. Integrins consist of one $\alpha$ - and one $\beta$-subunit that play key roles in several biological functions of mammals, for example in cell-cell interactions. Some of them are also involved in the regulation processes of diseases, in which the $\alpha_{\mathrm{V}} \beta_{3}$ and $\alpha_{\mathrm{V}} \beta_{5}$ integrins are believed to be involved in tumor induced angiogenesis [213-216]. Therefore, inhibition of these integrins by small peptides that contain a RGD-sequence is of high interest [217]. For the development of the cyclic RGD-pentapeptides the authors employed the Ugi/RCM/decarboxylation/coupling sequence, in which the RGD mimics 291 were obtained in overall yields of $12 \%$. In this procedure, the final peptidecoupling was performed with protected Arg-Gly-dipeptide and HATU as couplings reagent [218]. To validate the potency of these mimics, the authors screened their mimics against $\alpha_{V} \beta_{3}$ and $\alpha_{\mathrm{V}} \beta_{5}$ integrins and it was shown that the cis-isomer was a potent inhibitor of the $\alpha_{\mathrm{V}} \beta_{3}\left(\mathrm{IC}_{50}=1 \mu \mathrm{M}\right)$ and very weak against $\alpha_{V} \beta_{5}(>1 \mathrm{mM})$.

\section{Macrocycles}

An alternative approach to reduce the flexibility in a peptide backbone and thus limit the number of possible active conformations employs macrocyclization ( $>12$ membered rings) strategies. Such macrocyclic peptides have the additional<smiles>C=CCC(NC(=O)OCC)(OCC)C(=O)OCCC(=O)OC(C)(C)C</smiles>

GPHN

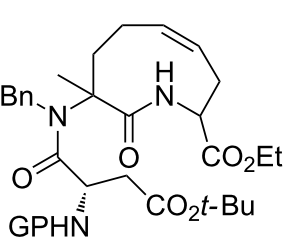

291 
advantage that no terminal groups are present, which makes them more stable (compared to linear analogues) towards degradation i.e. terminal groups are usually required for efficient protease-binding. In addition, the increased conformational order also reduces the folding-energy required for binding as compared to the flexible linear peptide or mimics [26,219-222]. In order to obtain such peptidic macrocycles via multicomponent reactions, several research groups have utilized post-MCR cyclization reactions such as RCMs, macrolactonizations or nucleophilic aromatic substitutions $\left(\mathrm{S}_{\mathrm{n}} \mathrm{Ar}\right)$. Alternatively, macrocycle synthesis via cyclizing multiple MCRs have been reported. In this part of the review first the post-MCR-condensations via $\mathrm{RCM}$, lactonization and $\mathrm{S}_{\mathrm{n}} \mathrm{Ar}$ will be considered, after that the multiple MCR-approaches will be discussed.

\section{Macrocycles via MCR-RCM-approaches}

In the past decade three research groups have developed peptide-like macrocycles via a MCR-RCM-sequence. Oikawa et al. reported a small library consisting of 12-15 membered cyclic peptidomimetics [223]. These mimics were synthesized in good yields via a three-step procedure involving an Ugi 4-CR, incorporation of the alkene functionalities and a subsequent RCM assisted by the second generation Hoveyda-Grubb's catalyst (Scheme 85). Depending on the acid component, the alkene moieties could be introduced by performing either a double amidation with allyl iodide yielding 295 or via a sequential cycloaddition/amidation with allyl amine and allyliodide, respectively, to afford 293. The follow-up RCM yielded the macrocycles as trans-isomer for the 12- and 15-membered cycles and as cis-isomer for the 13- and 14-membered cycles 294a-d.

Kazmaier et al, also active in this area, reported a stereoselective Ugi/RCM-approach by utilizing allyl isocyanoacetate and (four) different Alloc-amino acids as bifunctional substrates (Scheme 86) [224]. Whith $(S)$-amino acids and $(S)-2,2-(m-$ methoxyphenyl)ethylamine as chiral components, the Ugi-products 296 were obtained mainly as the (S,S,S)-diastereomers (de 44-90\%). Subsequent RCM with Grubb's $1^{\text {st }}$ generation catalyst afforded the 16-membered macrocycles 297 in good overall yields, favouring the $E$-isomer.

As an alternative, Dömling et al. applied a Passerini/RCM-approach for the construction of macrocycle 299 (Scheme 87) [225]. Both the carboxylic acid and the isocyanide substrate bear the alkene moiety and were derived from commercially available precursors. The addition of paraformaldehyde provided the linear Passerini-adduct in $67 \%$ yield, in which the post-RCM with Grubb's catalyst afforded the 22-membered macrocycle 299 in $17 \%$ overall yield.

\section{Macrocycles via MCR-macrolactonization protocols}

Macrolactonization was employed by Zhu and co-workers after the MCR described above in Scheme 43 generating oxazole

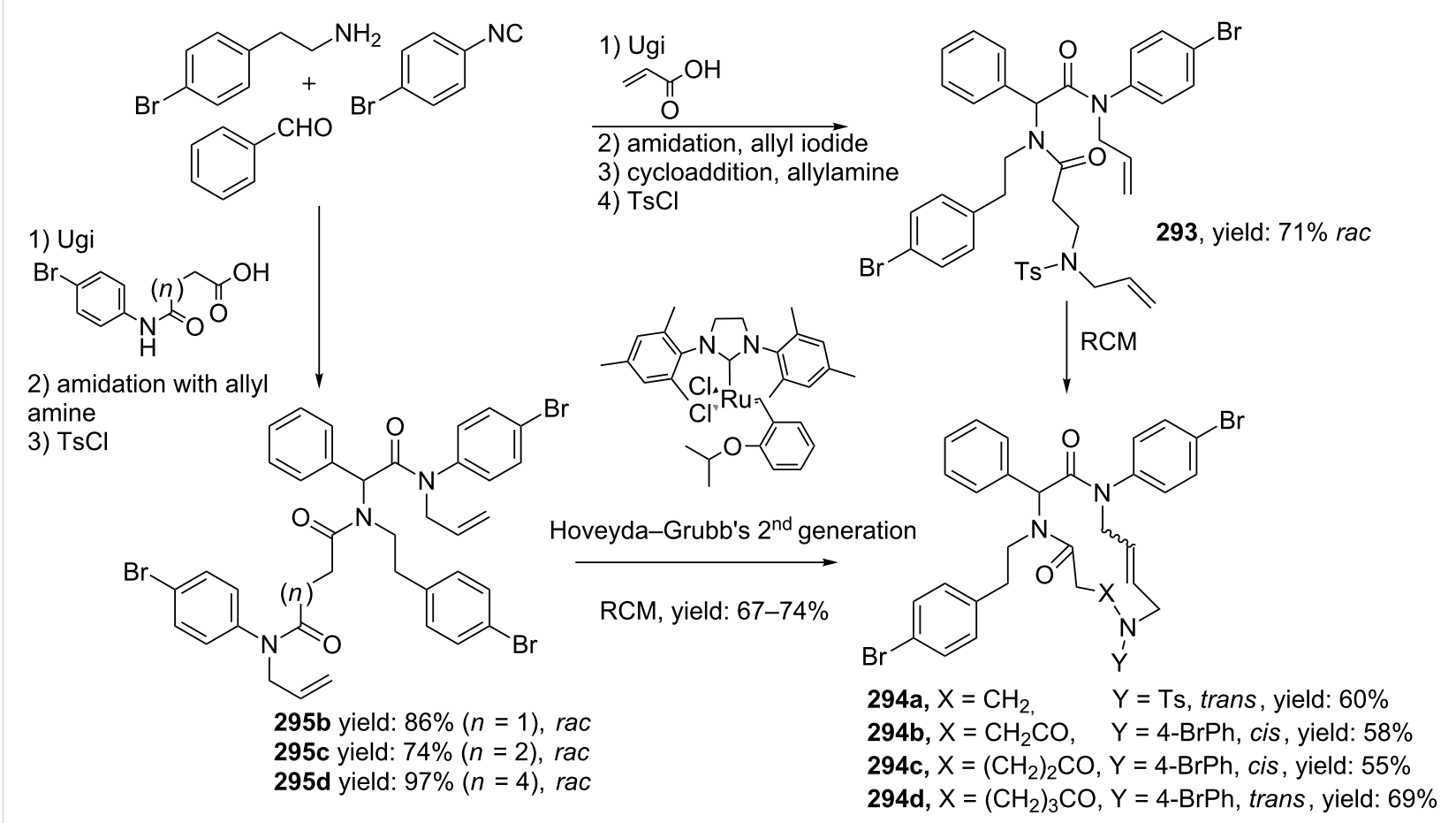




$$
\begin{aligned}
& \overbrace{\mathrm{OMe}}^{+\mathrm{CHO}} \\
& \text { Áloc } \mathrm{O}_{\mathrm{O}}^{\mathrm{OH}} \\
& \begin{array}{l}
\frac{\text { Ugi }}{\text { TFE, }-30^{\circ} \mathrm{C}, \mathrm{rt}} \\
2-7 \text { days } \\
\mathrm{R}^{1,2}=\mathrm{Me} / \mathrm{H}, \\
\text { iPr/Me, }-\mathrm{C}_{3} \mathrm{H}_{6}-
\end{array} \\
& \text { yield: } 72-96 \%
\end{aligned}
$$

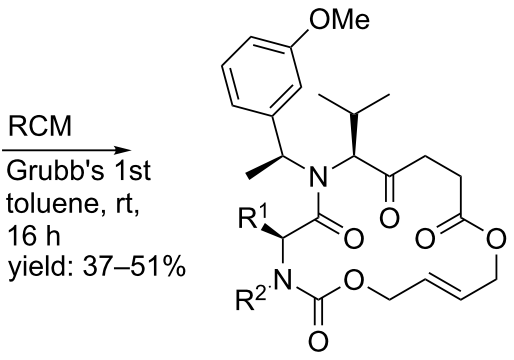

297, overall yield: $33-37 \%$

Scheme 86: Stereoselective Ugi/RCM approach towards 16-membered macrocycles.<smiles>C=CCC(C)/C=C(\C)COC(=O)c1ccccc1-c1ccccc1C(=O)O</smiles>

298

\author{
1) Passerini \\ $\mathrm{Et}_{2} \mathrm{O}, \mathrm{rt}, 72 \mathrm{~h}$, \\ yield: $67 \%$ \\ 2) RCM \\ Grubb's \\ DCM, reflux, $48 \mathrm{~h}$ \\ yield: $26 \%$
}<smiles>CC(=O)CNCC(=O)OCC(C)=CC(C)CC=CCN(C)C(=O)CNC(=O)COC(=O)c1ccccc1-c1ccccc1C</smiles>

299 overall yield: $17 \%$, rac

Scheme 87: Passerini/RCM-sequence to 22-membered macrocycles.

peptidomimetics. The procedure is based on the instability under acidic conditions of the initially formed amino oxazole [226,227]. The modification includes a hydrolysis/activation/ cyclization sequence to provide 12-18-membered cyclic depsipeptides in good overall yields (upto 64\%). As shown in Scheme 88 , the process starts with a base catalyzed hydrolysis of the alkyl ester followed by protonation of the oxazole-scaffold to provide imminium cation 301. Subsequent intramolecular cyclization induced by the carboxylate yielded the spiro- intermediate that via a nucleophilic attack of the tethered alcohol to the activated ester resulted in the macrocyclic depsipeptides $\mathbf{3 0 3}$.

Another interesting procedure involves a MCR/macrolactonization strategy in order to obtain two structural derivatives of the in vivo active antibiotic acyldepsipeptide, ADEP-4 [228]. It is noteworthy that the pipecolic acid moiety in ADEP-4 enhances the in vitro and in vivo antibiotic activity as compared to its

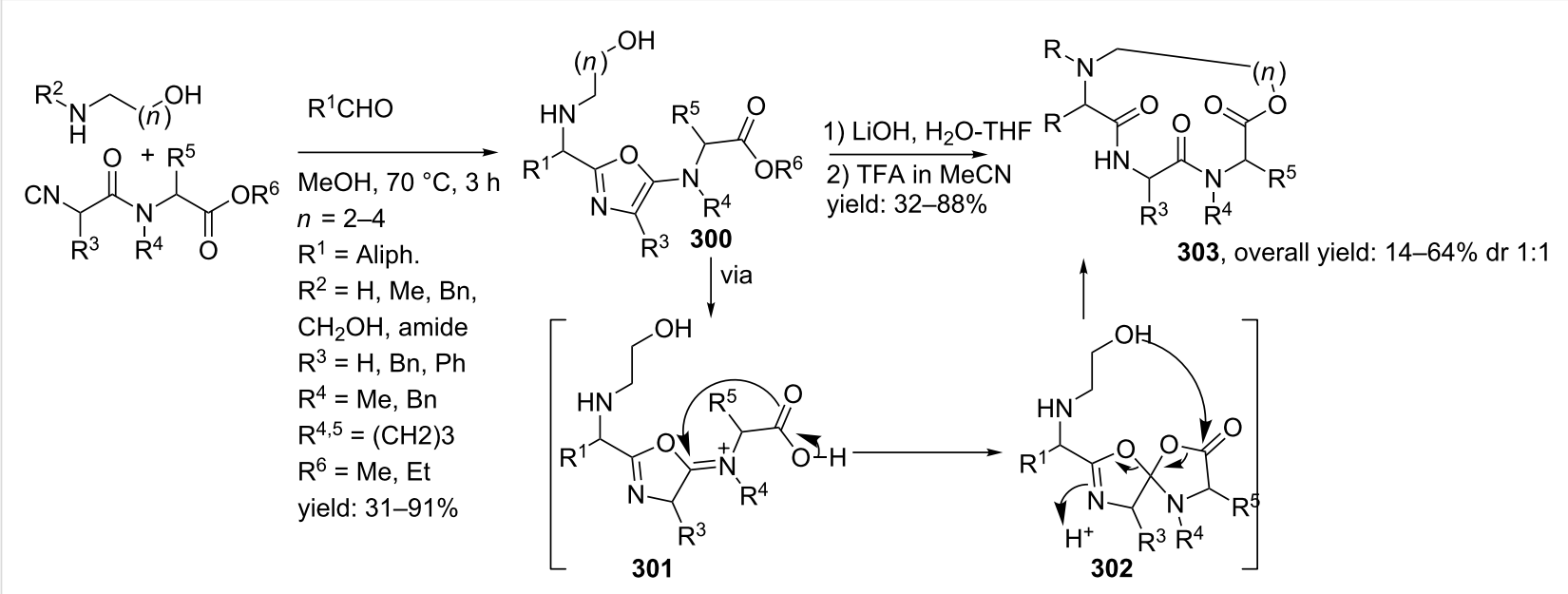




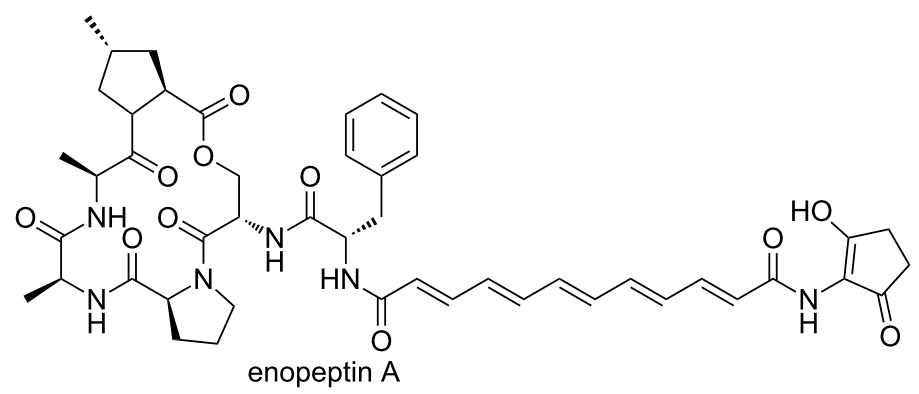<smiles></smiles>

Figure 4: Enopeptin A with its more active derivative ADEP-4.

$N$-methylaniline precursor enopeptin A, thereby reflecting the importance of conformationally restricted elements (Figure 4).

For these ADEP-4 derivatives, a Joullié-Ugi 3CR of cyclic imines, $N$-Boc-proline and isocyanopropanoate (derived from aniline methylester), followed by coupling with $\mathbf{3 0 5}$ and subsequent TFA-promoted saponification gave the macrocycle $\mathbf{3 0 7}$
(Scheme 89). Under these conditions the Ugi reaction proceeds in a diastereoselective fashion and for unclear reasons formation of the less active isomer (dr 30:70) was favoured. Chromatographic separation followed by an additional peptide coupling provided the final compounds 308 in $4-6 \%$ overall yield. In a variation an Ugi 4-CR was employed to construct $\alpha, \alpha$-dimethylated derivatives. Herein, the Ugi reaction of a)<smiles>[R][C@H](OC)[C@@H](OC)[Si](=O)O</smiles>

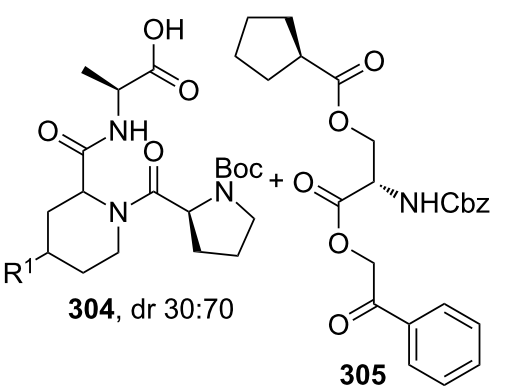

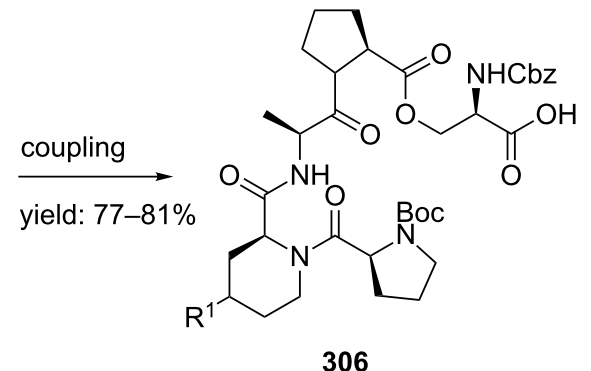

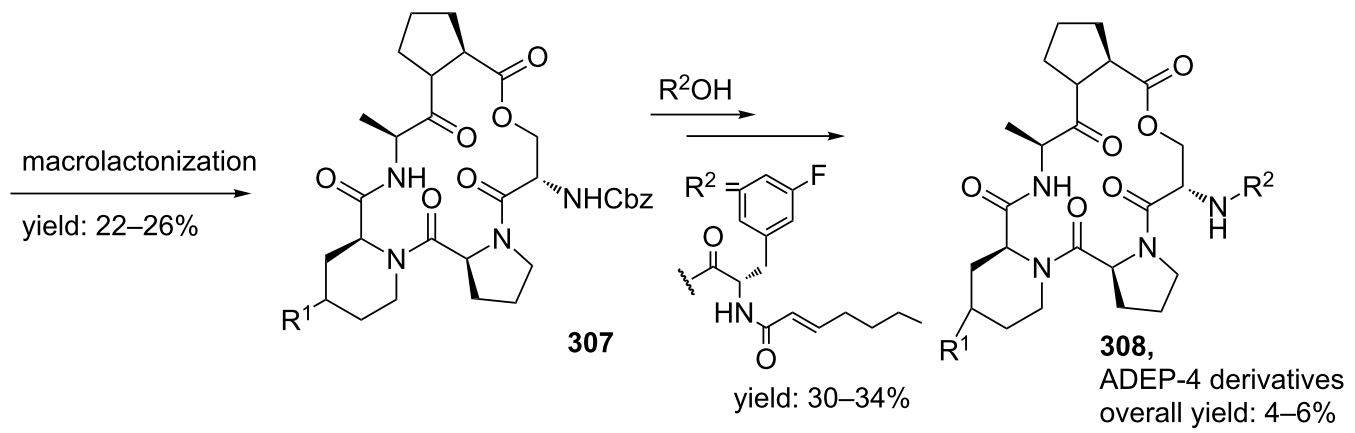

b)<smiles>[R][R1]1C2C(=O)C([R])[C@H]1C2=O</smiles>

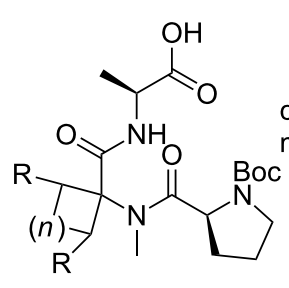

coupling/ macrolactonization

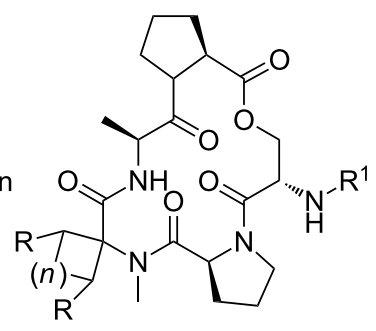

310, overall yield: $13-18 \%$ 
methylamine, $N$-Boc-proline, isocyanopropanoate and different ketones gave the desired tripeptides $\mathbf{3 0 9}$ in good to excellent yields (Scheme 89). The subsequent post-modification reactions provided macrocyclic analogues $\mathbf{3 1 0}$ in overall yields of $13-18 \%$. To validate the antibacterial activity, the different scaffolds were screened against several drug-resistant bacterial strains, however, only the pipecolic derivatives showed antibacterial activity.

\section{Macrocycles via MCR-Click-combinations}

A third approach that can be utilized to construct macrocyclic peptidomimetics is a sequential Ugi-Click-combination. Via this approach the cyclic mimics are linked via a triazole-unit. Recently, Sureshbabu and co-workers used such a two-step sequence for a small library of 15-membered cyclic glyco- peptidomimetics [229]. In this approach, the Ugi reaction was performed with a variety of sugar-1-amines, aldehydes, azido acids and Poc-amino methyl isocyanide and afforded the linear Ugi-products as a mixture of two diastereomers in a ratio of 95:5. The Poc-group functions as protecting group in the Ugi reaction while being reactive in the subsequent Click reaction (Scheme 90). The Click reaction gave the macrocycles 312 in $39-48 \%$ overall yield. It is noteworthy that the cyclization was performed at $\mathrm{mM}$ concentrations to minimize dimerization processes.

In a variation to the aforementioned 5-amino-oxazole Ugi $\mathrm{MCR} /$ macrolactonization, the group of Zhu also synthesized macrocycles via a subsequent $[3+2]$ cycloaddition reaction that contained both a triazole and an oxazole unit (Scheme 91)

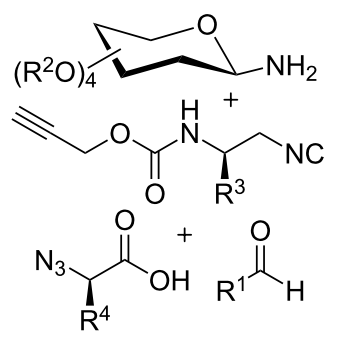

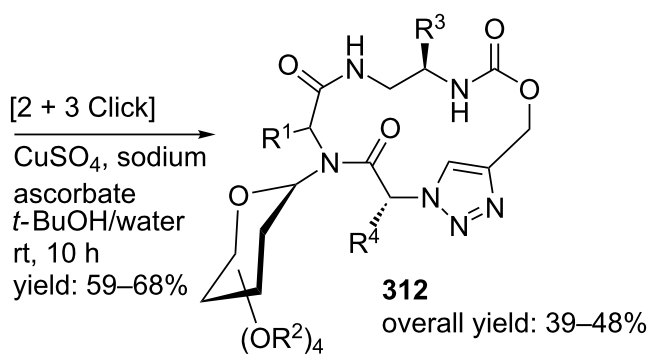

Scheme 90: Ugi-Click-strategy for 15-membered macrocyclic glyco-peptidomimetics.

a)

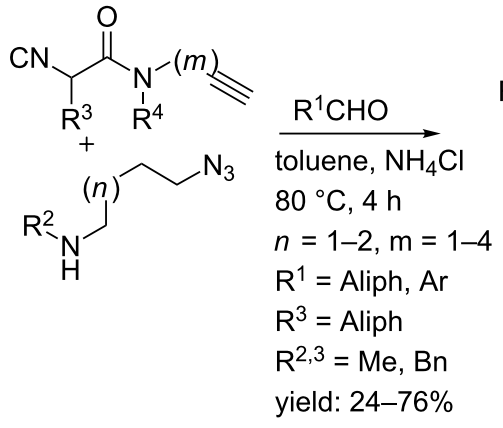

b)<smiles>[R2]NCCCCN</smiles>
$\mathrm{R}^{2,3}=\mathrm{Me}, \mathrm{Bn}$ yield: $24-76 \%$<smiles>[R]c1nc(C([R])N([R])CCCCN)oc1N([R])CC#C</smiles>

Cul $(\mathrm{iPr})_{2} \mathrm{NH}$ THF, rt $15 \mathrm{~h}$

314, yield: $24-76 \%$<smiles>[R]c1nc(C([R])N([R])CC)oc1N([R])CCc1cn(CC)nn1</smiles>

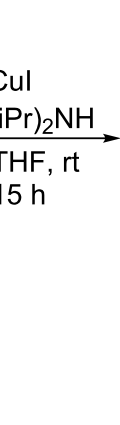

14, yield: $24-76 \%$ 
[230]. The Ugi reaction was performed in toluene and a variety of isocyanoacetamides and amines were employed as bifunctional inputs containing either a terminal alkyne or azide moiety. Herein, the isocyanoacetamides were derived from formylated amino acids via an azide-coupling and dehydration sequence. The subsequent cycloaddition was catalyzed by copper iodide, furnishing 14-16-membered macrocycles 314 in good yields $(24-76 \%)$ that all contain a triazole (as amide biosteres) and an oxazole moiety (as dipeptide surrogate). In addition, it is worth noting that the reaction sequence could also be performed with tethered azide and alkyne moieties in the aldehyde and isocyanide inputs, thereby providing macrocycles with an exo-tertiary amine $(\mathbf{3 1 5}, 35-40 \%)$.

\section{Macrocycles via MCR-S $\mathrm{Ar}$-procedures}

Macrocycles containing an aryl-ether bridge can be obtained via a combination of the Ugi reaction and a sequential aromatic substitution $\left(\mathrm{S}_{\mathrm{n}} \mathrm{Ar}\right)$. In Nature, these particular macrocycles have been found and some of them possess interesting antibiotic [231,232], antitumor [233], or antifungal activities $[234,235]$. In addition, they are also found as potent ACEinhibitors [236]. The most leading example is the antibiotic vancomycin, which found application as last remedy against multi-drug resistant microbial strains [237]. Zhu and co-workers designed both a solution and solid-phase synthesis of biaryl- ether-linked macrocycles (Scheme 92) [238,239]. In the solution-phase approach, they performed an Ugi reaction with a variety of aliphatic and aromatic amines and aldehydes, two acids and two isocyanides (synthetically derived) to arrive at the linear Ugi-products 318 in good yields (43-73\%, dr 1:1). During the reaction no formation of Passerini-like or ammonia derived side products were observed. The solid-phase synthesis afforded the linear precursors by reacting resin-bound isocyanide $\mathbf{3 2 0}$ with a variety of different amines, aldehydes and acids in $\mathrm{CDCl}_{3} / \mathrm{TFE}$ [240]. The subsequent ring closure reaction was performed under basic conditions, providing the 16-17 membered macrocycles as two atropisomers for each diastereomer in moderate to high yields. Slightly better overall yields were observed for the solution-phase process $(\mathbf{3 1 9}$, $24-69 \%)$, compared to the solid-phase route $(322,4-48 \%)$ [238].

The same authors also published a similar solution-phase sequence towards cyclophane based-macrocycles having an aryl- $N$-alkyl bridge (Scheme 93) [241]. In this route the Ugi reaction was performed with aliphatic carboxylic acids, furnishing the dipeptides 323 in $32-92 \%$ yield. Subsequent TFA treatment followed by $\mathrm{S}_{\mathrm{n}}$ Ar-cyclization provided the 15 -membered macrocycles 324 in 16-90\% overall yield, again as two atropisomers.<smiles>[R]C(c1ccc(F)c([N+](=O)[O-])c1)C([R16])[Y5]([H])([H])C(=O)O</smiles>

$317, n=1-2$

$\stackrel{\mathrm{R}^{1} \mathrm{CHO}, \mathrm{R}^{2} \mathrm{NH}_{2}}{\longrightarrow}$
toluene, $\mathrm{NH}_{4} \mathrm{Cl}$,
$60^{\circ} \mathrm{C}, 20 \mathrm{~h}$
$\mathrm{R}^{1}=\mathrm{iPr}, n$-hex, $\mathrm{Ph}$,
$\mathrm{PhEt}$, BocNHCH 2

$\mathrm{R}^{2}=\mathrm{iPr}, n-\mathrm{Bu}$,

4-MeOPh, Bn

$\mathrm{R}^{3}=\mathrm{H}, \mathrm{OAC}$

$\mathrm{R}^{4}=\mathrm{H}$, COOMe, COOEt

yield: $43-73 \%$, dr 1:1<smiles>[R]C(NC(=O)C([R])N([R])C(=O)[18O]c1cccc(O)c1)C([R])c1ccc(F)c([N+](=O)[O-])c1</smiles>

318

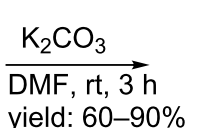<smiles>[R]CC([R])C([R])NC(=O)C([R])N([R])C(=O)c1cccc(Oc2cccc([O-])c2)c1</smiles>

319 , overall yield: $24-69 \%$<smiles>COC(=O)C(Cc1cccc(O)c1)Cc1ccc(F)c([N+](=O)[O-])c1</smiles>

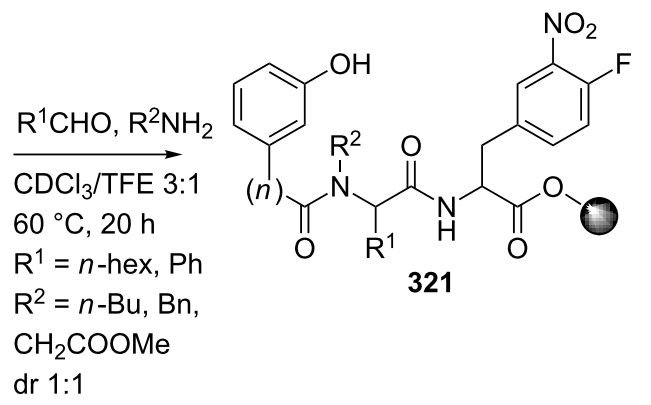

1) $\mathrm{K}_{2} \mathrm{CO}_{3}, \mathrm{DMF}, \mathrm{rt}$ $3 \mathrm{~h}$

2) TFA, DCM

3) $\mathrm{CH}_{2} \mathrm{~N}_{2}, \mathrm{Et}_{2} \mathrm{O}$<smiles>[R]C(C(=O)NC(C(=O)OC)C([R])N([R])C(=O)O)c1ccc(Oc2cccc(Cl)c2)c([N+](=O)[O-])c1</smiles>

322, yield: $4-48 \%$ 


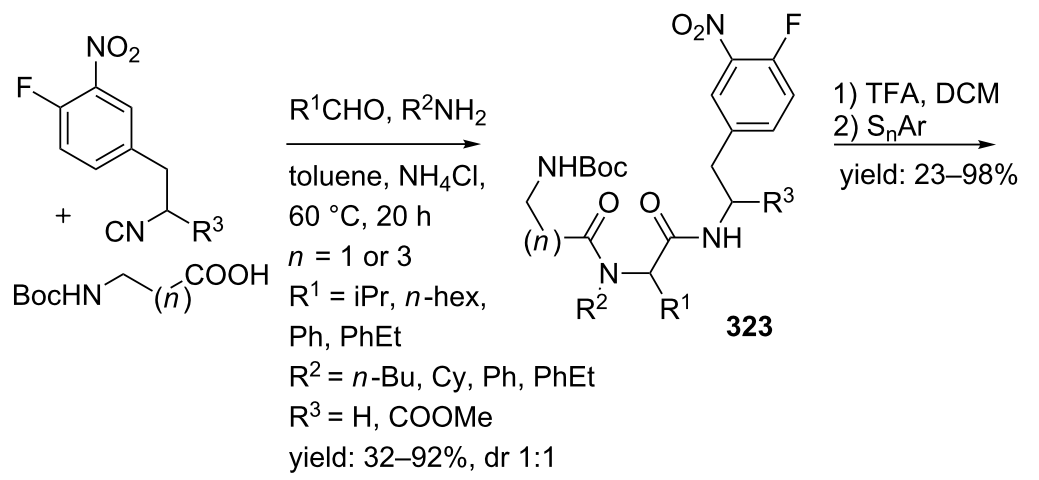

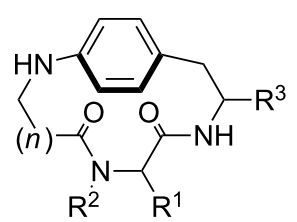

324, overall yield: $16-90 \%$

Scheme 93: Ugi/cyclization towards cyclophane based macrocycles.

\section{Passerini-amine deprotection-acyl migration pro- cedures}

The Passerini-amine-deprotection-acyl migration (PADAM) strategy is a useful alternative to provide dipeptides that can be cyclized to the corresponding macrocycles via a subsequent peptide-coupling. The PADAM-strategy has been used for the total synthesis of eurystatin A and cyclotheanamide C, both are potent $\alpha$-keto-amide-based protease inhibitors. Synthesis of eurystatin A was developed by Semple and co-workers and included $N$-protected amino acid 325, enantiopure aldehyde 326 and leucine isonitrile $\mathbf{3 2 7}$ as MCR-substrates (Scheme 94) [242]. Subsequent $N$-Fmoc deprotection of the resulting linear adduct induced acyl-migration, in which deprotection and hydrolysis of the two N/C-termini provided the cyclization substrate 329. A sequential $N$-Boc deprotection, acylation and oxidation provided the macrocyclic eurystatin A in 23\% yield over 8 steps.
The PADAM-based synthesis of cyclotheanamide C was published by Aitken et al. (Scheme 95) [243]. In this report, the $\alpha$-acyloxyamide precursor was obtained in $44 \%$ yield by reacting isocyanide $\mathbf{3 3 1}$ with a small excess of both Fmocamino aldehyde 332 and $N$-Boc dipeptide 333 (1.2 equiv). Again base promoted $N$-Fmoc deprotection induced acyl-migration, in which TFA treatment and subsequent peptide-coupling using TBTU/HOBt furnished macrocycle 336. Final oxidation with DMP and base-catalyzed Cbz-removal gave the cyclotheanamide C-compound in 13\% yield over 6 steps.

\section{MCR-MCR cyclizations}

Even more challenging is the construction of macrocycles in which the cyclization step is also performed by a multicomponent reaction. Wessjohann and co-workers reported a combination of three sequential Ugi-MCRs towards RGD-pentapeptoids (Scheme 96) [244]. All three MCRs involved an Ugi-

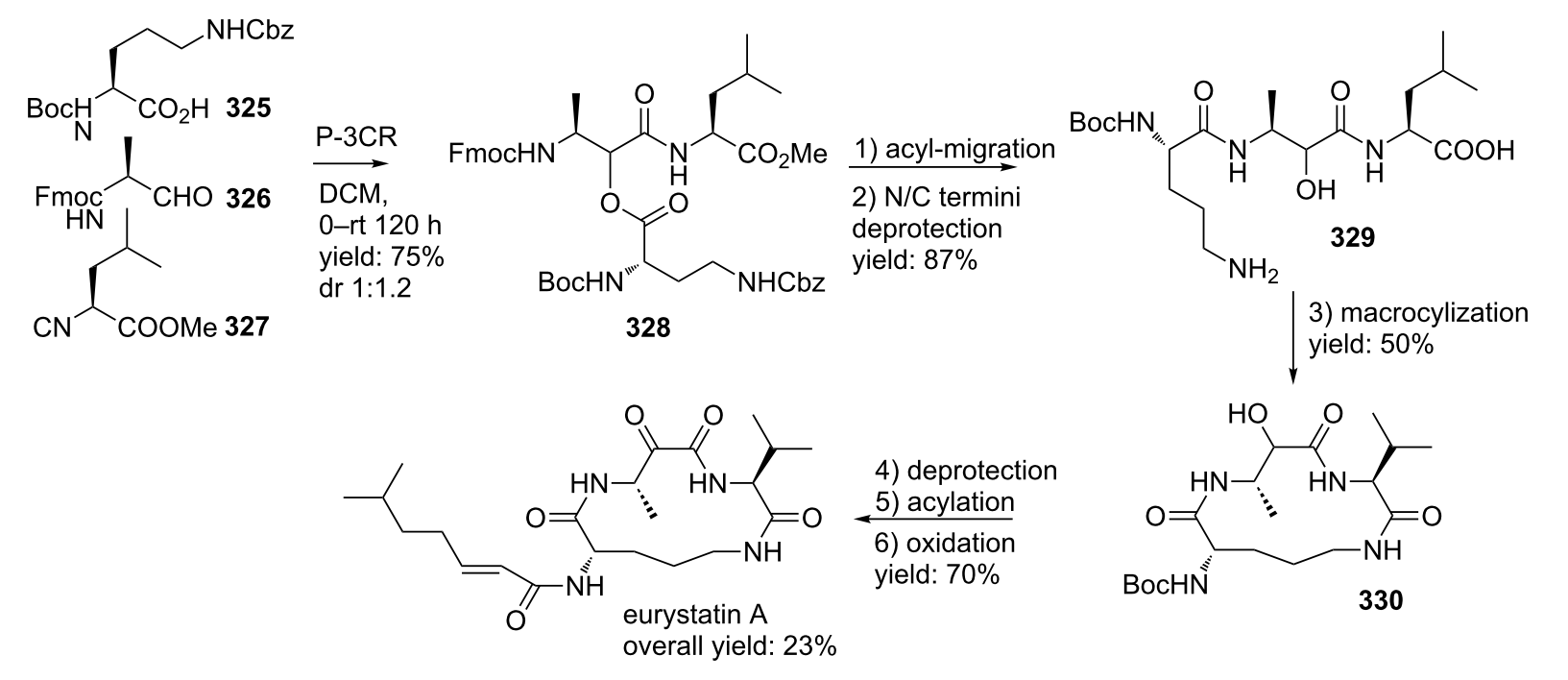




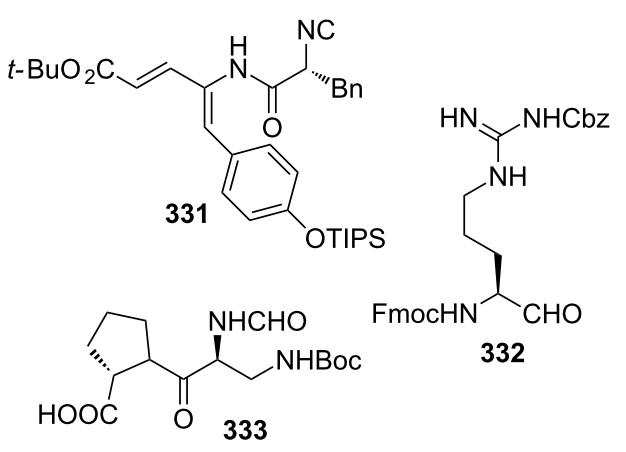

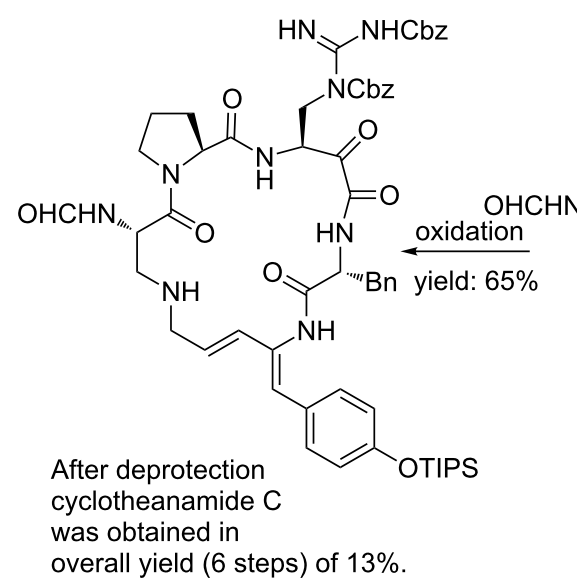

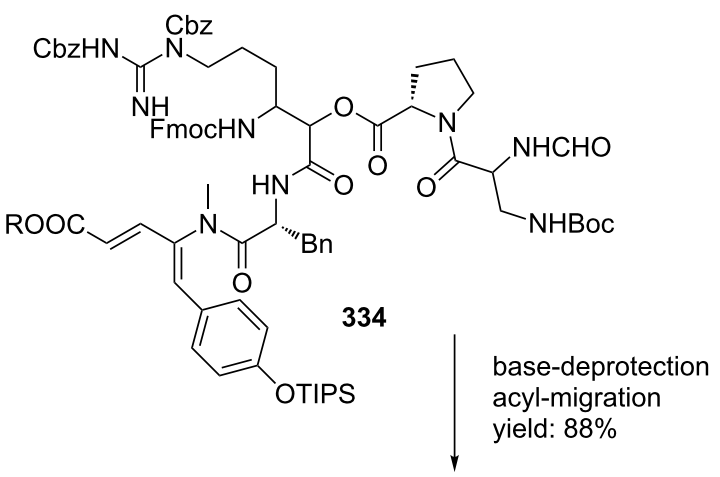

Scheme 95: PADAM-approach for cyclotheanamide.

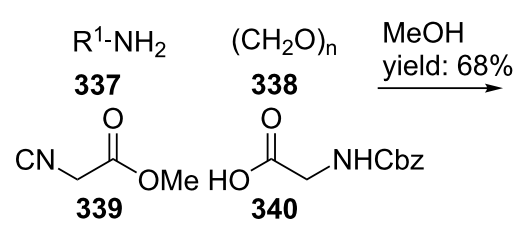<smiles>[R1]CCCN([R16])C(=N)NCCCNC(=O)OCc1ccccc1</smiles>

1) $\mathrm{LiOH}, \mathrm{THF} / \mathrm{H}_{2} \mathrm{O}$ 2) $\mathrm{R}^{2} \mathrm{NH}_{3}{ }^{+} \mathrm{Cl}^{-}, 339,338$<smiles>[R][Y]=CCC(=O)OC(C)(C)C</smiles>

1) $\mathrm{LiOH}$

2) $\mathrm{H}_{2}, \mathrm{Pd} / \mathrm{C}$

3) $338, t$-BuNC, $\mathrm{MeOH}$ 4) TFA
$\mathrm{Et}_{3} \mathrm{~N}, \mathrm{MeOH}$, yield: $85 \%$

$$
342 \prod_{O}^{R^{1}}
$$

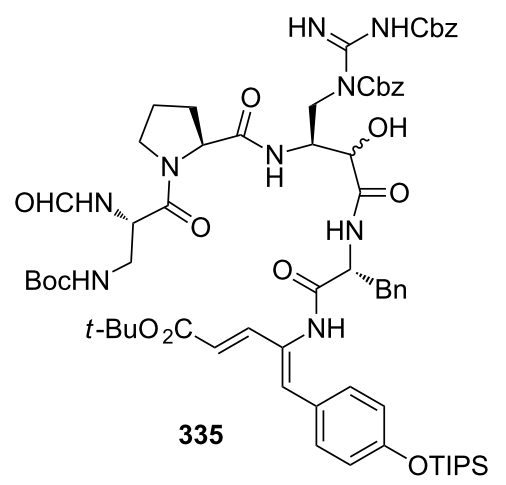

Scheme 96: A triple MCR-approach affording RGD-pentapeptoids.

MCR, in which the first two provided linear products 341 and 342, whereas the third MCR resulted in the ultimate macrocyclic peptoid structure. The final RGD-macrocycles 343 were obtained after TFA-deprotection in $33 \%$ overall yield. It was shown by the authors that a wide range of cyclic peptoids could be obtained by alternating the MCR-substrates. In particular, interchange of the amine component in the first two MCRs resulted in (retro)-peptoids consisting of a DGR-sequence. 
A second powerful strategy to obtain macrocycles exclusively from combinations of multicomponent reactions is the MiB-approach (multiple multicomponent macrocyclizations including bifunctional building blocks). Similar to the previous described MCR-MCR approach, macrocycles are in this approach obtained from two or more MCRs. However, in this particular process, the MCRs include two or more unprotected bifunctional groups such as diisonitriles, diamines or amino acids. The incorporation of these unprotected bifunctional substrates makes the construction of highly complex macrocycles even more straightforward and also allows scaffold diversification. In the literature, several Ugi or Passerini-based MiB-approaches have been reported and only two examples will be given in this review since they already have been extensively reviewed by the groups of Wessjohann and Rivera. For more details see also references [24,27-29,245,246].

An example of an Ugi-approach by Rivera and Wessjohann included symmetric diamines and diisonitriles in combination with formaldehyde and (protected) $\alpha$-amino acids (Scheme 97). Via this procedure peptoid-based macrocycles 344 were obtained that contain biologically relevant side chains [245].

The same group also reported a Passerini-based MiB-approach (Scheme 98) [247]. The multicomponent reactions were either performed with diacid/diisonitrile combinations or with diisonitrile/dialdehyde bifunctional groups, providing the macrocycles $\mathbf{3 4 5}$ and 346 in $32 \%$ and 33\% yield, respectively. It was shown that the latter combination requires in situ-generation of the dialdehydes from dialcohols via an oxidative Passerini reaction. One reason for this in situ generation was the acid-instability of aldehydes [248].

Finally, Yudin et al. [219,249] developed interesting and very effective strategies to construct macrocyclic peptidomimetics through an MCR-induced cyclization. Their approach includes macrocyclization of peptides of type 347 using so-called amphoteric aziridine-based aldehydes 348 (used as the corres-<smiles>[N-]Cc1ccc(CN=[N-])cc1</smiles>

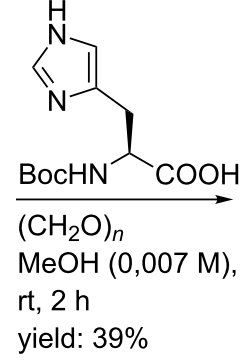

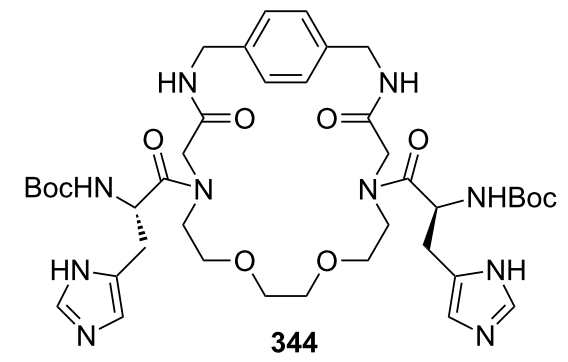

Scheme 97: Ugi-MiBs-approach towards peptoid macrocycles.
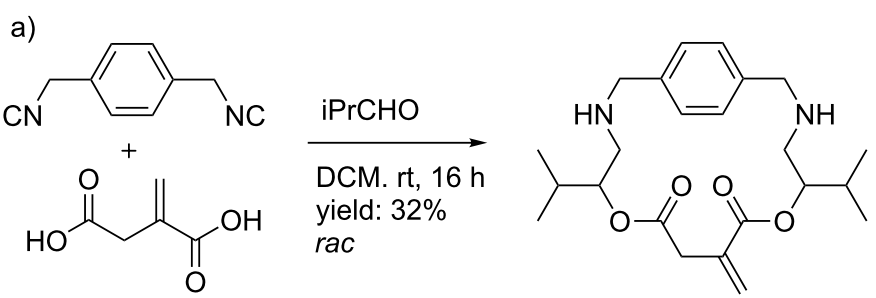

345

b)

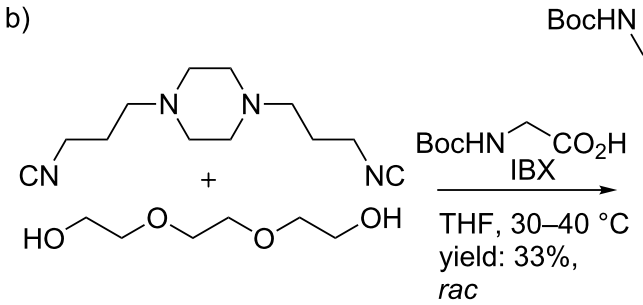

(34)

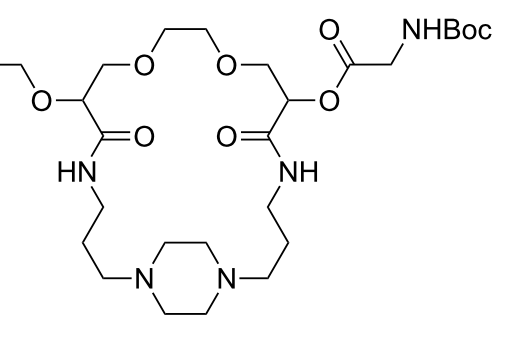

346 


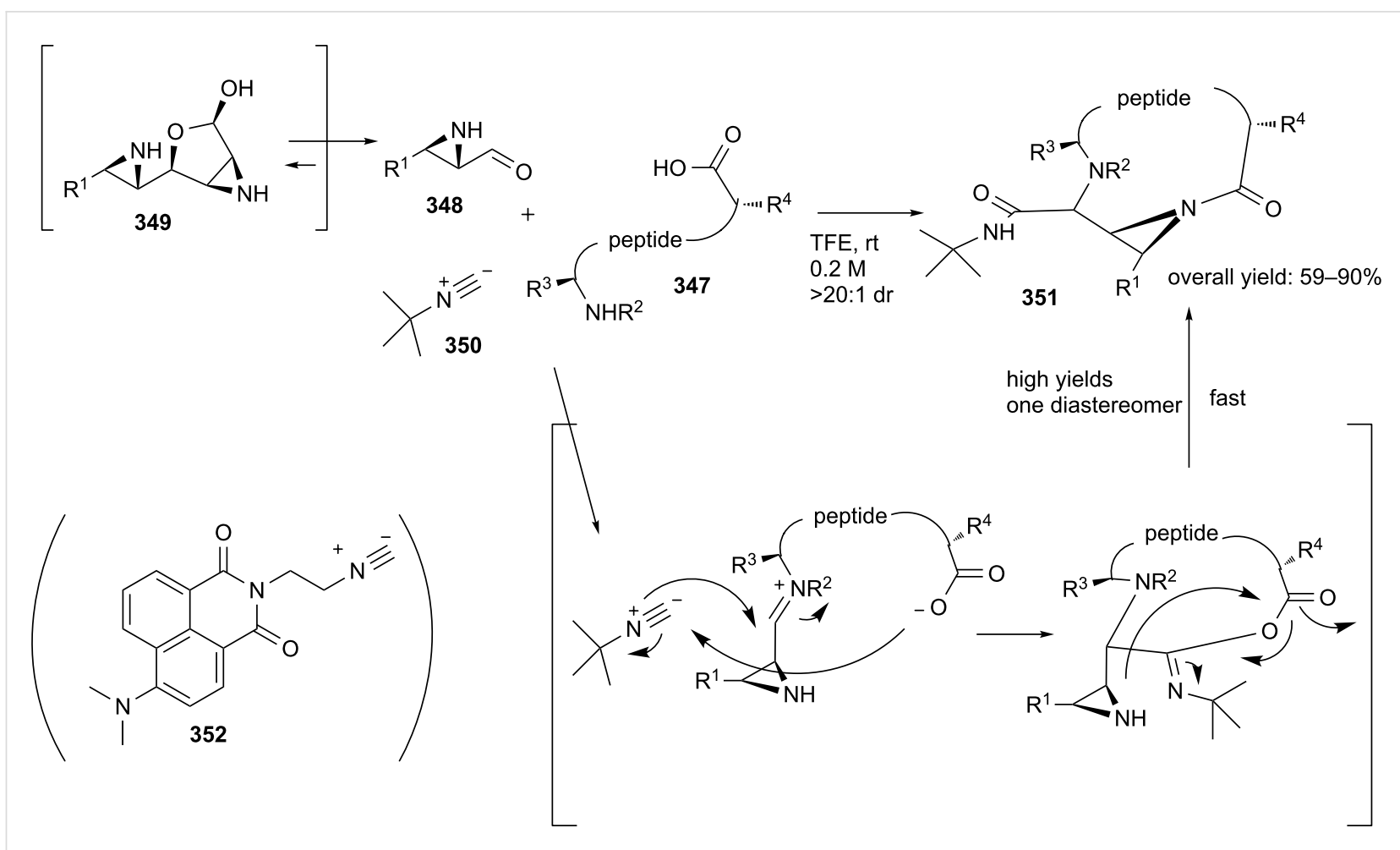

Scheme 99: Macrocyclic peptide formation by the use of amphoteric aziridine-based aldehydes.

ponding dimer 349) in combination with isocyanides 350 (Scheme 99). As became clear from discussions in this review, the use of the Ugi reaction in a "traditional" sense to induce macrocyclization of peptidic $\alpha$-amino acids (as bifunctional inputs), aldehydes and isocyanides usually produces mixtures of diastereoisomers of macrocyclic peptides and requires high dilution conditions to minimize overall dominant formation of cyclo di- or oligomerization products. The amphoteric aldehydes 348 in the Yudin macrocyclization strategy can be applied under conventional reactant conencentrations and overcomes both the stereoselectivity and oligomerization issues producing in good yields and excellent diastereoselectivities macrocyclic peptides 351 avoiding epimerization. In follow-up work a number of interesting applications were discussed [250] including the use of solvatochromic isocyanides $\mathbf{3 5 2}$ to access cell permeable macrocyclic peptide vectors [251] and RGD fluorescent probes [252]. In addition, the macrocyclization tool proved very useful in the exocyclic control over turn induction in macrocyclic petides [253].

\section{Conclusion}

Isocyanide-based multicomponent reactions in combination with subsequent cyclization reactions have become valuable tools in the design and synthesis of cyclic constrained peptidomimetics. These IMCRs give rapid access to these complex target molecules from relatively simple starting materials addressing both structural diversity and complexity. Furthermore, after the initial MCRs several post-cyclization condensations can be utilized, since a variety of unreactive or monoprotected functionalities are tolerated in the initial MCRs. This ultimately leads to cyclic constrained peptidomimetics in only a few steps as compared to often much longer more traditional sequential procedures.

We discussed many examples of four to seven membered (bi)cyclic dipeptide isosteres such as lactams, triazoles, oxazoles and thiazoles that can be easily incorporated via these IMCR/cyclization protocols, in which it was even possible to provide triazole based peptidomimetics. Incorporating dipeptide mimics into peptides introduces conformational order, improves stability against enzymatic degradation and allows the peptidic structures to adopt secondary structures such as turns and $\alpha$-helices. A nice example of this was the bicyclic diketopiperazines as they perfectly force the peptide-like structure into a type I $\beta$-turn.

In addition, the IMCR/cyclization strategies have also shown to be highly suitable for the synthesis of macrocyclic peptidomimetics. The interest for macrocycles is based on two important properties. These macrocyclic peptoids combine conformational order with flexibility and they are stable against terminal group degradation by proteases. As discussed here, the 
IMCR-based synthesis of such macrocycles usually requires a subsequent head-to-tail cyclization such as ring-closingmetatheses, cycloadditions, lactonizations, peptide-couplings or nucleophilic substitutions. Even more interestingly is the synthesis of cyclic peptidomimetics via multiple MCRs as was described for macrocyclic RGD-peptoids. These multiple MCRapproaches have the advantages to also introduce structural diversity and complexity at the cyclization step.

However, still a main flaw of MCR-based strategies for the synthesis of constrained peptidomimetics is the often poor stereocontrol in these reactions. This is crucial since optically pure peptide-like products are essential for proper study of peptidepeptide interactions, therefore, for the future of this chemistry in this field the design of (dia)stereoselective multicomponent reactions is highly desirable. Several research groups have indeed realized this challenge and are developing such asymmetric multicomponent reactions. Perhaps a prominent example is the bio-catalytic synthesis of optically active pyrrolidines that can be used in a MCR-based synthesis of telaprevir. Further developments may rely on the use of these asymmetric approaches and will make the multicomponent reaction an even more useful tool for the design of novel conformationally constrained peptidomimetics.

\section{References}

1. Kimmerlin, T.; Seebach, D. J. Pept. Res. 2005, 65, 229. doi:10.1111/j.1399-3011.2005.00214.x

2. Boyle, A. L.; Woolfson, D. N. Chem. Soc. Rev. 2011, 40, 4295. doi:10.1039/c0cs00152j

3. Ripka, A. S.; Rich, D. H. Curr. Opin. Chem. Biol. 1998, 2, 441. doi:10.1016/S1367-5931(98)80119-1

4. Goodman, M.; Shao, H. Pure Appl. Chem. 1996, 68, 1303. doi:10.1351/pac199668061303

5. Hill, D. J.; Mio, M. J.; Prince, R. B.; Hughes, T. S.; Moore, J. S. Chem. Rev. 2001, 101, 3893. doi:10.1021/cr990120t

6. Gante, J. Angew. Chem., Int. Ed. Engl. 1994, 33, 1699. doi:10.1002/anie.199416991

7. Grauer, A.; König, B. Eur. J. Org. Chem. 2009, 5099. doi:10.1002/ejoc.200900599

8. Cini, E.; Bifulco, G.; Menchi, G.; Rodriquez, M.; Taddei, M. Eur. J. Org. Chem. 2012, 2133. doi:10.1002/ejoc.201101387

9. Burgess, K. Acc. Chem. Res. 2001, 34, 826. doi:10.1021/ar9901523

10. Scheffelaar, R.; Nijenhuis, R. A. K.; Paravidino, M.; Lutz, M.; Spek, A. L.; Ehlers, A. W.; de Kanter, F. J. J.; Groen, M. B.; Orru, R. V. A.; Ruijter, E. J. Org. Chem. 2009, 74, 660. doi:10.1021/jo802052j

11. Dietrich, S. A.; Banfi, L.; Basso, A.; Damonte, G.; Guanti, G.; Riva, R. Org. Biomol. Chem. 2005, 3, 97. doi:10.1039/b414374d

12. Scheffelaar, R.; Paravidino, M.; Znabet, A.; Schmitz, R. F.; de Kanter, F. J. J.; Lutz, M.; Spek, A. L.; Guerra, C. F.; Bickelhaupt, F. M.; Groen, M. B.; Ruijter, E.; Orru, R. V. A. J. Org. Chem. 2010, 75, 1723. doi:10.1021/jo902613j

13. Banfi, L.; Basso, A.; Guanti, G.; Merlo, S.; Repetto, C.; Riva, R. Tetrahedron 2008, 64, 1114. doi:10.1016/j.tet.2007.10.058
14. Dömling, A. Chem. Rev. 2006, 106, 17. doi:10.1021/cr0505728

15. Ruijter, E.; Scheffelaar, R.; Orru, R. V. A. Angew. Chem., Int. Ed. 2011, 50, 6234. doi:10.1002/anie.201006515

16. Lesma, G.; Cecchi, R.; Crippa, S.; Giovanelli, P.; Meneghetti, F.; Musolino, M.; Sacchetti, A.; Silvani, A. Org. Biomol. Chem. 2012, 10, 9004. doi:10.1039/c2ob26301g

17. Dömling, A. Curr. Opin. Chem. Biol. 2002, 6, 306. doi:10.1016/S1367-5931(02)00328-9

18. Kolb, J.; Beck, B.; Dömling, A. Tetrahedron Lett. 2002, 43, 6897. doi:10.1016/S0040-4039(02)01621-0

19. Dömling, A.; Wang, W.; Wang, K. Chem. Rev. 2012, 112, 3083. doi:10.1021/cr100233r

20. Gulevich, A. V.; Zhdanko, A. G.; Orru, R. V. A.; Nenajdenko, V. G. Chem. Rev. 2010, 110, 5235. doi:10.1021/cr900411f

21. Dömling, A.; Ugi, I. Angew. Chem., Int. Ed. 2000, 39, 3169. doi:10.1002/1521-3773(20000915)39:18<3168::AID-ANIE3168>3.0.C $0 ; 2-U$

22. Zhu, J.; Bienaymé, H. Multicomponent reactions; Wiley-VCH: Weinheim, Germany, 2005. doi:10.1002/3527605118

23. Banfi, L.; Basso, A.; Guanti, G.; Riva, R. Mol. Diversity 2003, 6, 227. doi:10.1023/B:MODI.0000006778.42751.7f

24. Wessjohann, L. A.; Ruijter, E. Mol. Diversity 2005, 9, 159 doi:10.1007/s11030-005-1313-y

25. de Graaff, C.; Ruijter, E.; Orru, R. V. A. Chem. Soc. Rev. 2012, 41, 3969. doi:10.1039/c2cs15361k

26. Wessjohann, L. A.; Rhoden, C. R. B.; Rivera, D. G.; Vercillo, O. E. In Synthesis of Heterocycles via Multicomponent Reactions I; Orru, R. V. A.; Ruijter, E., Eds.; Topics in Heterocyclic Chemistry, Vol. 23; Springer-Verlag Berlin Heidelberg: Berlin, 2010; pp 199-226.

27. Wessjohann, L. A.; Rivera, D. G.; Vercillo, O. E. Chem. Rev. 2009, 109, 796. doi:10.1021/cr8003407

28. Ivachtchenko, A. V.; Ivanenkov, Y. A.; Kysil, V. M.; Krasavin, M. Y.; Ilyin, A. P. Russ. Chem. Rev. 2010, 79, 787. doi:10.1070/RC2010v079n09ABEH004086

29. Akritopoulou-Zanze, I. Chapter 12: Applications of Isocyanides in the Synthesis of Heterocycles. In Isocyanide Chemistry; Nenajdenko, V. D., Ed.; Wiley-VCH: Weinheim, 2012; pp 451-496.

30. Singh, G. S. Mini-Rev. Med. Chem. 2004, 4, 69. doi:10.2174/1389557043487501

31. Annunziata, R.; Benaglia, M.; Cinquini, M.; Cozzi, F.; Puglisi, A. Bioorg. Med. Chem. 2002, 10, 1813. doi:10.1016/S0968-0896(02)00017-2

32. Schneider, M.; Otto, H. H. Arch. Pharm. 2001, 334, 167. doi:10.1002/1521-4184(200105)334:5<167::AID-ARDP167>3.0.CO;2$\mathrm{O}$

33. Macchia, B.; Gentili, D.; Macchia, M.; Mamone, F.; Martinelli, A.; Orlandini, E.; Rossello, A.; Cercignani, G.; Pierotti, R.; Allegretti, M.; Asti, C.; Caselli, G. Eur. J. Med. Chem. 2000, 35, 53. doi:10.1016/S0223-5234(00)00111-2

34. Saturnino, C.; Fusco, B.; Saturnino, P.; De Martino, G.; Rocco, F.; Lancelot, J.-C. Biol. Pharm. Bull. 2000, 23, 654. doi:10.1248/bpb.23.654

35. Clemente, A.; Domingos, A.; Grancho, A. P.; lley, J.; Moreira, R.; Neres, J.; Palma, N.; Santana, A. B.; Valente, E. Bioorg. Med. Chem. Lett. 2001, 11, 1065. doi:10.1016/S0960-894X(01)00131-7

36. Sperka, T.; Pitlik, J.; Bagossi, P.; Tözsér, J. Bioorg. Med. Chem. Lett. 2005, 15, 3086. doi:10.1016/j.bmcl.2005.04.020 
37. Achilles, K.; Schirmeister, T.; Otto, H. H. Arch. Pharm. 2000, 333, 243. doi:10.1002/1521-4184(20008)333:8<243::AID-ARDP243>3.0.CO;2$\mathrm{O}$

38. Ruhland, B.; Bhandari, A.; Gordon, E. M.; Gallop, M. A. J. Am. Chem. Soc. 1996, 118, 253. doi:10.1021/ja953322p

39. Gedey, S.; Van der Eycken, J.; Fülöp, F. Org. Lett. 2002, 4, 1967. doi:10.1021/ol025986r

40. Kanizsai, I.; Gyonfalvi, S.; Szakonyi, Z.; Sillanpaa, R.; Fülöp, F. Green Chem. 2007, 9, 357. doi:10.1039/b613117d

41. Pirrung, M. C.; Das Sarma, K. J. Am. Chem. Soc. 2004, 126, 444. doi:10.1021/ja038583a

42. Kanizsai, I.; Szakonyi, Z.; Sillanpää, R.; Fülöp, F. Tetrahedron Lett. 2006, 47, 9113. doi:10.1016/j.tetlet.2006.10.069

43. Szakonyi, Z.; Martinek, T. A.; Sillanpää, R.; Fülöp, F. Tetrahedron: Asymmetry 2008, 19, 2296. doi:10.1016/j.tetasy.2008.09.026

44. Szakonyi, Z.; Sillanpaa, R.; Fülöp, F. Mol. Diversity 2010, 14, 59. doi:10.1007/s11030-009-9143-y

45. Pirrung, M. C.; Das Sarma, K. Tetrahedron 2005, 61, 11456. doi:10.1016/j.tet.2005.08.068

46. Vishwanatha, T. M.; Narendra, N.; Sureshbabu, V. V. Tetrahedron Lett. 2011, 52, 5620. doi:10.1016/j.tetlet.2011.08.090

47. Chakraborty, T. K.; Srinivasu, P.; Kumar, S. K.; Kunwar, A. C. J. Org. Chem. 2002, 67, 2093. doi:10.1021/jo010937y

48. Trabocchi, A.; Scarpi, D.; Guarna, A. Amino Acids 2008, 34, 1. doi:10.1007/s00726-007-0588-y

49. Lummis, S. C. R.; Beene, D. L.; Lee, L. W.; Lester, H. A.; Broadhurst, R. W.; Dougherty, D. A. Nature 2005, 438, 248. doi:10.1038/nature04130

50. Breznik, M.; Grdadolnik, S. G.; Giester, G.; Leban, I.; Kikelj, D. J. Org. Chem. 2001, 66, 7044. doi:10.1021/jo0159439

51. Banfi, L.; Basso, A.; Cerulli, V.; Guanti, G.; Riva, R. J. Org. Chem. 2008, 73, 1608. doi:10.1021/jo702087x

52. Hara, O.; Sugimoto, K.; Makino, K.; Hamada, Y. Synlett 2004, 1625. doi:10.1055/s-2004-829085

53. Nenajdenko, V. G.; Gulevich, A. V.; Balenkova, E. S. Tetrahedron 2006, 62, 5922. doi:10.1016/j.tet.2006.04.021

54. Hua, D. H.; Miao, S. W.; Bharathi, S. N.; Katsuhira, T.; Bravo, A. A. J. Org. Chem. 1990, 55, 3682. doi:10.1021/jo00298a062

55. Banfi, L.; Basso, A.; Guanti, G.; Riva, R. Tetrahedron Lett. 2004, 45, 6637. doi:10.1016/j.tetlet.2004.07.015

56. Schlemminger, I.; Janknecht, H.-H.; Maison, W.; Saak, W.; Martens, J. Tetrahedron Lett. 2000, 41, 7289. doi:10.1016/S0040-4039(00)01266-1

57. Gröger, H.; Saida, Y.; Arai, S.; Martens, J.; Sasai, H.; Shibasaki, M. Tetrahedron Lett. 1996, 37, 9291. doi:10.1016/S0040-4039(97)82944-9

58. Chapman, T. M.; Davies, I. G.; Gu, B.; Block, T. M.; Scopes, D. I. C.; Hay, P. A.; Courtney, S. M.; McNeill, L. A.; Schofield, C. J.; Davis, B. G. J. Am. Chem. Soc. 2005, 127, 506. doi:10.1021/ja043924I

59. Morana, F.; Basso, A.; Bella, M.; Riva, R.; Banfi, L. Adv. Synth. Catal. 2012, 354, 2199. doi:10.1002/adsc.201200140

60. Cerulli, V.; Banfi, L.; Basso, A.; Rocca, V.; Riva, R. Org. Biomol. Chem. 2012, 10, 1255. doi:10.1039/c1ob06632c

61. Znabet, A.; Ruijter, E.; de Kanter, F. J. J.; Kohler, V.; Helliwell, M.; Turner, N. J.; Orru, R. V. A. Angew. Chem., Int. Ed. 2010, 49, 5289. doi:10.1002/anie.201001592
62. Köhler, V.; Bailey, K. R.; Znabet, A.; Raftery, J.; Helliwell, M.; Turner, N. J. Angew. Chem., Int. Ed. 2010, 49, 2182. doi:10.1002/anie.200906655

63. Znabet, A.; Polak, M. M.; Janssen, E.; de Kanter, F. J. J.; Turner, N. J.; Orru, R. V. A.; Ruijter, E. Chem. Commun. 2010, 46, 7918. doi:10.1039/c0cc02823a

64. Freidinger, R. M.; Veber, D. F.; Perlow, D. S.; Brooks, J. R.; Saperstein, R. Science 1980, 210, 656. doi:10.1126/science.7001627

65. Reddy, P. A.; Hsiang, B. C. H.; Latifi, T. N.; Hill, M. W.; Woodward, K. E.; Rothman, S. M.; Ferrendelli, J. A.; Covey, D. F. J. Med. Chem. 1996, 39, 1898. doi:10.1021/jm9600196

66. Das Sarma, K.; Zhang, J.; Huang, Y.; Davidson, J. G. Eur. J. Org. Chem. 2006, 3730. doi:10.1002/ejoc.200600153

67. Spaltenstein, A.; Almond, M. R.; Bock, W. J.; Cleary, D. G.; Furfine, E. S.; Hazen, R. J.; Kazmierski, W. M.; Salituro, F. G.; Tung, R. D.; Wright, L. L. Bioorg. Med. Chem. Lett. 2000, 10, 1159. doi:10.1016/S0960-894X(00)00163-3

68. Kazmierski, W. M.; Andrews, W.; Furfine, E.; Spaltenstein, A.; Wright, L. Bioorg. Med. Chem. Lett. 2004, 14, 5689. doi:10.1016/j.bmcl.2004.08.039

69. Barnes, D. M.; Ji, J. G.; Fickes, M. G.; Fitzgerald, M. A.; King, S. A.; Morton, H. E.; Plagge, F. A.; Preskill, M.; Wagaw, S. H.; Wittenberger, S. J.; Zhang, J. J. Am. Chem. Soc. 2002, 124, 13097. doi:10.1021/ja026788y

70. Hanusch-Kompa, C.; Ugi, I. Tetrahedron Lett. 1998, 39, 2725. doi:10.1016/S0040-4039(98)00428-6

71. Short, K. M.; Mjalli, A. M. M. Tetrahedron Lett. 1997, 38, 359. doi:10.1016/S0040-4039(96)02303-9

72. Harriman, G. C. B. Tetrahedron Lett. 1997, 38, 5591. doi:10.1016/S0040-4039(97)01265-3

73. Hulme, C.; Ma, L.; Cherrier, M.-P.; Romano, J. J.; Morton, G.; Duquenne, C.; Salvino, J.; Labaudiniere, R. Tetrahedron Lett. 2000, 41, 1883. doi:10.1016/S0040-4039(00)00052-6

74. Krelaus, R.; Westermann, B. Tetrahedron Lett. 2004, 45, 5987. doi:10.1016/j.tetlet.2004.06.052

75. Ma, S.; Ni, B. Chem.-Eur. J. 2004, 10, 3286. doi:10.1002/chem.200305581

76. Ma, S.; Ni, B. Org. Lett. 2002, 4, 639. doi:10.1021/ol0172673

77. Miller, N.; Williams, G. M.; Brimble, M. A. Org. Lett. 2010, 12, 1375. doi:10.1021/ol1001208

78. Wan, Q.; Chen, J.; Chen, G.; Danishefsky, S. J. J. Org. Chem. 2006, 71, 8244. doi:10.1021/jo061406i

79. Tornoe, C. W.; Christensen, C.; Meldal, M. J. Org. Chem. 2002, 67, 3057. doi:10.1021/j0011148j

80. Whiting, M.; Tripp, J. C.; Lin, Y.-C.; Lindstrom, W.; Olson, A. J.; Elder, J. H.; Sharpless, K. B.; Fokin, V. V. J. Med. Chem. 2006, 49, 7697. doi:10.1021/jm060754+

81. Holub, J. M.; Kirshenbaum, K. Chem. Soc. Rev. 2010, 39, 1325. doi:10.1039/B901977B

82. Angell, Y. L.; Burgess, K. Chem. Soc. Rev. 2007, 36, 1674. doi:10.1039/b701444a

83. Appendino, G.; Bacchiega, S.; Minassi, A.; Cascio, M. G.; De Petrocellis, L.; Di Marzo, V. Angew. Chem., Int. Ed. 2007, 46, 9312. doi:10.1002/anie.200703590

84. Kolb, H. C.; Sharpless, K. B. Drug Discovery Today 2003, 8, 1128. doi:10.1016/S1359-6446(03)02933-7

85. Nenajdenko, V. G.; Gulevich, A. V.; Sokolova, N. V.; Mironov, A. V.; Balenkova, E. S. Eur. J. Org. Chem. 2010, 1445. doi:10.1002/ejoc. 200901326 
86. Vorobyeva, D. V.; Sokolova, N. V.; Nenajdenko, V. G.; Peregudov, A. S.; Osipov, S. N. Tetrahedron 2012, 68, 872. doi:10.1016/j.tet.2011.11.037

87. Bilgicer, B.; Kumar, K. Tetrahedron 2002, 58, 4105 doi:10.1016/S0040-4020(02)00260-0

88. Berlicki, L.; Kafarski, P. Curr. Org. Chem. 2005, 9, 1829. doi:10.2174/138527205774913088

89. Vorobyeva, D. V.; Karimova, N. M.; Vasilyeva, T. P.; Osipov, S. N.; Shchetnikov, G. T.; Odinets, I. L.; Röschenthaler, G.-V. J. Fluorine Chem. 2010, 131, 378. doi:10.1016/j.jluchem.2009.12.003

90. Shchetnikov, G. T.; Zotova, M. A.; Bruneau, C.; Dixneuf, P. H.; Osipov, S. N. Eur. J. Org. Chem. 2010, 1587. doi:10.1002/ejoc.200901354

91. Pramitha, P.; Bahulayan, D. Bioorg. Med. Chem. Lett. 2012, 22, 2598. doi:10.1016/j.bmcl.2012.01.111

92. Niu, T.-F.; Cai, C.; Yi, L. Helv. Chim. Acta 2012, 95, 87. doi:10.1002/hlca.201100253

93. Niu, T.-F.; Gu, L.; Yi, W.-b.; Cai, C. ACS Comb. Sci. 2012, 14, 442. doi:10.1021/co300061p

94. Lakontseva, E.; Krasavin, M. Tetrahedron Lett. 2010, 51, 4095. doi:10.1016/j.tetlet.2010.05.133

95. Cui, Y.-M.; Huang, Q.-Q.; Xu, J.; Chen, L.-L.; Li, J.-Y.; Ye, Q.-Z.; Li, J.; Nan, F.-J. Bioorg. Med. Chem. Lett. 2005, 15, 3732. doi:10.1016/j.bmcl.2005.05.055

96. Bycroft, B. W.; Gowland, M. S. J. Chem. Soc., Chem. Commun. 1978, 256. doi:10.1039/c39780000256

97. Socha, A. M.; Long, R. A.; Rowley, D. C. J. Nat. Prod. 2007, 70, 1793. doi:10.1021/np070126a

98. Marsham, P. R.; Hughes, L. R.; Jackman, A. L.; Hayter, A. J.; Oldfield, J.; Wardleworth, J. M.; Bishop, J. A. M.; Oconnor, B. M.; Calvert, A. H. J. Med. Chem. 1991, 34, 1594. doi:10.1021/jm00109a011

99. Pettit, G. R.; Kamano, Y.; Herald, C. L.; Tuinman, A. A.; Boettner, F. E.; Kizu, H.; Schmidt, J. M.; Baczynskyj, L.; Tomer, K. B.; Bontems, R. J. J. Am. Chem. Soc. 1987, 109, 6883. doi:10.1021/ja00256a070

100.Heal, W.; Thompson, M. J.; Mutter, R.; Cope, H.; Louth, J. C.; Chen, B. J. Med. Chem. 2007, 50, 1347. doi:10.1021/jm0612719

101.Kolb, J.; Beck, B.; Almstetter, M.; Heck, S.; Herdtweck, E.; Dömling, A. Mol. Diversity 2003, 6, 297. doi:10.1023/B:MODI.0000006827.35029.e4

102. Heck, S.; Dömling, A. Synlett 2000, 424. doi:10.1055/s-2000-6517 103.Schöllkopf, U.; Porsch, P.-H.; Blume, E. Justus Liebigs Ann. Chem. 1976, 2122. doi:10.1002/jlac.197619761118

104. Henkel, B.; Sax, M.; Dömling, A. Tetrahedron Lett. 2003, 44, 3679. doi:10.1016/S0040-4039(03)00662-2

105. Wieland, T.; Freter, K. Chem. Ber. 1954, 87, 1099. doi:10.1002/cber.19540870806

106. Thompson, M. J.; Chen, B. Tetrahedron Lett. 2008, 49, 5324. doi:10.1016/j.tetlet.2008.06.067

107. Thompson, M. J.; Chen, B. J. Org. Chem. 2009, 74, 7084 doi:10.1021/jo9014529

108. Kazmaier, U.; Persch, A. Org. Biomol. Chem. 2010, 8, 5442. doi:10.1039/c0ob00453g

109.Wang, W.; Joyner, S.; Khoury, K. A. S.; Dömling, A. Org. Biomol. Chem. 2010, 8, 529. doi:10.1039/b918214d

110.Sun, X.; Janvier, P.; Zhao, G.; Bienaymé, H.; Zhu, J. Org. Lett. 2001, 3, 877. doi:10.1021/ol007055q

111.Janvier, P.; Sun, X.; Bienaymé, H.; Zhu, J. J. Am. Chem. Soc. 2002, 124, 2560. doi:10.1021/ja017563a
112.Bonne, D.; Dekhane, M.; Zhu, J. Org. Lett. 2004, 6, 4771 doi:10.1021/ol0479388

113.Shaw, A. Y.; Xu, Z.; Hulme, C. Tetrahedron Lett. 2012, 53, 1998. doi:10.1016/j.tetlet.2012.02.030

114.Li, J.; Chen, S. Y.; Li, J. J.; Wang, H.; Hernandez, A. S.; Tao, S.; Musial, C. M.; Qu, F.; Swartz, S.; Chao, S. T.; Flynn, N.; Murphy, B. J.; Slusarchyk, D. A.; Seethala, R.; Yan, M.; Sleph, P.; Grover, G.; Smith, M. A.; Beehler, B.; Giupponi, L.; Dickinson, K. E.; Zhang, H.; Humphreys, W. G.; Patel, B. P.; Schwinden, M.; Stouch, T.; Cheng, P. T. W.; Biller, S. A.; Ewing, W. R.; Gordon, D.; Robl, J. A.; Tino, J. A. J. Med. Chem. 2007, 50, 5890. doi:10.1021/jm7010595

115.Zabrocki, J.; Smith, G. D.; Dunbar, J. B.; lijima, H.; Marshall, G. R. J. Am. Chem. Soc. 1988, 110, 5875. doi:10.1021/ja00225a045

116.Al-Hourani, B. J.; Sharma, S. K.; Mane, J. Y.; Tuszynski, J.; Baracos, V.; Kniess, T.; Suresh, M.; Pietzsch, J.; Wuest, F. Bioorg. Med. Chem. Lett. 2011, 21, 1823. doi:10.1016/j.bmcl.2011.01.057

117.Johansson, A.; Poliakov, A.; Akerblom, E.; Wiklund, K.; Lindeberg, G.; Winiwarter, S.; Danielson, U. H.; Samuelsson, B.; Hallberg, A. Bioorg. Med. Chem. Lett. 2003, 11, 2551.

118. Alexander, J. P.; Cravatt, B. F. J. Am. Chem. Soc. 2006, 128, 9699. doi:10.1021/ja062999h

119.Kang, S. Y.; Lee, S.; Seo, H. J.; Jung, M. E.; Ahn, K.; Kim, J.; Lee, J. Bioorg. Med. Chem. Lett. 2008, 18, 2385. doi:10.1016/j.bmcl.2008.02.061

120.Muraglia, E.; Kinzel, O. D.; Laufer, R.; Miller, M. D.; Moyer, G.; Munshi, V.; Orvieto, F.; Palumbi, M. C.; Pescatore, G.; Rowley, M.; Williarns, P. D.; Summa, V. Bioorg. Med. Chem. Lett. 2006, 16, 2748. doi:10.1016/j.bmcl.2006.02.024

121. O'Meara, J. A.; Jakalian, A.; LaPlante, S.; Bonneau, P. R.; Coulombe, R.; Faucher, A. M.; Guse, I.; Landry, S.; Racine, J.; Simoneau, B.; Thavonekham, B.; Yoakim, C. Bioorg. Med. Chem. Lett. 2007, 17, 3362. doi:10.1016/j.bmcl.2007.03.097

122. Nixey, T.; Hulme, C. Tetrahedron Lett. 2002, 43, 6833. doi:10.1016/S0040-4039(02)01505-8

123. Yue, T.; Wang, M.-X.; Wang, D.-X.; Zhu, J. Angew. Chem., Int. Ed. 2008, 47, 9454. doi:10.1002/anie.200804213

124. Mayer, J.; Umkehrer, M.; Kalinski, C.; Ross, G.; Kolb, J.; Burdack, C.; Hiller, W. Tetrahedron Lett. 2005, 46, 7393. doi:10.1016/j.tetlet.2005.08.101

125. Chen, J. J.; Golebiowski, A.; Klopfenstein, S. R.; West, L. Tetrahedron Lett. 2002, 43, 4083. doi:10.1016/S0040-4039(02)00700-1

126. Gunawan, S.; Petit, J.; Hulme, C. ACS Comb. Sci. 2012, 14, 160. doi:10.1021/co200209a

127. Gunawan, S.; Keck, K.; Laetsch, A.; Hulme, C. Mol. Diversity 2012, 16, 601. doi:10.1007/s11030-012-9373-2

128. Maison, W.; Lützen, A.; Kosten, M.; Schlemminger, I.; Westerhoff, O.; Saak, W.; Martens, J. J. Chem. Soc., Perkin Trans. 1 2000, 1867. doi:10.1039/B002258F

129. Kehagia, K.; Dömling, A.; Ugi, I. Tetrahedron 1995, 51, 139-144. doi:10.1016/0040-4020(94)00958-W

130.Genin, M. J.; Gleason, W. B.; Johnson, R. L. J. Org. Chem. 1993, 58, 860. doi:10.1021/jo00056a018

131. Maison, W.; Lützen, A.; Kosten, M.; Schlemminger, I.; Westerhoff, O.; Martens, J. J. Chem. Soc., Perkin Trans. 1 1999, 3515. doi:10.1039/a905119h 
132. Timmer, M. S. M.; Risseeuw, M. D. P.; Verdoes, M.; Filippov, D. V.; Plaisier, J. R.; van der Marel, G. A.; Overkleeft, H. S.; van Boom, J. H. Tetrahedron: Asymmetry 2005, 16, 177. doi:10.1016/j.tetasy.2004.11.079

133. Houston, D. R.; Synstad, B.; Eijsink, V. G. H.; Stark, M. J. R.; Eggleston, I. M.; van Aalten, D. M. F. J. Med. Chem. 2004, 47, 5713. doi:10.1021/jm049940a

134.Byun, H.-G.; Zhang, H.; Mochizuki, M.; Adachi, K.; Shizuri, Y.; Lee, W.-J.; Kim, S.-K. J. Antibiot. 2003, 56, 102. doi:10.7164/antibiotics.56.102

135.Fdhila, F.; Vazquez, V.; Sánchez, J. L.; Riguera, R. J. Nat. Prod 2003, 66, 1299. doi:10.1021/np030233e

136. Nicholson, B.; Lloyd, G. K.; Miller, B. R.; Palladino, M. A.; Kiso, Y.; Hayashi, Y.; Neuteboom, S. T. C. Anti-Cancer Drugs 2006, 17, 25. doi:10.1097/01.cad.0000182745.01612.8a

137.van der Merwe, E.; Huang, D.; Peterson, D.; Kilian, G.; Milne, P. J.; Van de Venter, M.; Frost, C. Peptides 2008, 29, 1305. doi:10.1016/j.peptides.2008.03.010

138. Jainta, M.; Nieger, M.; Bräse, S. Eur. J. Org. Chem. 2008, 5418. doi:10.1002/ejoc.200800605

139.Stark, T.; Hofmann, T. J. Agric. Food Chem. 2005, 53, 7222. doi:10.1021/jf051313m

140.Rhoden, C. R. B.; Rivera, D. G.; Kreye, O.; Bauer, A. K.; Westermann, B.; Wessjohann, L. A. J. Comb. Chem. 2009, 11, 1078. doi:10.1021/cc900106u

141.Ressurreição, A. S. M.; Delatouche, R.; Gennari, C.; Piarulli, U. Eur. J. Org. Chem. 2011, 217. doi:10.1002/ejoc.201001330 142. Borthwick, A. D. Chem. Rev. 2012, 112, 3641. doi:10.1021/cr200398y 143. Hulme, C.; Morrissette, M. M.; Volz, F. A.; Burns, C. J. Tetrahedron Lett. 1998, 39, 1113. doi:10.1016/S0040-4039(97)10795-X

144. Hulme, C.; Peng, J.; Morton, G.; Salvino, J. M.; Herpin, T.; Labaudiniere, R. Tetrahedron Lett. 1998, 39, 7227. doi:10.1016/S0040-4039(98)01593-7

145. Hulme, C.; Cherrier, M.-P. Tetrahedron Lett. 1999, 40, 5295. doi:10.1016/S0040-4039(99)00960-0

146.Santra, S.; Andreana, P. R. Org. Lett. 2007, 9, 5035. doi:10.1021/ol702256t

147.Kennedy, A. L.; Fryer, A. M.; Josey, J. A. Org. Lett. 2002, 4, 1167. doi:10.1021/ol0256015

148. Kobayashi, K.; Yoneda, K.; Mizumoto, T.; Umakoshi, H.; Morikawa, O.; Konishi, H. Tetrahedron Lett. 2003, 44, 4733. doi:10.1016/S0040-4039(03)01040-2

149. Hulme, C.; Chappeta, S.; Dietrich, J. Tetrahedron Lett. 2009, 50, 4054. doi:10.1016/j.tetlet.2009.04.095

150.Wyatt, P. G.; Allen, M. J.; Borthwick, A. D.; Davies, D. E.; Exall, A. M.; Hatley, R. J. D.; Irving, W. R.; Livermore, D. G.; Miller, N. D.; Nerozzi, F.; Sollis, S. L.; Szardenings, A. K. Bioorg. Med. Chem. Lett. 2005, 15, 2579. doi:10.1016/j.bmcl.2005.03.045

151.Borthwick, A. D.; Davies, D. E.; Exall, A. M.; Livermore, D. G.; Sollis, S. L.; Nerozzi, F.; Allen, M. J.; Perren, M.; Shabbir, S. S.; Woollard, P. M.; Wyatt, P. G. J. Med. Chem. 2005, 48, 6956. doi:10.1021/jm050557v

152.Borthwick, A. D. J. Med. Chem. 2010, 53, 6525. doi:10.1021/jm901812z

153.Sollis, S. L. J. Org. Chem. 2005, 70, 4735. doi:10.1021/jo0501137

154.Marcaccini, S.; Pepino, R.; Pozo, M. C. Tetrahedron Lett. 2001, 42, 2727. doi:10.1016/S0040-4039(01)00232-5

155. Hanessian, S.; McNaughton-Smith, G.; Lombart, H.-G.; Lubell, W. D Tetrahedron 1997, 53, 12789. doi:10.1016/S0040-4020(97)00476-6
156. Golebiowski, A.; Klopfenstein, S. R.; Shao, X.; Chen, J. J.; Colson, A. O.; Grieb, A. L.; Russell, A. F. Org. Lett. 2000, 2, 2615. doi:10.1021/ol006145s

157.Ball, J. B.; Hughes, R. A.; Alewood, P. F.; Andrews, P. R. Tetrahedron 1993, 49, 3467. doi:10.1016/S0040-4020(01)90207-8

158. Golebiowski, A.; Klopfenstein, S. R.; Chen, J. J.; Shao, X. Tetrahedron Lett. 2000, 41, 4841. doi:10.1016/S0040-4039(00)00669-9

159. Ball, J. B.; Alewood, P. F. J. Mol. Recognit. 1990, 3, 55 doi:10.1002/jmr.300030202

160. Golebiowski, A.; Jozwik, J.; Klopfenstein, S. R.; Colson, A.-O.; Grieb, A. L.; Russell, A. F.; Rastogi, V. L.; Diven, C. F.; Portlock, D. E.; Chen, J. J. J. Comb. Chem. 2002, 4, 584. doi:10.1021/cc020029u

161. Legeay, J. C.; Vanden Eynde, J. J.; Bazureau, J. P. Tetrahedron Lett. 2007, 48, 1063. doi:10.1016/j.tetlet.2006.11.148

162. Ochoa, E.; Suárez, M.; Verdecia, Y.; Pita, B.; Martín, N.; Quinteiro, M.; Seoane, C.; Soto, J. L.; Duque, J.; Pomés, R. Tetrahedron 1998, 54, 12409. doi:10.1016/S0040-4020(98)00760-1

163.Paravidino, M.; Bon, R. S.; Scheffelaar, R.; Vugts, D. J.; Znabet, A.; Schmitz, R. F.; de Kanter, F. J. J.; Lutz, M.; Spek, A. L.; Groen, M. B.; Orru, R. V. A. Org. Lett. 2006, 8, 5369. doi:10.1021/ol062204b

164.Paravidino, M.; Scheffelaar, R.; Schmitz, R. F.; De Kanter, F. J. J.; Groen, M. B.; Ruijter, E.; Orru, R. V. A. J. Org. Chem. 2007, 72, 10239. doi:10.1021/jo701978v

165.Vugts, D. J.; Jansen, H.; Schmitz, R. F.; de Kanter, F. J. J.; Orru, R. V. A. Chem. Commun. 2003, 2594. doi:10.1039/b308243a

166. Myers, A. C.; Kowalski, J. A.; Lipton, M. A. Bioorg. Med. Chem. Lett. 2004, 14, 5219. doi:10.1016/j.bmcl.2004.07.092

167.Zega, A. Curr. Med. Chem. 2005, 12, 589. doi:10.2174/0929867053362802

168. Piliero, P. J. Drugs Today 2004, 40, 901. doi:10.1358/dot.2004.40.11.872579

169. Abdel-Rahman, R. M. Pharmazie 2001, 56, 18.

170.Al-Etalbi, A.; Makhseed, S.; Al-Awadi, N. A.; Ibrahim, Y. A. Tetrahedron Lett. 2005, 46, 31. doi:10.1016/j.tetlet.2004.11.050

171.Borzilleri, R. M.; Cai, Z. W.; Ellis, C.; Fargnoli, J.; Fura, A.; Gerhardt, T.; Goyal, B.; Hunt, J. T.; Mortillo, S.; Qian, L. G.; Tokarski, J.; Vyas, V.; Wautlet, B.; Zheng, X.; Bhide, R. S. Bioorg. Med. Chem. Lett. 2005, 15, 1429. doi:10.1016/j.bmcl.2004.12.079

172.Borzilleri, R. M.; Zheng, X.; Qian, L.; Ellis, C.; Cai, Z.-w.; Wautlet, B. S.; Mortillo, S.; Jeyaseelan, R.; Kukral, D. W.; Fura, A.; Kamath, A.; Vyas, V.; Tokarski, J. S.; Barrish, J. C.; Hunt, J. T.; Lombardo, L. J.; Fargnoli, J.; Bhide, R. S. J. Med. Chem. 2005, 48, 3991. doi:10.1021/jm0501275

173. Hunt, J. T.; Mitt, T.; Borzilleri, R.; Gullo-Brown, J.; Fargnoli, J.; Fink, B.; Han, W.-C.; Mortillo, S.; Vite, G.; Wautlet, B.; Wong, T.; Yu, C.; Zheng, X.; Bhide, R. J. Med. Chem. 2004, 47, 4054. doi:10.1021/jm049892u

174.Sañudo, M.; Marcaccini, S.; Basurto, S.; Torroba, T. J. Org. Chem. 2006, 71, 4578. doi:10.1021/jo060434y

175. Groenendaal, B.; Vugts, D. J.; Schmitz, R. F.; de Kanter, F. J. J.; Ruijter, E.; Groen, M. B.; Orru, R. V. A. J. Org. Chem. 2008, 73, 719. doi:10.1021/jo701973d

176. Groenendaal, B.; Ruijter, E.; de Kanter, F. J. J.; Lutz, M.; Spek, A. L.; Orru, R. V. A. Org. Biomol. Chem. 2008, 6, 3158. doi:10.1039/b807138a 
177.Vugts, D. J.; Koningstein, M. M.; Schmitz, R. F.; de Kanter, F. J. J.; Groen, M. B.; Orru, R. V. A. Chem.-Eur. J. 2006, 12, 7178. doi:10.1002/chem.200600168

178. Koidl, B.; Miyawaki, N.; Tritthart, H. A. Eur. J. Pharmacol. 1997, 322, 243. doi:10.1016/S0014-2999(96)00995-8

179.Varney, M. D.; Palmer, C. L.; Romines, W. H., III; Boritzki, T.; Margosiak, S. A.; Almassy, R.; Janson, C. A.; Bartlett, C.; Howland, E. J.; Ferre, R. J. Med. Chem. 1997, 40, 2502. doi:10.1021/jm9607459

180.Marcaccini, S.; Pepino, R.; Torroba, T.; Miguel, D.; Garcia-Valverde, M. Tetrahedron Lett. 2002, 43, 8591. doi:10.1016/S0040-4039(02)02064-6

181.Beck, B.; Picard, A.; Herdtweck, E.; Dömling, A. Org. Lett. 2004, 6, 39. doi:10.1021/ol035787n

182.Breslin, H. J.; Kukla, M. J.; Ludovici, D. W.; Mohrbacher, R.; Ho, W.; Miranda, M.; Rodgers, J. D.; Hitchens, T. K.; Leo, G.; Gauthier, D. A.; Ho, C. Y.; Scott, M. K.; Declercq, E.; Pauwels, R.; Andries, K.; Janssen, M. A. C.; Janssen, P. A. J. J. Med. Chem. 1995, 38, 771. doi:10.1021/jm00005a005

183. Micale, N.; Kozikowski, A. P.; Ettari, R.; Grasso, S.; Zappala, M.; Jeong, J.-J.; Kumar, A.; Hanspal, M.; Chishti, A. H. J. Med. Chem. 2006, 49, 3064. doi:10.1021/jm060405f

184.Ettari, R.; Nizi, E.; Di Francesco, M. E.; Dude, M.-A.; Pradel, G.; Vicik, R.; Schirmeister, T.; Micale, N.; Grasso, S.; Zappalà, M. J. Med. Chem. 2008, 51, 988. doi:10.1021/jm701141u

185.Parks, D. J.; LaFrance, L. V.; Calvo, R. R.; Milkiewicz, K. L.; Gupta, V.; Lattanze, J.; Ramachandren, K.; Carver, T. E.; Petrella, E. C.; Cummings, M. D.; Maguire, D.; Grasberger, B. L.; Lu, T. Bioorg. Med. Chem. Lett. 2005, 15, 765. doi:10.1016/j.bmcl.2004.11.009

186. Koblish, H. K.; Zhao, S. Y.; Franks, C. F.; Donatelli, R. R.; Tominovich, R. M.; LaFrance, L. V.; Leonard, K. A.; Gushue, J. M.; Parks, D. J.; Calvo, R. R.; Milkiewicz, K. L.; Marugán, J. J.; Raboisson, P.; Cummings, M. D.; Grasberger, B. L.; Johnson, D. L.; Lu, T.; Molloy, C. J.; Maroney, A. C. Mol. Cancer Ther. 2006, 5, 160 doi:10.1158/1535-7163.MCT-05-0199

187.Leonard, K.; Marugan, J. J.; Raboisson, P.; Calvo, R.; Gushue, J. M.; Koblish, H. K.; Lattanze, J.; Zhao, S.; Cummings, M. D.; Player, M. R.; Maroney, A. C.; Lu, T. Bioorg. Med. Chem. Lett. 2006, 16, 3463. doi:10.1016/j.bmcl.2006.04.009

188. Rudolph, U.; Möhler, H. Curr. Opin. Pharmacol. 2006, 6, 18. doi:10.1016/j.coph.2005.10.003

189.Rosenström, U.; Sköld, C.; Lindeberg, G.; Botros, M.; Nyberg, F.; Karlen, A.; Hallberg, A. J. Med. Chem. 2006, 49, 6133. doi:10.1021/jm051222g

190.Banfi, L.; Basso, A.; Cerulli, V.; Guanti, G.; Lecinska, P.; Monfardini, I.; Riva, R. Mol. Diversity 2010, 14, 425. doi:10.1007/s11030-009-9210-4

191.Iden, H. S.; Lubell, W. D. J. Org. Chem. 2007, 72, 8980. doi:10.1021/jo701467d

192. Tempest, P.; Pettus, L.; Gore, V.; Hulme, C. Tetrahedron Lett. 2003, 44, 1947. doi:10.1016/S0040-4039(03)00084-4

193.Banfi, L.; Basso, A.; Guanti, G.; Kielland, N.; Repetto, C.; Riva, R. J. Org. Chem. 2007, 72, 2151. doi:10.1021/jo062626z

194.Zhou, H.; Zhang, W.; Yan, B. J. Comb. Chem. 2010, 12, 206. doi:10.1021/cc900157w

195. Hulme, C.; Chappeta, S.; Griffith, C.; Lee, Y.-S.; Dietrich, J. Tetrahedron Lett. 2009, 50, 1939. doi:10.1016/j.tetlet.2009.02.099

196.Sañudo, M.; García-Valverde, M.; Marcaccini, S.; Delgado, J. J.; Rojo, J.; Torroba, T. J. Org. Chem. 2009, 74, 2189. doi:10.1021/jo8025862
197.Lecinska, P.; Corres, N.; Moreno, D.; García-Valverde, M.; Marcaccini, S.; Torroba, T. Tetrahedron 2010, 66, 6783. doi:10.1016/j.tet.2010.06.062

198. Huang, Y.; Wolf, S.; Bista, M.; Meireles, L.; Camacho, C.; Holak, T. A.; Dömling, A. Chem. Biol. Drug Des. 2010, 76, 116. doi:10.1111/j.1747-0285.2010.00989.x

199. Puterova, Z.; Krutosikova, A.; Vegh, D. ARKIVOC 2010, (i), 209. SI-part.

200. Huang, Y.; Dömling, A. Mol. Diversity 2011, 15, 3. doi:10.1007/s11030-010-9229-6

201. Huang, Y.; Dömling, A. Chem. Biol. Drug Des. 2010, 76, 130. doi:10.1111/j.1747-0285.2010.00990.x

202. Nixey, T.; Kelly, M.; Semin, D.; Hulme, C. Tetrahedron Lett. 2002, 43, 3681. doi:10.1016/S0040-4039(02)00636-6

203. Nayak, M.; Batra, S. Tetrahedron Lett. 2010, 51, 510. doi:10.1016/j.tetlet.2009.11.051

204.Gunawan, S.; Ayaz, M.; De Moliner, F.; Frett, B.; Kaiser, C. Patrick, N.; Xu, Z.; Hulme, C. Tetrahedron 2012, 68, 5606. doi:10.1016/j.tet.2012.04.068

205.Gao, K.; Yu, C.-B.; Li, W.; Zhou, Y.-G.; Zhang, X. Chem. Commun. 2011, 47, 7845. doi:10.1039/c1cc12263k

206. Robl, J. A.; Simpkins, L. M.; Asaad, M. M. Bioorg. Med. Chem. Lett. 2000, 10, 257. doi:10.1016/S0960-894X(99)00671-X

207.Nagarajan, K.; David, J.; Kulkarni, Y. S.; Hendi, S. B.; Shenoy, S. J.; Upadhyaya, P. Eur. J. Med. Chem. 1986, 21, 21.

208. Klunder, J. M.; Hargrave, K. D.; West, M. A.; Cullen, E.; Pal, K.; Behnke, M. L.; Kapadia, S. R.; Mcneil, D. W.; Wu, J. C.; Chow, G. C.; Adams, J. J. Med. Chem. 1992, 35, 1887. doi:10.1021/jm00088a027

209.Banfi, L.; Basso, A.; Guanti, G.; Lecinska, P.; Riva, R. Org. Biomol. Chem. 2006, 4, 4236. doi:10.1039/b613056a

210.Banfi, L.; Basso, A.; Cerulli, V.; Rocca, V.; Riva, R. Beilstein J. Org. Chem. 2011, 7, 976. doi:10.3762/bjoc.7.109

211. Ilyin, A. P.; Parchinski, V. Z.; Peregudova, J. N.; Trifilenkov, A. S.; Poutsykina, E. B.; Tkachenko, S. E.; Kravchenko, D. V.; Ivachtchenko, A. V. Tetrahedron Lett. 2006, 47, 2649. doi:10.1016/j.tetlet.2006.01.158

212.Banfi, L.; Basso, A.; Guanti, G.; Riva, R. Tetrahedron Lett. 2003, 44, 7655. doi:10.1016/j.tetlet.2003.08.027

213. Marinelli, L.; Lavecchia, A.; Gottschalk, K.-E.; Novellino, E.; Kessler, H. J. Med. Chem. 2003, 46, 4393. doi:10.1021/jm020577m

214. Gottschalk, K.-E.; Kessler, H. Angew. Chem., Int. Ed. 2002, 41, 3767. doi:10.1002/1521-3773(20021018)41:20<3767::AID-ANIE3767>3.0.C O;2-T

215. Ruoslahti, E. Annu. Rev. Cell Dev. Biol. 1996, 12, 697. doi:10.1146/annurev.cellbio.12.1.697

216. Hodivala-Dilke, K. Curr. Opin. Cell Biol. 2008, 20, 514. doi:10.1016/j.ceb.2008.06.007

217.Danhier, F.; Le Breton, A.; Préat, V. Mol. Pharmaceutics 2012, 9, 2961. doi:10.1021/mp3002733

218.Banfi, L.; Basso, A.; Damonte, G.; De Pellegrini, F.; Galatini, A.; Guanti, G.; Monfardini, I.; Riva, R.; Scapolla, C. Bioorg. Med. Chem. Lett. 2007, 17, 1341. doi:10.1016/j.bmcl.2006.11.085

219. White, C. J.; Yudin, A. K. Nat. Chem. 2011, 3, 509. doi:10.1038/nchem.1062

220. Isidro-Llobet, A.; Murillo, T.; Bello, P.; Cilibrizzi, A.; Hodgkinson, J. T.; Galloway, W. R. J. D.; Bender, A.; Welch, M.; Spring, D. R. Proc. Natl. Acad. Sci. U. S. A. 2011, 108, 6793. doi:10.1073/pnas.1015267108 
221. Yoo, B.; Shin, S. B. Y.; Huang, M. L.; Kirshenbaum, K. Chem.-Eur. J. 2010, 16, 5528. doi:10.1002/chem.200903549

222.Davies, J. S. J. Pept. Sci. 2003, 9, 471. doi:10.1002/psc.491

223. Oikawa, M.; Naito, S.; Sasaki, M. Tetrahedron Lett. 2006, 47, 4763. doi:10.1016/j.tetlet.2006.04.098

224. Hebach, C.; Kazmaier, U. Chem. Commun. 2003, 596. doi:10.1039/b210952b

225.Beck, B.; Larbig, G.; Mejat, B.; Magnin-Lachaux, M.; Picard, A.; Herdtweck, E.; Dömling, A. Org. Lett. 2003, 5, 1047. doi:10.1021/ol034077e

226.Zhao, G.; Sun, X.; Bienaymé, H.; Zhu, J. J. Am. Chem. Soc. 2001, 123, 6700. doi:10.1021/ja015854d

227.Bughin, C.; Zhao, G.; Bienaymé, H.; Zhu, J. Chem.-Eur. J. 2006, 12, 1174. doi:10.1002/chem.200500703

228. Socha, A. M.; Tan, N. Y.; LaPlante, K. L.; Sello, J. K. Bioorg. Med. Chem. 2010, 18, 7193. doi:10.1016/j.bmc.2010.08.032

229.Samarasimhareddy, M.; Hemantha, H. P.; Sureshbabu, V. V. Tetrahedron Lett. 2012, 53, 3104. doi:10.1016/j.tetlet.2012.04.034

230.Pirali, T.; Tron, G. C.; Zhu, J. Org. Lett. 2006, 8, 4145. doi:10.1021/ol061782p

231. Nicolaou, K. C.; Boddy, C. N. C.; Bräse, S.; Winssinger, N. Angew. Chem., Int. Ed. 1999, 38, 2097. doi:10.1002/(SICI)1521-3773(19990802)38:15<2096::AID-ANIE2096> 3.0.CO;2-F

232. Gournelis, D. C.; Laskaris, G. G.; Verpoorte, R. Nat. Prod. Rep. 1997, 14, 75. doi:10.1039/np9971400075

233. Itokawa, H.; Kondo, K.; Hitotsuyanagi, Y.; Takeya, K. Heterocycles 1993, 36, 1837. doi:10.3987/COM-93-6382

234.Sano, S.; Ikai, K.; Kuroda, H.; Nakamura, T.; Obayashi, A.; Ezure, Y.; Enomoto, H. J. Antibiot. 1986, 39, 1674. doi:10.7164/antibiotics.39.1674

235. Joullié, M. M.; Richard, D. J. Chem. Commun. 2004, 2011. doi:10.1039/B400334A

236. Yasuzawa, T.; Shirahata, K.; Sano, H. J. Antibiot. 1987, 40, 455. doi:10.7164/antibiotics. 40.455

237.Wessjohann, L. A.; Ruijter, E.; Garcia-Rivera, D.; Brandt, W. Mol. Diversity 2005, 9, 171. doi:10.1007/s11030-005-1314-x

238. Cristau, P.; Vors, J.-P.; Zhu, J. Org. Lett. 2001, 3, 4079. doi:10.1021/ol0168420

239. Cristau, P.; Vors, J.-P.; Zhu, J. Tetrahedron 2003, 59, 7859 doi:10.1016/j.tet.2003.08.031

240.Cristau, P.; Vors, J.-P.; Zhu, J. Tetrahedron Lett. 2003, 44, 5575. doi:10.1016/S0040-4039(03)01378-9

241.Cristau, P.; Vors, J.-P.; Zhu, J. QSAR Comb. Sci. 2006, 25, 519. doi:10.1002/qsar.200540214

242. Owens, T. D.; Araldi, G. L.; Nutt, R. F.; Semple, J. E. Tetrahedron Lett. 2001, 42, 6271. doi:10.1016/S0040-4039(01)01287-4

243.Faure, S.; Hjelmgaard, T.; Roche, S. P.; Aitken, D. J. Org. Lett. 2009, 11, 1167. doi:10.1021/ol900048r

244.Vercillo, O. E.; Andrade, C. K. Z.; Wessjohann, L. A. Org. Lett. 2008, 10, 205. doi:10.1021/ol702521g

245. Rivera, D. G.; Vercillo, O. E.; Wessjohann, L. A. Org. Biomol. Chem. 2008, 6, 1787. doi:10.1039/b715393g

246. Michalik, D.; Schaks, A.; Wessjohann, L. A. Eur. J. Org. Chem. 2007, 149. doi:10.1002/ejoc.200600354

247.Leon, F.; Rivera, D. G.; Wessjohann, L. A. J. Org. Chem. 2008, 73, 1762. doi:10.1021/jo7022125
248. Rivera, D. G.; Leon, F.; Concepcion, O.; Morales, F. E.; Wessjohann, L. A. Chem.-Eur. J. 2013, 19, 6417. doi:10.1002/chem.201201591 See for a recent related work in this area.

249. Hili, R.; Rai, V.; Yudin, A. K. J. Am. Chem. Soc. 2010, 132, 2889. doi:10.1021/ja910544p

250. Chung, B. K. W.; Hickey, J. L.; Scully, C. C. G.; Zaretsky, S.; Yudin, A. K. Med. Chem. Commun. 2013, 4, 1124. doi:10.1039/c3md00054k

251.Rotstein, B. H.; Mourtada, R.; Kelley, S. O.; Yudin, A. K. Chem.-Eur. J. 2011, 17, 12257. doi:10.1002/chem.201102096

252.Roxin, A.; Chen, J.; Scully, C. C. G.; Rotstein, B. H.; Yudin, A. K.; Zheng, G. Bioconjugate Chem. 2012, 23, 1387. doi:10.1021/bc300239a

253.Zartetsky, S.; Scully, C. C. G.; Lough, A. J.; Yudin, A. K. Chem.-Eur. J. 2013, 19, 17668. doi:10.1002/chem.201303453

\section{License and Terms}

This is an Open Access article under the terms of the Creative Commons Attribution License

(http://creativecommons.org/licenses/by/2.0), which permits unrestricted use, distribution, and reproduction in any medium, provided the original work is properly cited.

The license is subject to the Beilstein Journal of Organic Chemistry terms and conditions:

(http://www.beilstein-journals.org/bjoc)

The definitive version of this article is the electronic one which can be found at: doi: $10.3762 /$ bjoc. 10.50 